NBER WORKING PAPER SERIES

\title{
SOCIAL NETWORKS AND HOUSING MARKETS
}

\author{
Michael Bailey \\ Ruiqing Cao \\ Theresa Kuchler \\ Johannes Stroebel \\ Working Paper 22258 \\ http://www.nber.org/papers/w22258 \\ NATIONAL BUREAU OF ECONOMIC RESEARCH \\ 1050 Massachusetts Avenue \\ Cambridge, MA 02138 \\ May 2016
}

This version: May 10, 2016. For helpful comments and discussions, we are grateful to Eduardo Davila, Anthony DeFusco, Marty Eichenbaum, Xavier Gabaix, Pedro Gete, Stefano Giglio, Adam Guren, Erik Hurst, Anil Kashyap, Ben Keys, Andres Liberman, Guido Lorenzoni, Brigitte Madrian, Ulrike Malmendier, Holger Mueller, Stijn van Nieuwerburgh, Cecilia Parlatore, Alp Simsek, Andrei Shleifer, Joe Vavra, Andreas Weber, Arlene Wong, Wei Xiong, and Basit Zafar, as well as seminar participants at Berkeley, Harvard, NYU, Northwestern, Penn State, the University of British Columbia, the Federal Reserve Banks of San Francisco, Philadelphia, and New York, the Consumer Financial Protection Bureau, Baruch, CHUM, and the Christmas Meeting of German Economists Abroad. This research was facilitated through a research consulting agreement between the academic authors and Facebook. This research cooperation was established to allow researchers to collaborate with Facebook in order to exploit anonymized data sets based on Facebook's unique data asset to address questions of policy importance. The views expressed herein are those of the authors and do not necessarily reflect the views of the National Bureau of Economic Research.

NBER working papers are circulated for discussion and comment purposes. They have not been peer-reviewed or been subject to the review by the NBER Board of Directors that accompanies official NBER publications.

(C) 2016 by Michael Bailey, Ruiqing Cao, Theresa Kuchler, and Johannes Stroebel. All rights reserved. Short sections of text, not to exceed two paragraphs, may be quoted without explicit permission provided that full credit, including ()$^{\text {notice, }}$ is given to the source. 
Social Networks and Housing Markets

Michael Bailey, Ruiqing Cao, Theresa Kuchler, and Johannes Stroebel

NBER Working Paper No. 22258

May 2016

JEL No. D12,D14,D84,G12,R21

\begin{abstract}
$\underline{\text { ABSTRACT }}$
We document that the recent house price experiences within an individual's social network affect her perceptions of the attractiveness of property investments, and through this channel have large effects on her housing market activity. Our data combine anonymized social network information from Facebook with housing transaction data and a survey. We first show that in the survey, individuals whose geographically-distant friends experienced larger recent house price increases consider local property a more attractive investment, with bigger effects for individuals who regularly discuss such investments with their friends. Based on these findings, we introduce a new methodology to document large effects of housing market expectations on individual housing investment decisions and aggregate housing market outcomes. Our approach exploits plausibly-exogenous variation in the recent house price experiences of individuals' geographically-distant friends as shifters of those individuals' local housing market expectations. Individuals whose friends experienced a 5 percentage points larger house price increase over the previous 24 months (i) are 3.1 percentage points more likely to transition from renting to owning over a two-year period, (ii) buy a 1.7 percent larger house, (iii) pay 3.3 percent more for a given house, and (iv) make a 7\% larger downpayment. Similarly, when homeowners' friends experience less positive house price changes, these homeowners are more likely to become renters, and more likely to sell their property at a lower price. We also find that when individuals observe a higher dispersion of house price experiences across their friends, this has a negative effect on their housing investments. Finally, we show that these individual-level responses aggregate up to affect county-level house prices and trading volume. Our findings suggest that the house price experiences of geographically-distant friends might provide a valid instrument for local house price growth.
\end{abstract}

Michael Bailey
Facebook
Economist
mcbailey@fb.com
Ruiqing Cao
Harvard University
ruiqingcao@fas.harvard.edu
Theresa Kuchler

Stern School of Business

New York University

44 West 4th Street

New York, NY 10012

tkuchler@stern.nyu.edu

Johannes Stroebel

Stern School of Business

New York University

44 West 4th Street

New York, NY 10012

and NBER

johannes.stroebel@nyu.edu 
The past decades have seen large swings in U.S. house prices. Due to the role of these price movements in precipitating the Great Recession, there have been significant efforts by policy makers and researchers to better understand the drivers of house price dynamics. A prominent class of explanations focus on the role of heterogeneous expectations and shifts between optimism and pessimism about future house price growth in causing house price fluctuations. ${ }^{1}$ However, the sources of cross-sectional and time-series variation in house price expectations are not well understood, and the quantitative importance of speculative motives for housing market decisions is yet to be established.

This paper documents that the house price experiences within an individual's social network affect her perceptions of the attractiveness of property investments, and through this channel have large effects on her housing market activity. We observe an anonymized snapshot of U.S. individuals' friendship networks on Facebook, the largest online social network, with 219 million active users in the U.S. and Canada. We match this information to individual-level demographics, survey data, and housing transaction data. This allows us to investigate how the house price movements in counties where an individual has friends affect her housing market expectations and investment decisions. ${ }^{2}$

We first analyze 1,242 responses to a housing market survey among Los Angeles-based Facebook users. Over half of the survey respondents report to regularly talk to their friends about investing in the housing market. The survey also asked respondents to assess the attractiveness of property investments in their own zip code relative to other financial investments. Holding respondent characteristics fixed, we find a strong relationship between the recent house price movements in counties where a respondent has friends, and whether that respondent believes that local property is a good investment. To remove confounding effects from a possible extrapolation of own house price experiences, we instrument for total social network house price experience with the experiences of friends in geographically-distant housing markets. Importantly, the relationship between the house price experiences in an individual's social network and her assessment of the attractiveness of local property investments is stronger for individuals who regularly talk to their friends about investing in property, pointing to an important role for social interactions in influencing housing market expectations.

Based on these findings, we propose a new methodology to analyze the extent to which perceptions of the attractiveness of property investments influence individuals' housing market decisions, house prices, and aggregate trading volume. Such an analysis is generally complicated by the absence of large-scale and high-frequency expectations data linked to housing market decisions, and a concern

\footnotetext{
${ }^{1}$ See, for example, Piazzesi and Schneider (2009), Akerlof and Shiller (2010), Foote, Gerardi and Willen (2012), Goetzmann, Peng and Yen (2012), Carlin, Longstaff and Matoba (2014), Cheng, Raina and Xiong (2014) Favara and Song (2014), Landvoigt (2014), Nathanson and Zwick (2014), Berger et al. (2015), Geerolf (2015), Glaeser and Nathanson (2015), Kaplan, Mitman and Violante (2015), Shiller (2015), and Burnside, Eichenbaum and Rebelo (2016).

${ }^{2}$ While Facebook's "social graph" might not contain the complete set of real-world social connections, we believe that these data provide the best possible setting for measuring an individual's true social network. As of September 2014, 71\% of U.S. online adults (58\% of all U.S. adults) used Facebook (Duggan et al., 2015), and the average individual in our sample has more than 400 connections. In the U.S., 93\% of Facebook friends have met in the real world, and $90 \%$ have met more than once (Hampton et al., 2011). In addition, we do not require that communication about housing investments occurs primarily through Facebook - instead, we need to assume that an individual's social network on Facebook provides us with an unbiased estimate of the geographic distribution of the people she would interact with both online and offline.
} 
that any observed expectations may be partially determined by factors that can also directly influence individuals' housing market decisions. Our approach is to exploit the plausibly-exogenous variation in the recent house price experiences of an individual's geographically-distant friends as shifters of her local housing market expectations. These expectation shifters can be computed at monthly frequencies, and our approach only requires information on the geographic distribution of individuals' social networks, combined with county-level house price data. By relating the house price experiences within individuals' geographically-distant social networks to their housing market decisions, we can thus analyze the effects of cross-sectional and time-series variation in housing market expectations.

To implement this methodology, we match anonymized social network data on Los Angeles-based Facebook users to housing transaction data, property characteristics, and demographic information. Our sample contains anonymized data on 1.4 million individuals and 525,000 housing transactions. We analyze the effects of the house price experiences in an individual's social network on four aspects of her housing market behavior: the extensive margin decision (i.e., whether to rent or own), the intensive margin decision (i.e., the square footage of properties bought), the willingness to pay for a particular house, and the leverage chosen to finance the purchase. As before, we only exploit variation in the house price experiences of geographically-distant friends.

We find that the house price experiences within an individual's social network have quantitatively large effects on all four aspects of her housing investment decision. First, a five percentage point higher house price experience of an individual's friends between 2008 and 2010 leads to a 3.1 percentage point increase in the probability of that individual transitioning from being a renter in 2010 to being a homeowner in 2012 , relative to a baseline transition probability of $18 \%$. This is over half the size of the effect of adding a family member. We also find that homeowners are more likely to transition to renting when their friends experience below-average house price changes. Second, conditional on an individual buying a property, a five percentage point increase in friends' house price experiences over the 24 months prior to the purchase is associated with the individual buying a 1.7 percent larger property. Third, conditional on observable property characteristics, a five percentage point increase in the house price experiences in an individual's social network is associated with that individual paying 3.3 percent more for the same property. This result is robust to adding property fixed effects to account for unobservable property characteristics. When we also control for the house price movements in the seller's social network, we find that sellers whose friends experienced higher house price appreciations also demand higher sales prices. In addition, when we compare friends' house price experiences across matched buyers and sellers in the same transaction, we find that buyers' friends have about 30 basis points more positive experiences. Fourth, we show that a five percentage point higher house price appreciation within a homebuyer's social network is associated with that buyer making a $7 \%$ larger downpayment. This average effect is driven by differences in the left tail of the return distribution within homerbuyers' social networks. This suggests that individuals who believe house prices are less likely to fall are less willing to pay the higher interest rates that 
compensate lenders for the increased default probability associated with smaller downpayments.

In addition to considering the effects of the average house price experiences in individuals' social networks, we also analyze the effects of higher within-network dispersion in those experiences. We find that, conditional on the average house price experiences, a larger dispersion of those experiences is associated with a lower probability of buying for renters, with a higher probability of selling for owners, with buyers purchasing a smaller house, and with lower transaction prices for a given house. This suggests that individuals consider housing a more risky and less attractive investment after having been exposed, through their friends, to a wider set of possible market outcomes.

We argue that the relationship between the house price experiences in an individual's social network and her housing market behavior is due to the effects of social interactions on her housing market expectations. We rule out a number of alternative explanations. A first concern is that the house price experiences of an individual's friends might correlate with her own house price experiences or past capital gains, which could affect her expectations and behavior through a different channel. As discussed above, we address this by only exploiting variation in house price experiences of geographically-distant friends. We also ensure that our results are not driven by individuals who recently moved from those geographically-distant locations to Los Angeles.

Second, one might worry that the geographic distribution of an individual's social network could be correlated with other characteristics that affect her housing investments. This by itself, however, cannot explain our findings, as the house price experiences within an individual's social network are affected by the interaction of the geographic distribution of her friends and how house prices in those areas move in a given year. While it might be true that people with friends in Boston are different to people with friends in Miami, relative house price movements in Miami and Boston change over time. Comparing the behavior of individuals with friends in Boston across different years thus allows us to remove any time-invariant confounding effect of the geographic distribution of an individual's friends. In fact, in some of the specifications, we observe multiple transactions of the same individual across different years. We find that this same individual is willing to pay more for a given house in years following stronger relative house price increases in her social network. ${ }^{3}$

Third, one might be concerned that shocks to an individual's ability or desire to buy a house in a given year might be correlated with her friends' house price experiences in that year through a channel other than social interactions. This challenge is much weaker than that encountered by the peer effects literature, which has to establish that correlated behavior does not arise from correlated shocks or common characteristics within friendship groups (Manski, 1993). In our setting, alternative interpretations require a shock to an individual's ability or desire to buy a house in a given housing market that contemporaneously moves house prices in geographically-distant regions where she has friends. We address one such challenge that we were able to identify. In particular, many people have friends that work in the same sector. If economic activity in that sector features significant geographic

\footnotetext{
${ }^{3}$ Consistent with this, we find that the average house price experiences of a person's out-of-commuting-zone friends do not vary with that person's characteristics.
} 
clustering (e.g., tech in Silicon Valley), positive shocks to that sector in a given year might both enable an individual to buy a house, and drive up aggregate house prices in those sector-exposed regions where the individual has friends. To rule out this alternative explanation, we show that all results are robust to restricting the sample to individuals working in geographically non-clustered professions (e.g., teachers). The results are also robust to directly including controls for the economic conditions in a person's social network, and to interacting all individual demographics with year fixed effects, which allows, for example, the effect of different education levels on behavior to vary over time.

We rule out further alternative explanations for our findings. First, we show that our results are not driven by a bequest story in which the value of a person's expected housing bequest, and thereby her wealth, is increasing in the house price movements experienced by her geographically-distant family members. In particular, we show that house price experiences within an individual's network of college friends and work friends is equally predictive of subsequent housing investments as the experiences within her family network. We also show that our results are, if anything, slightly larger for individuals who are originally from LA, and whose families' real estate wealth is therefore less likely to be exposed to house price movements outside LA.

We also argue that our findings cannot be explained by a story of consumption externalities, such as a desire to "keep up with the Joneses" (see Abel, 1990). A specific concern was that even though our measure of social network house price experience does not depend on the behavior of individuals' friends, more housing transactions take place in areas where house prices go up. This would make it more likely that a person has more friends buying a house when her social network experiences higher appreciation, which might induce that individual to buy a house to keep up with her friends. We find that this cannot explain our findings. First, our results persist when we control for the level and change in trading volume within a person's social network. Second, the results are identical if we focus on the house price experiences of the subset of friends that we can verify to be renters.

While our analysis does not allow us to distinguish between all possible explanations for why individuals update their housing market expectations and behavior based on the experiences in their social networks, we present some evidence that suggests it is unlikely to be the result of purely rational behavior. First, the degree of updating is independent of how predictive a person's social network house price experience is for future LA house price movements; the effect also does not vary with the geographic dispersion of the network. We also find the extent of updating to be weakly declining in education levels. However, there remain many possible explanations. For example, our findings could be due to the spread of irrational sentiments, or due to overconfidence, with individuals over-reacting to noisy signals they receive through their social networks (Barberis and Thaler, 2003). The questions addressed in this paper do not require us to identify the mechanism behind the observed correlation between a person's social network house price experience and her housing market expectations.

After documenting an important role of social interactions in influencing individual-level housing market expectations and investments, the last section of the paper analyzes the role of housing market 
expectations in driving aggregate housing market outcomes. We construct an annual panel of house price changes and transaction volumes in 831 counties between 1998 and 2012, and relate those to the house price experiences in the social networks of people living in those counties. We only exploit variation coming from the population's out-of-state friends, and control for lagged dependent variables measured over the same period as friends' house price experiences. This allows us to absorb, to the extent possible, any effects of common shocks to counties that are connected through friendship links.

We find that an increase in the within-county across-population dispersion of average friends' house price experiences is associated with larger housing transaction volumes: a one standard deviation increase in our measure of dispersion is associated with a 0.22 standard deviation increase in trading volume. This is consistent with some previous renters becoming more optimistic about investing in property, and therefore wanting to buy, and some previous owners becoming more pessimistic and therefore wanting to sell. We also find that a higher within-county dispersion of friends' house price experiences is associated with larger house price increases: a one standard deviation increase in dispersion is associated with a 1.9 percentage point higher house price growth. Similarly, an increase in the average network house price experience in a county is also associated with larger increases in county-level house prices: a one within-year standard deviation (3.1 percentage point) increase in friends' house price experiences is associated with a 0.4 within-year standard deviation (2.5 percentage point) increase in county-level house price growth. We discuss a number of implications of these findings. First, we show that social dynamics might be an important mechanism to explain the geographic contagion in house prices documented by DeFusco et al. (2015). In addition, we argue that the across-county-population average house price experiences of geographically-distant friends can, in many settings, constitute a valid instrument for house price changes.

We view our paper as making three contributions. First, we show that house price experiences within social networks are an important source of heterogeneity in individuals' housing market expectations. This result contributes to a research effort analyzing how people form expectations about economic outcomes. One popular explanation is that such expectations depend on own experiences. For example, Kuchler and Zafar (2015) show that locally-experienced house prices influence individuals' expectations of national house prices. Guren (2015), Glaeser and Nathanson (2015), and Barberis et al. (2015) explore the implications of such extrapolation for price dynamics. Recent experiences or events also affect expectations in other settings (e.g., Vissing-Jorgensen, 2003; Malmendier and Nagel, 2011, 2015; Choi et al., 2009; Greenwood and Shleifer, 2014; Armona, Fuster and Zafar, 2016). Related to these, we find that individuals' expectations are also affected by recent experiences of their friends.

The perspective that social dynamics might influence financial markets is not new. Shiller (1984) writes: "Investors spend a substantial part of their leisure time discussing investments, reading about investments, or gossiping about others' successes or failures in investing. It is thus plausible that investors' behavior (and hence prices of speculative assets) would be influenced by social movements." We contribute to the ongoing debate about the importance of social interactions in economics by conducting the first systematic 
empirical analysis of the extent to which such interactions affect expectations and behavior in the housing market. ${ }^{4}$ By doing so, we provide empirical support for theories in which communication between agents propagates shocks to expectations (e.g., Akerlof and Shiller, 2010; Acemoglu et al., 2011, 2013; Angeletos and La'O, 2013; Shiller, 2015; Burnside, Eichenbaum and Rebelo, 2016).

Our second contribution is to introduce a new methodology for analyzing the role of individuals' housing market expectations in determining individual and aggregate housing market outcomes. In particular, we argue that differences in the house price experiences within different social networks can induce heterogeneity in expectations among individuals in the same housing market. We show that individuals with networks that experienced more positive house price movements, and who thus believe that real estate is a more attractive investment, actually do invest more in real estate, and are willing to pay more for a given house. These findings provide support for a large and important class of models in which expectation heterogeneity influences asset valuations and motivates individuals to trade (e.g., Miller, 1977; Harrison and Kreps, 1978; Varian, 1989; Harris and Raviv, 1993; Hong and Stein, 1999, 2007; Scheinkman and Xiong, 2003; Geanakoplos, 2009; Simsek, 2013a,b; Brunnermeier, Simsek and Xiong, 2014; Barberis et al., 2015). Furthermore, our county-level results document an important effect of investor disagreement on aggregate prices and trading volume in housing markets, and are thus highly consistent with aggregate predictions from these models. ${ }^{5}$

Our third contribution is to document that, at the county level, friendship networks are a mechanism that can propagate house price shocks through the economy; we also argued that since this transmission works through house price expectations, shocks to geographically-distant counties that are linked through friendship links might be a valid instrument for county-level house price growth. ${ }^{6}$ In related work, Bailey et al. (2016) document that other measures of social and economic activity, such as trade flow, migration, and patent citation are also related to this friendship network.

The paper proceeds as follows. Section 1 describes the data and empirical approach. Section 2 analyzes the housing market survey. Sections 3 and 4 explore the relationship between the mean and dispersion of the house price experiences in an individual's social network and that individual's housing market investments. Section 5 analyzes how county-level house prices and trading volume vary with the house price experiences in the social networks of the population.

\footnotetext{
${ }^{4}$ Empirical evidence for a role of social interactions in influencing decision making has been explored in other settings, including equity markets (Shiller and Pound, 1989; Feng and Seasholes, 2004; Brown et al., 2008; Hong, Kubik and Stein, 2004; Li, 2014; Ozsoylev et al., 2014), holdings of money managers (Hong, Kubik and Stein, 2005; Cohen, Frazzini and Malloy, 2008; Pool, Stoffman and Yonker, 2015), bank deposits (Kelly and Gráda, 2000), lending (Haselmann, Schoenherr and Vig, 2013), loan repayment (Breza, 2015; Breza and Chandrasekhar, 2015), foreign exchange trading (Heimer and Simon, 2012), bank runs (Iyer and Puri, 2012), venture capital funding (Hochberg, Ljungqvist and Lu, 2007), managerial decision making (Shue, 2013; Leary and Roberts, 2014), and retirement savings (Duflo and Saez, 2002; Beshears et al., 2015a). In housing markets, Bayer et al. (2014) argue that individuals are more likely to become property investors when their neighbors have started to speculate in the housing market. See Allen and Babus (2009) and Hirshleifer and Teoh (2009) for recent reviews.

${ }^{5}$ Existing tests of such models have mainly focused on the stock market, with expectation dispersion measured through relatively small-scale surveys or dispersion in analysts' forecasts (e.g., Bessembinder, Chan and Seguin, 1996; Goetzmann and Massa, 2005; Li and Li, 2011). More recently, Giannini, Irvine and Shu (2015) and Cookson and Niessner (2016) analyze messages posted to an online investment community to measure disagreement among the participants.

${ }^{6}$ This relates to research studying the propagation of shocks through input-ouput networks (Acemoglu et al., 2012; Kelly, Lustig and Van Nieuwerburgh, 2013; Barrot and Sauvagnat, 2015) or firm internal networks (Giroud and Mueller, 2016).
} 


\section{Data Description and Empirical Approach}

Our empirical analysis builds on a number of anonymized data sets that contain information about individual housing market participants, their social networks, property transactions, and property characteristics. In this section, we describe the construction of our two primary regression samples and provide summary statistics. We also outline our empirical strategy for identifying the effect of social networks on housing market investments.

\subsection{Underlying Data Sets}

Our first data set contains information on the Facebook social graph. Facebook was created in 2004 as a college-wide online network for students to maintain a profile and to communicate with their friends. It has since grown to become the world's largest online social networking service, with over 1.6 billion monthly active users globally, and 219 million monthly active users in the U.S. and Canada (Facebook, 2015). Our baseline sample includes a de-identified snapshot of all U.S.-based monthly active Facebook users from July 1, 2015. ${ }^{7}$ For these users, we observe demographic information, such as their age and county of residence, as well as the set of other Facebook users they are connected to. Using the language adopted by Facebook and its users, we call these connections "friends." 8 Since we want to anonymously merge Facebook users to public-record information on their housing transactions, we restrict our analysis to studying the housing market behavior of individuals living in Los Angeles county. Focusing on one county ensures conformity in the availability of transaction information, which is recorded at the county level, while analyzing Los Angeles county, the largest U.S. county by population, provides a large sample to maximize statistical power.

Our second data set includes snapshots from Acxiom InfoBase for the years 2010 and 2012. These data are maintained by Acxiom, a leading marketing services and analytics company, and contain a wide range of contemporaneous individual-level information compiled from a large number of sources (e.g., public records, surveys, subscriptions, and warranty registrations). The data include individual-level information on demographics (e.g., age, marital status, education, occupation, income), household size, and homeownership status. For homeowners, it also includes information on housing transactions from public deeds records (e.g., transaction date, transaction price, and mortgage amount), and property details such as property size from public assessor records. Facebook creates a unique, anonymized link to the Acxiom data, based on common characteristics in both data sets. ${ }^{9}$ We use these data to construct the two main regression samples we describe below.

\footnotetext{
${ }^{7}$ To be considered "monthly active", a user must have interacted with Facebook products within the past 30 days.

${ }^{8}$ In the U.S., Facebook mainly serves as a platform for real-world friends and acquaintances to interact online, and people usually only add connections to individuals on Facebook whom they know in the real world (Jones et al., 2013; Gilbert and Karahalios, 2009; Hampton et al., 2011). In our analysis, we treat each friendship link identically. We do not observe any communication or interaction between friends on Facebook that might allow us to infer differential tie strengths.

${ }^{9}$ Linking these data to the friendship network was done exclusively for this research project, and involved a scrambled merge-key based on common characteristics. 53\% of merges relied on email address. Other characteristics were full date of birth (51\%) or year-month of date of birth (28\%), last name (45\%) and first name $(84 \%)$, location at the level of zip code (44\%), county $(37 \%)$, and CBSA $(8 \%)$, and telephone number $(2 \%)$. Most matches are based on a number of these characteristics.
} 


\subsection{Regression Samples and Summary Statistics}

Change-of-Tenure Sample: Our first main regression sample consists of an anonymized panel of about 1.4 million Facebook users who lived in Los Angeles County in 2010, and whom we can match across the 2010 and 2012 Acxiom snapshots. In Section 3.1, we use these data to analyze how an individual's propensity to change homeownership status is affected by the house price experiences of her friends. We therefore call this regression sample the "change-of-tenure" sample. Table 1 shows summary statistics on characteristics of these individuals, split by 2010 homeownership status. The average renter had 348 total U.S.-based friends, of whom 155 lived outside the LA commuting zone, which includes Los Angeles and five surrounding counties. The average homeowner had 285 total friends, and 113 out-of-commuting zone friends. Panels A and B of Appendix Figure A1 show the full distribution of friend counts. In 2010, the average renter was 37 years old, the average homeowner was 43 years old. The average income of renters was lower than that of homeowners ( $\$ 52 \mathrm{k} v \mathrm{vs}$. $\$ 77 \mathrm{k}$ ). In $2010,18 \%$ of renters and $67 \%$ of owners were married. The average household size for renters was 1.9 , while the average household size for owners was 3.5.

Transaction Sample: The unit of observation in our second main regression sample is a housing transaction. For all homeowners in both Acxiom snapshots we have details on the transaction that started the current ownership spell. We can match more than 520,000 housing transactions in Los Angeles county since 1993 to the Facebook account of the respective homebuyer. The data contain transaction details and information on the underlying property. In Sections 3.2 and 3.3, we use these data to analyze how the house price experiences of an individual's friends in the 24 months prior to buying a house affects the size of her housing market investment, and the price paid for a particular house. We therefore call this regression sample the "transaction sample." Table 2 provides summary statistics, and Panels $\mathrm{C}$ and D of Appendix Figure A1 show the distribution of U.S.-based friends. The average transaction price was $\$ 403 \mathrm{k}$, the average loan-to-value ratio was about $85 \%$, and the average property size was $1,775 \mathrm{ft}^{2}$. The average homebuyer was 34 years old.

Other Data Sets: The smaller data sets used in our analysis of survey responses and county-level outcomes are described in Sections 2 and 5.

\subsection{Empirical Strategy to Identify Effect of Social Interactions}

In the following sections, we analyze how the house price experiences within an individual's social network affect that individual's housing market beliefs and behavior. We next describe our empirical approach and the construction of our key explanatory variables. Our baseline specifications in Sections 2 and 3 are regressions of outcome variables such as the size of the housing market investment on measures of the house price experiences within individuals' social networks, and control variables:

$$
\text { Outcome }_{i, t_{2}}=\alpha+\beta \text { FriendHPExp }_{i, t_{1}, t_{2}}^{N}+\gamma \mathbf{x}_{i, t_{2}}+\psi_{t_{2}}+\epsilon_{i, t_{2}}
$$


The key explanatory variable, FriendHPExp $p_{i, t_{1}, t_{2}}^{N}$, captures the average house price experience in individual $i$ 's social network $N$ between times $t_{1}$ and $t_{2}$. Each individual has different social networks, $N$ : the broadest network covers all her friends, but other sub-networks include, for example, her out-ofcommuting zone friends or her work friends. FriendHPExp $p_{i, t_{1}, t_{2}}$ is constructed as in equation 2, where $c$ indexes counties, ShareFriend $s_{i, N, c}$ measures the share of person $i$ 's network $N$ that live in county $c_{,}^{10}$ and $\Delta H P_{c, t_{1}, t_{2}}$ captures the house price changes in county $c$ between $t_{1}$ and $t_{2}$, as provided by Zillow.

$$
\text { FriendHPExp } P_{i, t_{1}, t_{2}}^{N}=\sum_{c} \text { ShareFriends } s_{i, N, c} \times \Delta H P_{c, t_{1}, t_{2}}
$$

In order to interpret estimates of $\beta$ in regression 1 as evidence for social interactions, we rule out a number of potential alternative channels that might also induce a correlation between a person's housing market expectations and investments and her friends' recent house price experiences.

A first concern is that FriendHPExp might be correlated with an individual's own house price experiences or her own past capital gains, which could directly affect her expectations and investment decisions. In particular, since most people have many local friends, shocks to LA house prices will shift FriendHPExp, and more so for people with a larger share of friends in LA. Since our sample is restricted to LA residents, any direct effect of past LA house prices that is equal across LA residents is absorbed by time fixed effects, $\psi_{t_{2}}$. However, any direct effect that was stronger for people with a larger share of friends in LA would confound our interpretation of $\beta$. For example, suppose that a person who has lived in LA for longer has a larger share of her friends in LA, and is more likely to own a house in LA. In that case, higher LA house prices can have a stronger effect on this person's housing market investments both because her network has experienced larger house price increases, and because she has larger past capital gains on her existing home. If we cannot control for such past capital gains in $\mathbf{X}_{i, t_{2}}$, we would erroneously attribute all observed effects to social interactions. ${ }^{11}$

To address this challenge, we estimate regression 1 using an instrumental variables approach, where we instrument for FriendHPExp with the house price experiences of friends living outside of the Los Angeles commuting zone. ${ }^{12}$ This approach identifies $\beta$ using only variation in FriendHPExp that is independent of both LA house price movements and individual-specific variation in the share of LA-based friends, which, as discussed, might interact to induce a correlation between FriendHPExp and our outcome variables through a channel other than social interactions.

\footnotetext{
${ }^{10}$ We only observe one snapshot of the Facebook social graph, so we cannot exploit time-series variation in an individual's social network. FriendHPExp $p_{i, t_{1}, t_{2}}^{N}$ therefore measures the house price experiences between $t_{1}$ and $t_{2}$ of today's social network. For some of the transactions in the transaction sample, a property is purchased by more than one individual, and we can find both individuals on Facebook. In these cases, we pool the set of friends of the two buyers in our calculation of FriendHPExp $p_{i, t_{1}, t_{2}}^{N}$. Only considering the friend experiences of the head of household yields very similar results. Finally, to allow for consistent recording of house price movements, we only consider the experiences of U.S.-based friends.

${ }^{11}$ An alternative story would be that people who have lived in LA for longer might be more likely to directly extrapolate from LA house prices when forming their expectations, independently of the experiences in their social network. This would induce a relationship between housing market expectations and FriendHPExp that is not driven by any social interactions.

${ }^{12}$ Appendix Table A2 shows that our findings are nearly identical when restricting the instrument to the house price experience of friends living outside of California.
} 
Even with this approach, a related concern arises if there were many people that recently moved to LA from parts of the country where they have many friends. For these people there might be a strong correlation between their own experiences and past capital gains, and the experience of their friends that live outside of the LA commuting zone. To address this concern, we document that all results are robust to removing recent movers to LA from our regression samples.

To interpret the instrumental variables estimates of $\beta$ as evidence for social interactions requires that in any given year the house price movements experienced by an individual's out-of-commuting zone friends only affect her beliefs and behavior through a social interactions channel. Importantly, this does not mean that individuals' social networks cannot systematically vary with those individuals' characteristics, even if not all these characteristics are observable. For example, it might be that people with graduate degrees are more likely to have friends in Boston, and are more likely to buy a house. However, since house prices in Boston in a given year can be either above or below the U.S. average, the same individual's social network will experience both above-average and below-average house price appreciation over time. ${ }^{13}$ This means that there is no social network that always experiences above-average or below-average house price appreciation. Consistent with this, Section 1.4 documents the absence of a correlation between observable individual characteristics and FriendHPExp in our data. In addition, in some specifications in Section 3.3, we can include buyer fixed effects, thus exploiting only within-individual time-variation in friends' house price experiences.

On the other hand, our interpretation does require that any shocks to an individual's desire or ability to buy a house in a given year do not vary systematically with the house price movements in that year in those geographically-distant areas where this individual has friends. This is a much weaker assumption than what is commonly needed in the peer effects literature to overcome the identification challenges highlighted by Manski (1993). For example, it would not be problematic if people have children around similar times as their friends do, and therefore buy houses around similar times as their friends. This is because FriendHPExp does not depend on the housing market decisions of an individual's friends. Instead, it is only driven by the house price movements in the counties where those friends live. ${ }^{14}$ Therefore, challenges to our identification have to come from shocks which not only affect an individual's own housing market expectations and decisions, but which also move equilibrium house prices in geographically-distant counties where that individual has friends.

Along those lines, we have been able to identify and address one potential challenge to our interpretation. Suppose that people who work in the tech sector have more friends in Silicon Valley. During tech booms, tech employees in LA might have more resources to buy a house, and the increase in

\footnotetext{
${ }^{13}$ In that sense, we exploit a variation similar to Bartik-instruments regularly employed in public finance. See Conley and Udry (2010) for a related empirical strategy. Appendix Figure A5 shows that the set of counties experiencing above-average house price growth varies over time.

${ }^{14}$ There might be additional interesting peer effects in the housing market behaviors of individuals. For example, consumption externalities such as a "keeping up with the Joneses" effect might make people more likely to buy a bigger house when their friends buy bigger houses. Identifying the importance of such effects is beyond the scope of this paper. Indeed, as discussed above, we view the fact we do not focus on the effect of friends' actions, but only on the effect of friends' experiences as a strength of our paper, since it vastly limits the set of alternative interpretations of our empirical results.
} 
housing demand by the many tech employees in Silicon Valley drives up house prices there. Without controlling for time $\times$ employment sector fixed effects, one might falsely attribute large housing investments by Los Angeles-based tech employees in those years to social interactions. We directly address this identification challenge by showing that our results are robust to focusing on the sample of buyers who work in geographically non-clustered professions (e.g., teachers and legal professionals). In addition, to further address concerns about possible confounding effects from income shocks to connected counties, we present specifications that control for friend-weighted income and unemployment rates, both in levels and in changes, over the past 24 months. ${ }^{15}$ These measures are constructed similarly to equation 2, where $\Delta H P_{c, t_{1}, t_{2}}$ is replaced by $I n c_{c, t_{2}}, \Delta I n c_{c, t_{1}, t_{2}}, U n e m p l_{c, t_{2}}$, and $\Delta U n e m p l_{c, t_{1}, t_{2}}$. We also estimate specifications that include year-specific controls for a rich set of observable individual characteristics. We find that none of these controls affect our estimates of $\beta$. These findings suggest that our estimates are not driven by changes to the economic conditions of an individual's friends, which may correlate with both this individual's own behavior and her friends' house price experiences.

Finally, in Section 3.5 we also rule out a number of remaining alternative explanations for our findings. In particular, we show that bequest-related stories and consumption externality stories such as a "keeping up with the Joneses" cannot explain our findings.

\subsection{Summary Statistics of Experience Measures}

There is significant variation across individuals in their friends' average house price experiences. Table 1 shows that the average 2010 renter in the change-of-tenure sample had friends who experienced a 7.2\% house price decrease between December 2008 and December 2010. ${ }^{16}$ The standard deviation of this measure across individuals is about $2 \%$. The standard deviation of out-of-commuting zone friends' house price experiences is about twice as large. Panels A and B of Figure 1 plot the distribution

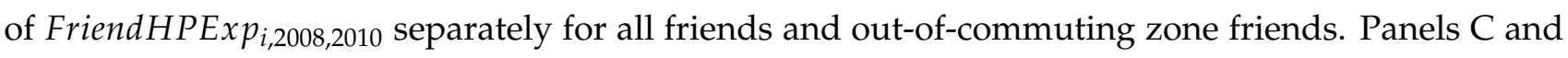
D show the respective distributions of FriendHPExp $p_{i, t, t-24 m}$ of buyers in the transaction sample. Some of the variation in these latter measures comes from pooling transactions across years with different levels of U.S. house price changes. Indeed, in Table 2 the across-transactions standard deviation of FriendHPExp $p_{i, t, t-24 m}$ falls from $20.1 \%$ to $3.6 \%$ after conditioning on the transaction quarter.

In Section 4 we estimate a version of regression 1 in which we also control for the dispersion of individuals' friends' house price experiences in addition to FriendHPExp, allowing us to test whether having friends with more varied house price experiences has an effect on housing market behavior. We construct this second variable, Dispersion $_{i, t_{1}, t_{2}}^{N}$ as the 5-95 percentile difference in the house price experiences of the network- $N$ friends of individual $i$ between $t_{1}$ and $t_{2}$. Tables 1 and 2 and Panels $\mathrm{E}$ and $\mathrm{F}$ of Figure 1 document a large average dispersion of the house price experiences of the same individual's friends, with an average 5-95 percentile spread in friends' house price experiences in the change-of-tenure sample of $19.0 \%$ for renters, and $18.4 \%$ for home owners.

\footnotetext{
${ }^{15}$ We use gross income per capita from the IRS Tax Statistics SOI. Unemployment statistics come from LAUS.

${ }^{16}$ We drop the $17 \%$ of individuals with fewer than 10 out-of-commuting zone friends, for whom the measure of friends' out-of-commuting zone house price experience is noisy; however, our results are robust to variation in this cutoff.
} 
Variation within and across individuals in friends' house price experiences is driven by differences in the geographic spread of individuals' social networks, together with different regional house price movements. In fact, the median individual across our samples has friends in only about 35 of the more than 3,000 U.S. counties. Consider Figure 2, which maps the friendship networks of three different individuals renting in Los Angeles in 2010. Panels A and B show these friendship networks for two individuals whose friends are clustered around Chicago and Oklahoma, respectively; Panel $\mathrm{C}$ presents the friendship network of an individual whose friends are more evenly distributed across U.S. population centers (see Appendix Figures A2 and A3 for additional examples). These differences are driven, for example, by where individuals grew up, or where they went to college.

As discussed in Section 1.3, our identifying assumption is that the house price movements experienced by an individual's out-of-commuting zone friends only affect her beliefs and behavior through a social interactions channel. A first test of how reasonable this assumption is considers whether an individual's out-of-commuting zone friends' house price experiences are correlated with observable characteristics of that individual. When we regress FriendHPExp OutCZ change-of-tenure sample on the characteristics presented in Table 1, the regression yields an $R^{2}$ of only $2 \%$, suggesting that essentially none of the variation in friends' house price experiences is explained by characteristics of the individual. This is despite the fact that those characteristics have significant predictive power for homeownership transition probabilities in this sample (see Section 3.1). ${ }^{17}$

\section{Facebook Survey on the Attractiveness of Property Investments}

In this section we document that social interactions have important effects on individuals' perceptions of the attractiveness of housing market investments, and thus have the potential to induce expectation heterogeneity among otherwise similar individuals operating in the same local housing market.

To establish this fact, we show that individuals' perceptions of whether buying local property is a good investment respond to the recent house prices experiences in their social networks. We analyze responses to a short user survey conducted by Facebook in November 2015. The survey targeted Facebook users living in Los Angeles through a post on their News Feed. ${ }^{18}$ It informed users that "Facebook is helping researchers understand what real people think about the economy. Your survey responses will be combined with the information that you publicly share on Facebook and average house prices to better help us understand the housing economy. Help us out by answering the following questions, your responses will be kept anonymous," followed by four multiple-choice questions. As we discuss below, the ordering of the questions was varied to minimize the role of framing effects in explaining variation in responses.

\footnotetext{
${ }^{17}$ We control for these characteristics in a flexible way, as discussed in Section 3. For example, we put in fixed effects for 5 -year age buckets, for each of the 15 different occupations, for each education level, for each value of household size, and for each income bucket. We also control for the change in marital status and income between 2010 and 2012.

${ }^{18}$ A person's News Feed is a personalized, constantly-updating list of content posted by friends and followed pages (e.g., messages, photos, videos), advertisements, and surveys. It is shown to users as the landing page when they log onto Facebook. Appendix Figure A4 shows a screenshot of the survey interface in a user's News Feed.
} 
1. How informed are you about house prices in your zip code?
$[x]$ Not at all informed
$[x]$ Somewhat informed
[x] Well informed
$[x]$ Very well informed

2. How informed are you about house prices where your friends live?

$[x]$ Not at all informed $[x]$ Somewhat informed $\quad[x]$ Well informed $\quad[x]$ Very well informed

3. How often do you talk to your friends about whether buying a house is a good investment?

\section{$[x]$ Never $\quad[x]$ Rarely $\quad[x]$ Sometimes $\quad[x]$ Often}

4. If someone had a large sum of money that they wanted to invest, would you say that relative to other possible financial investments, buying property in your zip code today is: ${ }^{19}$

$[x]$ A very good investment $[x]$ A somewhat good investment $[x]$ Neither good nor bad as an investment $\quad[x]$ A somewhat bad investment $\quad[x]$ A very bad investment

We observe 1,242 survey responses. 55\% of respondents are male. The respondents' age ranges between 19 and 75 years, with an average of 46 years, and an interquartile range of 35 - 56 years. Respondents are spread over 113 Los Angeles zip codes, but 24\% (40\%) of them live in the 10 (20) most represented zip codes. In the next section, we analyze how the average house price movements in individual $i$ 's social network in the 24 months before answering the survey, Friend HPExp All ${ }_{i, 2013,2015}$, affect her optimism about property investments. There is significant variation in this experience measure, which has a mean of $18.3 \%$, a standard deviation of $2 \%$, and a $10-90$ percentile range of $4.5 \%$. Panel E of Figure 3 plots the full distribution of FriendHPExp All ${ }_{i, 2013,2015}$ across the survey respondents.

Panels A - D of Figure 3 plot the distribution of responses to each survey question. Most respondents believe that buying property is at least a somewhat good investment, but we observe significant heterogeneity in respondents' beliefs about the attractiveness of real estate investments. About $77 \%$ of individuals claim to be at least "somewhat well informed" about house prices where their friends live, while $27 \%$ are "well informed" or "very well informed." Over half of the respondents report talking at least "sometimes" to their friends about whether buying property is a good investment, while $15 \%$ talk "often." There is no relationship between an individual's friends' house price experiences and her propensity to talk to her friends about investing in the housing market: the average house price experiences of the respondents to the four possible answers to Question 3 are $18.4 \%, 18.3 \%, 18.3 \%$, and $18.5 \%$ respectively. ${ }^{20}$ Overall, we find that many individuals regularly interact with their social network to discuss the attractiveness of property investments, suggesting a potentially important role for social interactions in influencing housing market expectations and investments.

\footnotetext{
${ }^{19}$ The wording to this question, which will be our main outcome variable of interest, corresponds to the wording of a question on the New York Fed Survey of Consumer Expectations.

${ }^{20}$ During the 2013-2015 period, nearly all housing markets in the U.S. saw house price increases. Therefore, our finding suggests that conditional on living in an area with increasing house prices, how much prices increase does not influence how much people talk to their friends about housing market investments. We cannot rule out that such communication becomes more or less common during periods of falling house prices.
} 


\subsection{Friend Experiences and Perceptions of the Attractiveness of Property Investment}

Regression 3 analyzes the relationship between the house price experiences of an individual's friends and her belief whether buying property is a good investment. The dependent variable is an individual's response to Question 4. $\mathbf{X}_{i}$ controls for the age and gender of the respondent. Since respondents are asked to evaluate the attractiveness of buying property in their own zip code, and the true attractiveness of such investments can vary across zip codes, we also include zip code fixed effects, $\psi_{z i p}$.

$$
\text { ResponseQ4 } 4_{i}=\alpha+\beta \text { FriendHPExp } p_{i, 2013,2015}^{A l l}+\gamma \mathbf{X}_{i}+\psi_{z i p}+\epsilon_{i}
$$

We take two approaches to deal with the ordinal nature of the responses to Question 4. In Table 3 we code the answers to Question 4 with the numbers 1 to 5, with 5 corresponding to the most optimistic view on property investments. This approach assumes that the "distance" between each of the 5 possible answers to Question 4 is the same. Using this coding, the dependent variable measuring optimism about property investments has a standard deviation of 1.06. Importantly, most of this heterogeneity is across individuals responding about investing in property in the same zip code: when conditioning on $\psi_{z i p}$, the standard deviation of Response $Q 4_{i}$ remains at 0.98 .

Column 1 presents OLS estimates of equation 3. Holding zip code, age, and gender fixed, an increase in friends' house price experiences makes respondents more optimistic about the attractiveness of investing in property: a one-standard deviation increase in FriendHPExp $p_{i, 2013,2015}^{A l l}$ is associated with a statistically significant 0.08 standard deviation increase in our measure of optimism, ResponseQ $4_{i}$.

As discussed in Section 1.3, one concern with the OLS specification in column 1 is that in years when Los Angeles house prices go up, those individuals with more friends in Los Angeles have higher FriendHPExp All ${ }_{i, 2013,2015}$. If higher local house prices also had a particularly strong direct effect on the expectations of individuals with more local friends through channels other than social interactions, this would confound our interpretation of $\beta .{ }^{21}$ We therefore move to an instrumental variables (IV) estimation of regression 3, where we instrument for FriendHPExp All $P_{i, 2013,2015}$ with the house price experience of respondent $i$ 's out-of-commuting zone friends. Column 2 of Table 3 shows the reduced form, and column 3 the IV specification. The point estimates are similar to those in the OLS specification. ${ }^{22}$

For survey respondents that only recently moved to LA, possibly from areas in which they also have many friends, FriendHPExp $p_{i, 2013,2015}^{\mathrm{OutCZ}}$ might be correlated with their own house price experience, in which case even the IV strategy could not separate the effect of social interactions from that of extrapolative expectations. In column 4, we thus restrict the sample to survey respondents that already lived in LA in 2012. The results in this subsample are very similar. In column 5, we winsorize FriendHPExp (and the instrument) at the 5\% level, to test the importance of outliers in driving our results. The effect of friends' house price experiences is slightly stronger in this sample.

\footnotetext{
${ }^{21}$ For example, people who have lived in LA for longer might have a larger friend share in LA, and might also be more likely to form expectations by extrapolating past LA house price movements. Past house price increases in LA could thus lead to more optimism about housing investments both through more extrapolation and through social interactions.

${ }^{22}$ Results are similar when instrumenting with the house price experiences of out-of-state friends (Appendix Table A2).
} 
A common concern with analyzing survey data is the possibility that the framing and ordering of questions affects the responses. In particular, given the order of questions described above, one might worry that by first asking the respondents whether they knew about house prices where their friends live, one might prime them to place more weight on those experiences when subsequently reporting their own perceptions of the attractiveness of housing market investments. To rule out such effects, for about $35 \%$ of respondents the order of questions was reversed, asking them first about their housing market expectations ("Question 4"), before eliciting responses to the other questions. Column 6 shows that the correlation between a respondent's friends' house price experiences and her own expectations is, if anything, slightly stronger in the sample of respondents who first reported their own housing market perceptions. This suggests that framing effects do not significantly affect our results.

We next provide additional evidence that the correlation between friends' house price experience and own housing market beliefs is driven by social interactions, and not by other confounding shocks. In column 7, we interact FriendHPExp with each possible response to Question $2{ }^{23}$ The relationship between an individual's assessment of whether buying property is a good investment and the house price experiences of that individual's friends is stronger for individuals who report to be aware of house prices where their friends live. Similarly, in column 8 we interact FriendHPExp with each possible response to Question 3. For respondents who report that they regularly talk to their friends about whether property is a good investment, we find a strong relationship between their friends' house price experiences and their own assessment whether property in their own zip code is a good investment. Indeed, for respondents that often talk to their friends about property investments, the effect size is twice the effect size of the average individual. For respondents that never talk to their friends about investing in the housing market, no statistically significant relationship is found. This finding suggests that the observed correlation is truly driven by social interactions, and not, for example, by people reading local newspapers from areas where they have friends. ${ }^{24}$

We also take a second approach to dealing with the ordinal nature of the responses to Question 4. Appendix Table A1 presents cumulative odds ratios from an ordered logit model, giving us the effect of a one unit increase in Friend HPExp on the odds of belonging to a certain category or higher versus belonging to one of the lower categories. ${ }^{25}$ In this specification, we cannot use an instrumental vari-

\footnotetext{
${ }^{23}$ We also include non-interacted indicator variables for each possible response to Question 2, but, in the interest of space, do not report the corresponding coefficients.

${ }^{24}$ For many of the questions we address in the next Sections, it would also be interesting if belief dispersion were induced by reading different newspapers. Indeed, as we discuss below, all we require is a force that shifts beliefs, but that does not affect housing investment behavior through a channel other than affecting beliefs.

${ }^{25}$ An ordered logit models presumes the existence of a latent continuous dependent variable, in our case a measure how good an investment buying a house is, that can only be observed as a set of categories, in our case the five possible responses to Question 4. The model imposes that the slope of the response of the latent dependent variable to a one-unit increase in friends' house price experiences is the same for the entire span of the latent variable. Since no consistent estimator for an ordered logit model explicitly incorporates fixed effects, the literature proposes different estimation strategies. We estimate the ordered logit model using the "Blow Up and Cluster (BUC)" approach of Baetschmann, Staub and Winkelmann (2015). This approach recodes the original dependent variable with 5 categories into 4 different dichotomizations with 4 different thresholds. Each observation of the original data is then duplicated 4 times, once for each dichotomization. After "blowing up" the data, a conditional logit estimation with clustered standard errors is applied to the whole sample. Riedl and Geishecker (2014) show that this BUC approach delivers the most unbiased and most efficient parameter estimates.
} 
ables approach, but instead directly include the house price experience of all friends. The statistically significant estimate in column 1 suggests that the odds that an individual perceives buying property in her zip code at least a somewhat good investment increase by a factor of 1.08 for every percentage point increase in the house price appreciation in her social network. The results in the other columns are also consistent with the findings from the specifications in Table 3. For example, for individuals who report to often talk to their friends about investing in the housing market, a one percentage point increase in the house price experience within their social network increases the probability of perceiving buying local property an at least somewhat good investment by $25 \%$.

Overall, these results suggest an important role for social interactions in affecting individuals' assessments of the attractiveness of housing market investments. All else equal, an individual perceives property to be a more attractive investment when there are larger house price gains within her social network. These effects are statistically significant, economically large, and more pronounced the more an individual reports to be talking with their friends about whether housing is a good investment.

\section{Individual-Level Outcomes: Average Friends' House Price Experience}

We next build on our findings from Section 2 to argue that friends' house price experiences provide a quasi-exogenous shifter of individuals' housing market expectations. We then analyze the effect of differences in expectations induced by this variation on housing market behavior. In particular, we argue that any correlation between individuals' housing market behavior and their friends' house price experiences is only driven by the effect of these experiences on individuals' expectations, and rule out a number of alternative possible mechanisms. Our empirical approach thus allows us to assess the quantitative importance of housing market expectations for housing investment decisions, relative to, for example, life-cycle motives or credit market access.

We first focus on the effect of friends' house price experiences on the extensive margin of housing investment. We document that individuals whose friends experienced larger recent house price increases are more likely to transition from renting to owning, and less likely to transition from owning to renting. Section 3.2 shows that the intensive margin of an individual's housing investment - the square footage of the home bought - also responds to the house price experiences in her social network. Section 3.3 documents that individuals whose friends experienced more positive house price movements are willing to pay more for a given home. A higher house price appreciation of the sellers' friends is also associated with higher transaction prices. Section 3.4 shows that individuals whose friends experienced more positive house price movements make a bigger downpayment. This effect is primarily driven by having friends with extreme negative house price experiences. Section 3.5 presents evidence against bequest motives and consumption externalities as alternative explanations of our findings. Section 3.6 explores possible reasons for why households might adjust their expectations based on their friends' housing market experiences. 


\subsection{Extensive Margin of Housing Market Investments: Tenure Choice}

We first analyze the effect of friends' house price experiences on the extensive margin of the housing investment choice, i.e., the decision of being a homeowner or a renter. We begin by focusing on the 433,836 Los Angeles-based renters in 2010 in the change-of-tenure data set. Regression 4 considers whether their propensity to transition to homeownership by 2012 is affected by the house price experiences of their friends in the previous two years, FriendHPExp All

$$
\mathbb{1}_{\text {Owner }_{i, 2012}}=\alpha+\beta \text { FriendHPExp }_{i, 2008,2010}^{A l l}+\gamma \mathbf{X}_{i, 2010}+\omega \Delta \mathbf{X}_{i, 2010,2012}+\psi_{z_{2 i p_{2010}, z i p_{2012}}}+\epsilon_{i}
$$

The dependent variable is an indicator of whether individual $i$ is a homeowner in 2012. We control for paired $2010 \times 2012$ zip code fixed effects (e.g., an indicator variable for all individuals that lived in zip code 90001 in 2010 and in zip code 90005 in 2012), which allows us to isolate the decision of whether to buy a house from the decision of where to live. We also control for the 2010 demographics of individual $i, \mathbf{X}_{i, 2010}$, and changes in these demographics between 2010 and 2012, $\Delta \mathbf{X}_{i, 2010,2012}$. As outlined in Section 1.3, we use the house price experiences of friends who live outside the LA commuting zone as an instrumental variable for the experiences of all friends, allowing us to isolate the effect of social interactions from any direct effects of past local house price changes.

Panel A of Table 4 shows results from regression 4 . Standard errors are clustered at the zip $2010-$ level. On average, about $18 \%$ of 2010 renters own a home by 2012. The estimate of $\beta$ suggests that every percentage point increase in house price experiences of an individual's friends increases her probability of becoming a homeowner by 0.61 percentage points. ${ }^{26}$ A one standard deviation increase in FriendHPExp All ${ }_{i, 2008,2010}$ thus increases the probability of buying a home by 1.2 percentage points.

Throughout our analysis, we control for demographics of the individuals. We deal with missing characteristics in two ways. In column 1 and most other specifications, we replace missing characteristics with their own fixed effect. This approach allows us to use the full data in the estimation of $\beta$, but is potentially problematic if missing characteristics occur non-randomly in a way that is correlated with FriendHPExp. In column 2, we focus only on the sample of individuals for which we observe a complete set of control variables. The point estimates of $\beta$ are similar in both cases.

Appendix Table A3 shows the coefficients on the control variables for the estimates in column 1 of Table 4. Larger households, growing households, households with higher income, and households with higher income growth are all more likely to transition from renting to owning. Both getting married and getting divorced raise the probability of buying a house. Medical professionals are the most likely to transition from renting to owning. The probability of transitioning from renting to owning is lowest in a person's 20s, increases until their mid-30s, and is then flat before jumping again for retirees. In addition to documenting the quality of our demographic controls, these estimates allow us to interpret the magnitude of the effect of changes in friends' house price experiences relative to

\footnotetext{
${ }^{26}$ Appendix Table A2 shows that results are robust to using price experiences of out-of-state friends as the instrument.
} 
important life-cycle factors. For example, we find that for renters, a 10 percentage point higher house price experience in their social network has a similar effect on the probability of buying a house as the addition of a family member. This suggests that house price expectations have effects on housing market investments that are of similar magnitude as life-cycle motives.

While the $\psi_{z i p_{2010}, z i p_{2012}}$ fixed effects help us to separate the choice of location from the choice of tenure, in column 3, we restrict our analysis to individuals that lived in the same zip code in 2010 and 2012 , i.e., to people for whom moving to a different part of LA is not a driver of ownership change. The average probability of transitioning from renting to owning is lower in this sample, at $10.2 \%$. The estimated effect of friends' house price experiences on the probability of buying a home is only marginally smaller than the full-sample estimates (0.52 compared to 0.61 ).

In column 4, we restrict the sample to individuals who moved within LA between 2010 and 2012. In this sample, $29 \%$ of individuals transitioned from renting to owning; the effect of friends' house price experiences on transitioning to homeownership is almost twice as large as our baseline estimates. In column 5, we restrict the sample to individuals older than 35. This tests how much of the effect on the transition from renting to owning comes from individuals that form a household for the first time. The estimate in this sample is the same as for the full sample, suggesting that the effect of friends' house price experiences on renters' purchasing decision does not depend on their age.

Finally, we address one possible concern about our interpretation of these estimates as evidence for an important role of house price expectations, proxied for by differences in friend experiences, in explaining individuals' home buying decisions. As discussed in Section 1.3, many individuals have friends in the same sector of employment. If this sector featured significant geographic clustering, positive shocks to that sector might both enable an individual to buy a house, and drive up house prices in the regions where the individual has friends. To rule out that such confounding effects are driving our results, column 6 only exploits variation in friends' house price experiences among individuals who are either retired or who work in geographically non-clustered professions. The estimated effect of friends' house price experiences is similar in this specification. ${ }^{27}$ Table 8 provides additional evidence that common shocks to individuals and their social networks do not confound our interpretation, by directly controlling for friend-weighted levels and changes of economic conditions (income and unemployment rate) in individuals' social networks. The estimated effect of friends' house price experience on the purchasing decision remains unchanged.

So far, we have focused on the effect of friends' house price experiences between 2008 and 2010 on a renter's decision whether to become a homeowner between 2010 and 2012. However, friends' house price experiences between 2010 and 2012 might also affect the decision to buy a house by 2012. In column 7, we therefore also include friends' house price experiences between 2010 and 2012 in addition to their experiences between 2008 and 2010. A one percentage point higher house price

\footnotetext{
${ }^{27}$ In this specification, we add an indicator that is equal to 1 for all professions not identified as geographically nonclustered, and set FriendHPExp equal to zero for these individuals. This allows us to only exploit variation in FriendHPExp coming from individuals in geographically non-clustered professions while using the full sample to estimate the effect of the control variables and fixed effects.
} 
appreciation by an individual's friends between 2010 and 2012 indeed further increases the likelihood of that individual becoming a homeowner by 0.32 percentage points. The effect of friends' house price experiences between 2008 and 2010 is unaffected.

Panel A of Table 4 focused on the behavior of 2010 renters. In Panel B, we instead focus on 2010 homeowners, and test how their friends' house price experiences affect the probability that they sell their home by 2012. About $94 \%$ of 2010 homeowners continue to own a home in 2012. Columns 1 and 2 show that for 2010 homeowners, the effect of friends' house price experiences on the probability of owning a home in 2012 is a quarter to a third of the size of the effect for 2010 renters. However, conditional on moving within LA between 2010 and 2012, the effect of friends' house price experiences on the probability of owning in 2012 is of similar magnitude for 2010 owners and renters (see column 4). These findings suggest that homeowners with a less positive outlook on the housing market, proxied for by the house price experiences in their social network, are more likely to sell their house.

\subsection{Intensive Margin of Housing Market Investments}

We next analyze whether, conditional on buying a house, the house price experiences of buyers' friends affect the intensive margin of property investment. This allows us to further test predictions from models of investment with differentially informed agents, which suggest that the portfolio share in an asset is increasing in an investor's optimism. The unit of observation in regression 5 is a property purchase of individual $i$ at time $t$. The dependent variable is the log square footage of the purchased property, multiplied by 100 to facilitate interpretation of the coefficients. The key explanatory variable, FriendHPExp All $p_{i, t, t-24 m}$ is constructed as given by equation 2, and captures the average house price changes experienced by the buyer's friends in the 24 months prior to the purchase.

$$
\log \left(\text { PropSize }_{i, t}\right)=\alpha+\beta \text { FriendHPExp } p_{i, t, t-24 m}^{\text {All }}+\gamma \mathbf{X}_{i, 2010}+\psi_{t}+\epsilon_{i, t}
$$

In column 1 of Table 5, we control for purchase-month fixed effects and buyer characteristics in $\mathbf{X}_{i, 2010}$. The estimates suggest that a 5 percentage point (1.4 within-quarter standard deviation) increase in friends' average house price experiences is correlated with buyers purchasing a $1.7 \%$ larger property. ${ }^{28}$ These estimates confirm that buyers increase their portfolio share in housing when their friends have experienced larger house price increases; we argue that this is because social interactions with those friends have made these buyers more optimistic about local housing market investments.

As discussed in Section 1.3, challenges to this interpretation of the estimates would have to come from characteristics of the buyer that have a particularly strong direct effect on property investments in years when the buyers' friends experience particularly high house price increases. In column 2, we limit the scope of such possible confounding effects by interacting buyer characteristics with purchase-

\footnotetext{
${ }^{28}$ We observe buyer age at the time of the transaction, but for other buyer characteristics, such as occupation, marital status, and household size, we use values from the most proximate Acxiom snapshot. While the coefficients on the individual household characteristics are not the direct object of interest in this paper, Appendix Table A4 shows the coefficients on these characteristics. Richer and older people generally purchase larger properties. Larger households purchase larger properties, and married individuals buy larger properties than single individuals.
} 
year fixed effects. The estimates of $\beta$ are identical. In addition, in column 3, we only exploit variation in FriendHPExp among buyers working in geographically non-clustered professions. The effect of friends' house price experiences on individuals' buying behavior is only slightly smaller in this sample. Table 8 includes direct controls for the economic conditions within the buyers' social networks. The estimates are unaffected by these controls, indicating that common income or labor market shocks to individuals and their social networks do not explain the effect of friends' house price experiences.

For purchases before 2010, we do not know where the buyers previously lived. This introduces the possibility that housing wealth effects and not social interactions might explain some of our findings, even when we only exploit variation in the house price experiences of friends living outside the LA commuting zone. In particular, consider an individual moving to LA from Boston, where she has many out-of-commuting zone friends. If that individual previously owned a home in Boston, her wealth will depend on Boston house price movements in the years prior to the move. If this person then bought a larger property in LA, this might be either because her friends experienced a higher house price appreciation, or because she is richer, having had larger capital gains herself. To address this concern, we next focus on transactions since 2010 by individuals we can identify in the 2010 Acxiom snapshot. In column 4, which only analyzes buyers living in LA county in 2010, we remove any individuals whose past housing capital gains might be correlated with the house price experiences of their out-of-commuting zone friends. In column 5, we restrict the sample to individuals that were renting in 2010, removing any potential of housing wealth effects driving our results. In both subsamples, we estimate very similar effects of friends' house price experiences on housing market behavior as in the full sample. These results suggest that housing wealth effects that are correlated with friends' house price experiences do not explain our findings.

We also analyze to what extent purchasing a larger property is driven by purchasing a different type of home, such as a single family residence instead of an apartment. Column 6 includes property type fixed effects and the estimate is, if anything, larger than in the full sample, suggesting that buyers do not switch to a different type of home. Finally, when individuals choose to purchase larger properties, they can either purchase a larger house in the same neighborhood or move to a different neighborhood where larger properties are available. In column 7 , we add zip code fixed effects to measure the relative importance of these two factors. The estimate of $\beta$ drops by about $20 \%$, suggesting that most of the adjustment involves buying a larger property in a given area.

\subsection{Transaction Price Conditional on Property Characteristics}

So far, we have documented that the house price experiences within individuals' social networks affect the extensive and intensive margins of their property investment decision. In this section, we analyze the effects of the house price experiences of both the buyer's friends and the seller's friends on transaction prices. Conceptually, the reservation prices of both buyers and sellers would be affected by their perception of the attractiveness of local property investments, which we argue varies with their friends' house price experiences. In any bargaining model, the final transaction prices will then 
vary (weakly) with these reservation prices (Wheaton, 1990; Piazzesi, Schneider and Stroebel, 2015).

For this analysis, we again consider the transaction sample, and run hedonic regression 6 . The unit of observation is a transaction of house $h$, bought by individual $i$, at time $t$. The dependent variable is the log of the transaction price, multiplied by 100 to facilitate interpretation of the coefficients. ${ }^{29}$ All specifications include zip code fixed effects, $\phi_{z i p}$, and purchase-month fixed effects, $\psi_{t}$. We control for characteristics of the house, $\mathbf{X}_{h}$, including property type, size, and age. We also control for characteristics of the buyer, $\mathbf{Z}_{i}$, including buyer age, marital status, household size, and occupation.

$$
\log \left(\text { Price }_{h, i, t}\right)=\alpha+\beta_{1} \text { FriendHPExp } p_{i, t, t-24 m}^{A l l}+\beta_{2} \mathbf{X}_{h}+\beta_{3} \mathbf{Z}_{i}+\psi_{t}+\phi_{z i p}+\epsilon_{h, i, t}
$$

Table 6 presents the results of regression 6 . The estimate in column 1 suggests that when homebuyers' friends experience a 5 percentage point higher house price appreciation, the transaction price for a given home is $3.3 \%$ higher. The $R^{2}$ of the regression is almost $80 \%$, confirming that our hedonic property characteristics capture many of the important determinants of house prices. ${ }^{30}$

As before, we rule out effects of FriendHPExp on transaction prices through channels other than the effect of social interactions on buyers' housing market expectations. In column 2, we interact buyer characteristics with the transaction year. Column 3 only exploits variation among employees in geographically non-clustered professions. Column 4 restricts the sample to home purchases since 2010 in which the buyer was a renter in LA in 2010. The result in the first specification is very similar to our baseline effect. The estimated coefficient is slightly smaller when we only exploit variation among people working in geographically non-clustered professions, and slightly larger when we focus on prior renters in LA. In Table 8, we directly control for economic conditions in the counties where an individual has friends. The estimated coefficient on friends' house price experience is similar, suggesting that our findings are not driven by common shocks to individuals and their friends.

While our hedonic regression controls for many of the important determinants of property price, one might be concerned that individuals with larger house price increases in their social networks purchase properties that differ on unobservable characteristics, which could bias the estimates of $\beta_{1}$. To rule out such confounding effects, column 5 of Table 6 includes property fixed effects in the regression. In this specification, $\beta_{1}$ is only identified by transactions of properties that we observe trading at least twice. Since we are comparing transaction prices for the same property, this specification holds constant all unobservable characteristics of the properties. Overall, we observe 36,892 transactions for properties that trade at least twice in our sample. As one would expect, including property fixed effects increases the $R^{2}$ further, to well over $90 \%$. Reassuringly, the effect of positive house price

\footnotetext{
${ }^{29}$ We observe transaction prices in ranges of about $\$ 50,000$. We take the mid-point of the range as the transaction price.

${ }^{30}$ While the coefficients on the individual property and buyer characteristics are not our object of interest, Appendix Table A5 shows these coefficients. Larger properties and single family residences trade at a premium. Married individuals and those employed in higher-paying professions pay a premium for purchases, either because they are purchasing properties that are superior on unobservable characteristics, or because they have higher search costs, and are therefore willing to pay more for a house to guarantee they are the eventual purchaser.
} 
experiences among a buyer's friends on the transaction price is unaffected. ${ }^{31}$

As discussed in Section 1.3, one concern with our interpretation of these results is that friends' house price experiences might also be correlated with unobserved buyer characteristics rather than just with buyer expectations. We argued above that this is unlikely to be the case, since our identification comes from the interaction of the geographic spread of an individual's friends and the timevarying house price experience in those counties. To highlight this source of identification, in column 6 of Table 6, we include buyer fixed effects. In this specification, all identification comes from individuals that we observe purchasing more than one property. ${ }^{32}$ Across those transactions, the friendship networks and unobservable characteristics of the individuals are held fixed, and the only force shifting FriendHPExp across the transactions is the house price development in the individuals' friendship networks across the periods in which the individuals bought a house. Our estimate of $\beta_{1}$ is very similar in this specification. The same individual pays $2.8 \%$ more for a house if her friends experienced a 5 percentage point higher house price appreciation over the previous 24 months.

So far, we have focused on the effect of the house price experiences of the buyers' friends on the transaction price. However, the transaction price in any bargaining model will depend on the valuations of both the buyer and the seller (Wheaton, 1990; Piazzesi, Schneider and Stroebel, 2015). In columns 7 and 8 of Table 6 , we thus also include the average house price experiences of the sellers' friends in the 24 months before the sale as an additional regressor. ${ }^{33}$ Our estimates suggest that when sellers' friends experience a 5 percentage point higher house price appreciation, they demand a higher price, leading to a $2.6 \%$ increase in transaction prices.The estimated effect of the buyers' friends' house price experiences on the transaction price remains unaffected. Column 8 further includes property fixed effects to ensure that the results are not driven by differences in unobserved property characteristics. The results are only somewhat smaller in this specification.

Lastly, we test an additional prediction of models with differences in individuals' expectations. In particular, these models predict that if expectations of market participants are orthogonal to other factors driving their investment decision, as we argue they are given our identification strategy, then the average buyer will be more optimistic than the average seller (e.g., Dávila, 2014). Indeed, we find that the house price experiences of buyers and sellers differ across the transactions in which we observe both. We find that, on average, buyers' friends have about 30 basis points less negative house price experiences than sellers' friends (-3.47\% vs. $-3.78 \%)$.

\footnotetext{
${ }^{31}$ In addition, one might worry that some of these properties were "flipped" and updgraded between the two transactions that we observe. However, the results are identical if we restrict the repeat sales sample to transactions that are more than five years apart or more than ten years apart.

${ }^{32}$ To observe multiple transactions by the same individual, we exploit the two cross-sections in the change-of-tenure data. This requires observing individuals living in two different owner-occupied properties across the two snapshots.

${ }^{33}$ In order to identify a seller in a transaction, we need to have observed that person previously as an owner of the same house, limiting ourselves to transactions after the 2010 Acxiom snapshot. We match the seller in about 20,000 transactions to their Facebook account. We include all transactions in the regression, even if we cannot match the seller to Facebook, in order to increase statistical power in estimating the coefficients on the property characteristics and the buyer experience. In particular, in that specification, we also include an indicator, $F B M i s_{i}$, that is equal to 1 for all transactions where we cannot match the seller to their Facebook profile, and 0 otherwise. We set FriendExp equal to zero when FBMiss $s_{i}=1$.
} 


\subsection{Loan-To-Value (LTV) Ratio}

In this section, we analyze the effect of friends' house price experiences on individuals' choice of downpayment. When taking out a mortgage, homebuyers face a menu of possible interest rates and downpayments. To understand how lenders set this menu, and how borrowers choose among the various options, it is useful to think of defaulting on a mortgage as exercising a put-option on the house: by defaulting, the borrower can return the house to the mortgage lender in exchange for being forgiven the remaining outstanding mortgage balance, which corresponds to the strike price of the option. ${ }^{34}$ The interest rates charged by the lender, which correspond to the option premia, depend on the lenders' expectations about future house prices, with lower interest rates charged when lenders think house prices are less likely to fall. In addition, when borrowers make a larger downpayment, house prices have to fall by more before it is in the borrowers' interest to default (i.e., the option is further "out of the money"), and lenders charge a lower interest rate.

When borrowers choose their downpayment, they trade off the higher interest cost of a mortgage with a higher LTV ratio against the benefits of having to put up less cash upfront and having a default option that is less "out of the money." More optimistic borrowers value the default option less, pushing them towards making larger downpayments. This effect is larger for borrowers that are less constrained, and for whom the cost of increasing the downpayment is thus smaller. In addition, the perceived value of the default option depends primarily on the probability assigned to large house price declines: disagreement about the probability of downside events thus has a larger effect on the choice of downpayment than disagreement about the probability of upside events. Hence, the left-tail of the return distribution within a buyer's social network should have a particularly strong effect on her choice of downpayment. We next provide evidence for each of these predictions.

In our data, we observe information on any mortgage that is still current at the time of the Acxiom snapshots. We focus our analysis on mortgages originated when the home was purchased; this means that our sample only includes information from transactions where the mortgage was not refinanced prior to 2010. For these mortgages, we calculate the LTV ratio at origination. ${ }^{35}$ In regression 7 , this LTV ratio is regressed on the borrowers' friends' house price experiences in the 24 months prior to taking out the mortgage. We include controls for buyer characteristics and month-of-origination fixed effects. We also control for the property's transaction price in a non-parametric way, so that the choice of the downpayment can be interpreted as being conditional on the total property value.

$$
\text { LTV_Ratio }{ }_{h, i, t}=\alpha+\beta_{1} \text { FriendHPExp } p_{i, t, t-24 m}^{\text {All }}+\beta_{2} \mathbf{X}_{i, t}+\psi_{t}+\epsilon_{h, i, t}
$$

Table 7 presents the results of regression 7 . The estimates in column 1 suggest that when homebuyers' friends experience a 5 percentage point higher house price appreciation, these buyers reduce the LTV

\footnotetext{
${ }^{34}$ In recourse states, lenders can seize other assets of the borrower, which complicates the analogy.

${ }^{35}$ We use all mortgages present at origination, and thus construct the combined loan-to-value ratio (CLTV). As with the transaction price, we do not observe precise mortgage amounts, but instead observe the amount in relatively-finely structured bins. We take the mortgage amount to be the mid-point of the bin.
} 
ratio by 1 percentage point; given an average downpayment of about $15 \%$, this corresponds to a $7 \%$ increase in the downpayment. In columns 2-4, we present evidence that our findings are not driven by common shocks to individuals and their social networks (see also the robustness checks in Table 8, were we directly control for the economic conditions in the counties where an individual has friends).

In column 5, we interact FriendHPExp with how constrained borrowers are, proxied for by the ratio of their income to the value of the purchased property. This variable has a mean of 0.28 and a standard deviation of 0.31 . The idea is that agents whose income is larger relative to the price of the property find it less costly to make larger downpayments. Consistent with this, we find that households with a higher income-property value ratio make larger downpayments on average. In addition, a two standard deviations increase in the income-price ratio increases the sensitivity of the downpayment to friends' house price experiences by about $12 \%$.

In columns 6 and 7, we analyze which parts of the distribution of friends' house price experiences have the largest effect on individuals' downpayment choices (in Section 4 we analyze the effects on the dispersion of experiences on all outcomes studied in this section). As discussed above, the value of the default option is primarily sensitive to the probability that individuals assign to large drops in house prices. To the extent that the subjective probability of such events is particularly affected by the worst house price experiences within individuals' social networks, we would expect the tails of the distribution of friends' house price experiences to have a particularly large effect on the downpayment. To see whether this is indeed the case, in column 6 we include, for each borrower, the 5th and 95th percentile of the distribution of experiences within their social networks, in addition to the mean of that distribution. As before, all moments of the distribution are instrumented for with their out-of-commuting zone counterparts. We find that a decline in the 5th percentile of the distribution is associated with agents making significantly smaller downpayments, consistent with such a move increasing their valuation of the default option. Interestingly, shifts in the 95th percentile of the distribution do not affect the choice of downpayment, consistent with that part of the distribution being less relevant for the value of the default option. In column 7 we include the median return instead of the mean return: again, we find strong effects of movements of the lower tail of the return distribution within a social network, and no effects of movements in the upper tail of that distribution.

\subsection{Remaining Alternative Stories}

We next present additional evidence against alternative stories of how friends' house price experiences may affect an individual's housing market behavior through channels other than social interactions.

Bequests: A first possible concern is that the house price experiences in a person's social network may directly affect the value of her expected bequests, which could influence her purchasing behavior through a wealth effect that is unrelated to social dynamics. We present three pieces of evidence that this mechanism cannot explain our findings. First, we separately exploit variation in the overall social network house price experience coming from three sub-sets of out-of-commuting zone friends: family members, work colleagues, and college friends. Appendix Figure A6 shows that house price 
movements across these three sub-networks are relatively uncorrelated, i.e., it is not necessarily the case that out-of-commuting zone work and college friends live in similar areas as out-of-commuting zone family friends. ${ }^{36}$ While an individual might expect higher future bequests when her family members experience higher house price growth, this is not the case for her college or work friends. Yet, Appendix Table A6 shows that the influence of the house price experiences in all three sub-networks on investment behavior is very similar, suggesting the bequest channel is relatively unimportant.

As a second piece of evidence against a bequest story, we show that our estimates are similar among individuals whose bequests are less likely to be affected by the house price movements of their U.S.-based out-of-commuting-zone friends: Appendix Table A7, Panel A shows the effects of friends' house price experience on housing investments when restricting the sample to individuals whose hometown is Los Angeles, and Panel B shows these effects when restricting the sample to individuals whose hometown is outside the United States.

Lastly, since most individuals can only expect bequests from a few close relatives within their social network, a bequest channel should be stronger when individuals' social networks are more geographically concentrated, and friends' overall house price experience more closely corresponds to that of those close relatives. Yet, Appendix Table A8 shows that the effects are unrelated to how many counties an individual has friends in, providing further evidence against a bequest story.

Consumption Externalities: A second alternative explanation for our findings is the possible presence of consumption externalities across individuals and their friends. For example, an individual might buy a house to "keep up with the Joneses" after her friends purchased a home. Since house prices and transaction volumes co-move, people are more likely to buy a house on average in regions where house prices go up. FriendHPExp could therefore be picking up the effect of friends' buying behavior on individuals' own investments, even though the actual behavior of an individual's friends is not used to construct this measure. There are two reasons why we believe that consumption externalities cannot explain our findings. First, Appendix Table A9 introduces controls for the level and change of trading volume in the counties where an individual has friends. ${ }^{37}$ The estimated effects of friends' house price experiences are nearly identical. Second, in Appendix Table A10 we only exploit variation in the house price experiences of out-of-commuting zone friends who are identified as renters in 2010, and who are thus unlikely to have bought a house when their house price experiences were measured. ${ }^{38}$ The estimates are, if anything, slightly larger in this sample, suggesting that we are indeed capturing an effect on individuals' housing market expectations through social dynamics.

\footnotetext{
${ }^{36}$ Facebook allows users to self-identify friends that are family members. College friends or work colleagues are identified as Facebook friends who went to the same college or report the same employer. Since not all individuals identify family members, or report where they work and went to college, sample sizes are somewhat smaller in these specifications. Robustness checks confirm that our baseline effect in these sub-samples is similar to the baseline effect in the full sample.

${ }^{37}$ Trading volume is measured as the annualized share of housing stock that transacts, and is obtained from Zillow. These data are only available since 1998. Hence the sample size for the price paid and size bought regression samples is lower.

${ }^{38}$ We can only ascertain the homeownership status of individuals in the Acxiom snapshots; therefore, we can only identify renters among those individuals that we could match to the Acxiom data. Overall, about 11.5\% of all out-of-commutingzone friends for an average individual in the transaction sample are identified as 2010 renters. Since homeowners generally remain homeowners, it is likely that a 2010 renter used to rent before 2010 .
} 


\subsection{Reasons for Updating}

While the questions addressed in this paper do not require us to identify why households update their housing market expectations based on the experiences within their social networks, we next present some evidence that might help to differentiate between various possible explanations.

First, many initially plausible explanations of the behavior we document involve individuals learning about some aggregate housing demand shock from observing house price growth across multiple geographies. If this were an important channel, we would expect individuals to respond more to their friends' experiences if these friends were more geographically dispersed, since the average experience of these friends would then be more informative about the national shock. Yet, Appendix Table A8 shows that, instead, the response of households to the experiences of their friends did not vary with the number of counties an individual has friends in.

Second, people might not be learning about a national housing demand shock, but about a more regional shock that has the potential to also affect Los Angeles house prices. To test whether such an effect is large, in Appendix Table A11 we split individuals into groups based on how predictive the house price experiences of their out-of-commuting zone social networks are for subsequent Los Angeles house price movements. We then obtain a separate estimate of the effect of network house price experience for each group. There is no evidence that people with more predictive networks respond systematically differently to others.

Third, Appendix Table A12 shows that the effect of friends' average house price experience on an individual's investment behavior declines weakly in the educational attainment of that individual. While the ability to engage in rational learning is not necessarily related to education levels, there is growing evidence that lower-income and lower-educated individuals are less likely to engage in optimal behavior along a large number of dimensions (e.g., Nielsen et al., 2014; Beshears et al., 2015b).

All these pieces of evidence point away from a purely rational explanation of our findings, though the precise predictions from a rational model would be sensitive to the specific details and assumptions of the underlying framework. This is perhaps unsurprising: If the house price movements in a particular part of the country were truly so informative that they would affect the valuation of a given house by a rational agent by thousands of dollars, then, in a rational world, everybody should update their expectation equally based on these house prices, which are available for free and in real time.

\section{Within-Individual Dispersion of Friends' House Price Experiences}

In the previous sections, we considered the effects of the average house price experiences within individuals' social networks on those individuals' housing market expectations and behavior. In this section, we analyze the effects of the dispersion in the house price experiences across an individuals' friends on these outcomes. As discussed in Section 1.3, we measure this dispersion as the 5-95 percentile difference in the 24-month house price experiences within the individual's social network.

From a theoretical perspective, the effect of a higher dispersion of individuals' friends' house price 
experiences on housing market expectations and behavior is ambiguous. In particular, one might expect that a higher dispersion would induce individuals to perceive housing to be a riskier, less attractive investment with a lower Sharpe Ratio. On the other hand, there is prior evidence suggesting that individuals are more likely to talk to their friends about successful investments (Heimer and Simon, 2012; Han and Hirshleifer, 2015), in which case a higher dispersion of true experiences might lead individuals to perceive a higher average experience among their friends. ${ }^{39}$ While the evidence presented in Section 2 suggests that there was no differential propensity to discuss property investments with friends depending on their house price experiences, this relationship might be different during periods of falling house prices. In addition, given the large fixed transaction costs for trading houses, higher uncertainty might increase the set of housing market beliefs under which investors are unwilling to adjust their portfolio. For renters' decision to buy, the "lower Sharpe ratio" and "higher inaction region" go in the same direction: both would reduce their propensity of buying a house. However, for owners, a higher dispersion of friends' house price experiences could make them either more likely to sell (since the investment is perceived to have a lower Sharpe ratio) or less likely to sell (due to the option value of delaying decisions in uncertain environments).

Table 9 presents results of the main specifications in Sections 2 and 3 when also controlling for the dispersion measure, instrumented for by its out-of-commuting zone counterpart. Column 1 finds no statistically significant relationship between the dispersion of friends' house price experiences and individuals' assessments of whether buying property is a good investment. On the other hand, columns 2 and 3 show that the dispersion in friends' house price experiences has a significant effect on the probability of buying or selling a house. Panel E of Figure 1 shows the across-individual variation in the dispersion measure in this sample, which has a mean of $19.0 \%$ and a standard deviation of $5.9 \%$ (see Table 1). The estimates in column 2 of Table 9 suggest that for renters, a one standard-deviation increase in the dispersion of their friends' house price experiences between 2008 and 2010 is associated with a 1.2 percentage point decline in the probability of buying a house between 2010 and 2012; column 3 shows that the same increase in the dispersion of friends' house price experiences increases the probability that 2010 homeowners sell their home by 2012 by 0.4 percentage points.

In columns 4 to 5 of Table 9, we analyze the transaction sample. We consider the effects of the dispersion of house price experiences within an individual's social network on the size of property bought, and on the transaction price paid. In this sample, our measure of dispersion has a withinquarter standard deviation of 6.1\% (see Table 2, and Panel F of Figure 1). Our estimates show that a one within-quarter standard deviation increase in the dispersion of friends' house price experiences is associated with buying a 0.9 percentage points smaller house, and a 2.5 percent lower transaction price for a given house. In column 6 we analyze the effects of dispersion on the choice of leverage: after observing more dispersed house price movements within the social network, households make

\footnotetext{
${ }^{39}$ Note that our measure of friends' house price experiences does not distinguish between the experiences of friends that are renters, and friends that are owners. This means that when house prices go up, some of those friends that are homeowners might be better off, while friends that are renters might actually be worse off.
} 
a smaller downpayment. Section 3.4 documented that this was primarily driven by the effects of a thicker left-tail of the return distribution within individuals' social networks.

These results show that an increase in the dispersion of house price experiences within individuals' social networks makes these individuals less willing to invest in the housing market. While the relatively small-scale survey does not detect an effect of dispersion on stated perceptions about the attractiveness of property investments, higher within-network dispersion of house price experiences is associated with a lower probability of buying for renters and a higher probability of selling for owners, with buying smaller properties, and with a lower transaction price for a given house.

\section{County-Level Prices and Trading Volume}

In the previous sections, we documented that the house price experiences within an individual's social network affect both her house price expectations and her actual housing investment behavior. In this final section of the paper, we analyze whether the characteristics of the social network house price experiences of individuals within a county affect aggregate county-level trading volume and prices. ${ }^{40}$ For this analysis, we construct an annual panel of house price changes and housing transaction volumes in 831 U.S. counties between 1998 and 2012, combined with information on the social networks of all Facebook users living in those counties. ${ }^{41}$ While identifying a causal impact of social dynamics on housing market activity at the county level is more challenging, our results suggest that the individual-level effects identified in the previous sections translate into significant aggregate effects.

We consider the effect of two county-level measures of house price experiences. The first measure computes the average of FriendHPExp $p_{i, t, t-12 m}^{N}$ over all individuals $i$ living in county $c, I_{c}$ :

$$
\overline{\text { FriendHPExp }}_{c, t}^{N}=\frac{1}{\left|I_{c}\right|} \sum_{i \in I_{c}} \text { FriendHPExp } N_{i, t, t-12 m}^{N}
$$

Variation in $\overline{\text { FriendHPExp }}_{c, t}^{N}$ is driven by where people in a county have friends, and how house prices in those areas move in a given year. Appendix Figures A7 - A9 give examples of the aggregate friendship networks of a number of U.S. counties; darker areas correspond to counties with a larger share of total friends. In most counties, between $40 \%$ and $60 \%$ of all friendship links are to people living in the same county. In addition, while all counties have a clustering of friendship links to geographically-

\footnotetext{
${ }^{40}$ Such a relationship does not necessarily follow from our individual-level findings. In particular, as discussed by Hong, Kubik and Stein (2005) in the context of financial markets: "But if one is only ever able to find evidence of word-of-mouth behavior among individuals, there will always be the objection that individuals are by themselves unlikely to exert a significant influence on stock prices, given the potentially powerful offsetting effects of professional arbitrage."

${ }^{41}$ County-level price and transaction volume data come from Zillow. The counties we analyze have a total 2010 population of 225 million. We observe a full set of annual observations for 654 counties (with a population of 207 million). For the other counties, we do not observe prices or volume for all years; restricting the sample to a balanced panel does not affect the results. For each county in the sample, house price experiences are aggregated over all individuals on Facebook who have at least 10 friends, which covers $53.7 \%$ of the county's Census population on average, ranging from $43.2 \%$ at the 10 th percentile to $64.0 \%$ at the 90 th percentile. In the average county, individuals have an average of 321 friends (134 out-of-state friends), ranging from 246 friends (86 out-of-state friends) at the 10th percentile of the county distribution to 408 friends (191 out-of-state friends) at the 90 th percentile of the county distribution.
} 
proximate counties, most counties are also connected to regional and national population centers, with significant variation in which more distant housing markets different counties are connected to. See Bailey et al. (2016) for a more detailed exploration of county-level friendship networks.

Our second county-level measure is the across-county-population dispersion in the average house price experiences of the friends of people living in that county. We measure this dispersion as the 5-95 percentile range of average network experiences across the people living in that county:

$$
\operatorname{Disp} p_{c, t}^{N}=\operatorname{Perc}_{c, t}\left[\text { FriendHPExp } p_{i, c, t, t-12 m}^{N}\right]-\operatorname{Perc5}_{c, t}\left[\text { FriendHPExp } p_{i, c, t, t-12 m}^{N}\right]
$$

Cross-county variation in this variable is partly driven by how concentrated a county's friendship network is: Panels A and B of Figure 4 show the cross-county correlation of the average measure of Dis $p_{c, t}^{N}$ between 1998 and 2012, and the share of friends living within 100 and 500 miles, respectively. ${ }^{42}$

\subsection{County-Level Trading Volume}

Section 3.1 documents that homeowners whose friends experienced more negative house price movements are more likely to sell their house, while renters whose friends had more positive house price experiences are more likely to buy a home. Building on these findings, we would expect more overall trading activity in areas and at points in time when some parts of the population have networks with very positive experiences, and some parts of the population have networks with very negative experiences. In other words, we would expect trading volume to increase with the dispersion in individuals' housing market expectations (see Hong and Stein, 2007; Daniel and Hirshleifer, 2015, for recent reviews of the literature on trading volume and disagreement in the stock market).

To test whether this is indeed the case, we first consider the relationship between the average dispersion of friends' house price experiences in a county, Dis $p_{c, t}^{N}$, and the average trading volume, measured in percent of the housing stock that trades every year. Panel C of Figure 4 shows that those counties in which people had more dispersed average house price expectations, proxied for by the average dispersion in their friends' house price experiences between 1998 and 2012, also had higher average trading volume over that period. Column 1 of Appendix Table A13 provides estimates from the corresponding OLS regression: a one-standard deviation increase in $\operatorname{Dis} p_{c}^{N}$ is associated with a 0.38 standard deviation increase in the average annual trading volume. Similarly, Panel D of Figure 4 shows that counties with a higher across-year variance in our measure of dispersion had a higher across-year variance in trading volumes; column 3 of Appendix Table A13 presents the OLS estimates.

Inferring a causal response from these cross-sectional relationships is problematic, since counties with more dispersion in the house price experiences of the population's friends might also differ on other characteristics that could affect trading volume directly. As a first step to mitigate such concerns, Panels E and F show binned scatter plots of these relationships that also control for countylevel characteristics such as log-income, log-population, the unemployment rate, and median age, all

\footnotetext{
${ }^{42}$ Appendix Figure A10 shows the geographic distribution of these "friendship concentration" measures. Counties in the Midwest and the Southeast have the most geographically-concentrated friendship networks.
} 
taken from the 2013 snapshot of the American Community Survey. The correlations between the level and variance of the dispersion of friend experiences, and the level and variance of trading volume, respectively, survive the addition of these control variables. Indeed, columns 2 and 4 of Appendix Table A13 shows that while the inclusion of these control variables increases the $R^{2}$ of the regressions by a factor of 2-3, the magnitude and significance of the relationship between measures of dispersion and trading volume are unaffected.

To further address concerns of confounding explanations for the correlation between experience dispersion and trading volume, regression 10 exploits within-county time-series variation in $\operatorname{Dis} p_{c, t}^{N}$.

$$
\text { Volume }_{c, t}=\alpha_{t}+\psi_{c}+\beta_{1} \text { Disp }_{c, t-1}^{\text {All }}+\beta_{2} \text { Volume }_{c, t-1}+\beta_{3} \mathbf{X}_{c, t}+\epsilon_{c, t}
$$

Including county-level fixed effects controls for all time-invariant county characteristics. Year fixed effects control for any national factors, such as interest rates, that drive housing market turnover. We also include lagged volume, to allow for any persistence of shocks to volume. In addition, lagged volume will absorb any shocks that might have a direct, contemporaneous effect on the dispersion in friends' house price experiences and trading volume. This significantly reduces the concern that the relationship between lagged dispersion and contemporaneous volume is driven by such unobserved shocks. In $\mathbf{X}_{c, t}$, we also control for changes in average income, the level and changes in the unemployment rate, and year-specific controls for the share of population without a high-school degree. ${ }^{43}$

Table 10 presents the results from regression 10. We instrument for Dis $p_{c, t-1}^{\text {All }}$ with the dispersion in the house price experiences of out-of-state friends. This allows us to further limit the role of confounding shocks that could drive both Dis $p_{c, t-1}^{A l l}$ and the trading volume in county $c$ directly. Standard errors are clustered at the county level. ${ }^{44}$ The estimates in column 1 suggest that a one within-county standard deviation increase in Disp $p_{c, t-1}^{A l l}$ is associated with a 0.22 within-county standard deviation increase in trading volume. ${ }^{45}$ In column 2 we also control for the lagged average house price experiences of people living in the county, $\overline{\text { FriendHPExp }}_{c, t-1}$, instrumented for by their out-of-state counterparts. This variable does not appear to influence trading volume, and its inclusion does not affect the estimated effect of higher dispersion of experiences within a county. This is consistent with a story where higher average experiences proxying for a higher average level of optimism make renters more willing to buy, but buyers less willing to sell, without an effect on the overall trading volume. It is only when expectations become more dispersed that the trading volume is affected. In column 3, we also include contemporaneous house price changes as a control variable. This variable captures some con-

\footnotetext{
${ }^{43}$ Income data come from IRS Tax Statistics SOI database; specifically, we control for the annual average gross income per capita. County-level unemployment statistics come from Local Area Unemployment Statistics (LAUS). The share of population without a high-school degree comes from the 2000 U.S. Census.

${ }^{44}$ Two-way clustering at the year and the county level does not affect the statistical significance of the results. However, the asymptotics of these standard errors rely on the number of years going to infinity, an assumption that is somewhat questionable given that the length of our panel is 14 years.

${ }^{45}$ The within-county standard deviation in Dis $p_{c, t-1}^{A l l}$ is $2.29 \%$, the within-county standard deviation in the share of houses trading per year (transaction volume) is $1.84 \%$.
} 
temporaneous demand shocks to county $c$ that will also affect trading volume. Indeed, consistent with the previous literature, higher house prices and higher trading volume are positively correlated. The addition of this control variable leaves the estimated effect of Dis $p_{c, t-1}^{A l l}$ on trading volume unaffected.

\subsection{County-Level House Prices}

Section 3.3 documents that in a given housing transaction, higher house price experiences in both the social network of the buyer and the social network of the seller are associated with a higher transaction price. Building on this finding, in this section we analyze how county-level house prices are affected by the average house price experiences of the friends of people living in that county.

The interpretation of such an analysis is complicated by the fact that counties that are exposed to similar shocks are likely to also have many friendship links, for example if people are friends with others working in similar industries. Shocks to those industries can then directly affect house prices both in county $c$ and in connected counties, inducing correlation between higher house price growth experienced by friends of people living in county $c$, and house price changes in that county; such a correlation would be unrelated to changes in the house price expectation through a social dynamics channel. As before, in regression 11 we thus instrument for $\overline{\text { FriendHPExp }}_{c, t-1}$ with its out-of-state counterpart, removing any common shocks to counties in the same state, which are likely linked by many friendship links. In addition, and very importantly, we also control for the lagged house price changes in county $c$. These are measured over the same time horizon as the lagged house price experiences of the friends of county $c$ 's population. The addition of this control variable significantly reduces the scope of possibly confounding effects of common shocks to connected counties, since these should generally move house prices in the two counties at the same time.

$$
\Delta H P_{c, t}=\alpha_{t}+\psi_{c}+\beta_{1} \overline{\text { FriendHPExp }}_{c, t-1}^{A l l}+\beta_{2} \Delta H P_{c, t-1}+\beta_{3} \mathbf{X}_{c, t}+\epsilon_{c, t}
$$

The estimates in column 4 of Table 10 suggest that a one within-year standard deviation (3.12\%) increase in the across-county-population average of friends' house price experiences is associated with a 2.5 percentage point ( 0.4 within-year standard deviation) increase in house price growth. ${ }^{46}$ In column 5 , we add the across-county-population dispersion of friends' house price experiences as a further control variable. While there is little effect on our estimates of $\beta_{1}$, we find that a larger dispersion of friends' house price experiences is associated with faster house price growth. In particular, a one within-year standard deviation increase of Dis $p_{c, t-1}^{A l l}$ is associated with a 1.9 percentage point (0.3 standard deviation) higher house price growth. This is consistent with the predictions of models in the spirit of Harrison and Kreps (1978) and Scheinkman and Xiong (2003), where, in the presence of shortselling constraints, more belief dispersion leads to higher prices as the asset values are reflective of the valuations of the most optimistic agents (see the exposition in Giglio, Maggiori and Stroebel, 2015).

\footnotetext{
${ }^{46}$ The within-year standard deviation in $\overline{\text { Friend }} H P E x P_{c, t-1}$ is $3.12 \%$, the within-year standard deviation in the house price increase is $6.4 \%$. The within-year standard deviation of Disp $p_{c, t-1}^{A l l}$ is $2.07 \%$.
} 
It also provides support for models such as that in Piazzesi and Schneider (2009), which shows that in the presence of housing search frictions, a small number of optimists can cause large measured price increases even if they do not end up holding most of the housing stock. In column 6, we also control for the contemporaneous trading volume, allowing us to better account for demand shocks. The estimated effect of the across-county-population average and dispersion of friends' house price experiences on house price changes remains unaffected.

\subsection{Additional Implications of Findings}

In the rest of this section we explore two implications of these findings. First, we discuss to what extent our results might provide an explanation for the degree of regional house price contagion that has been documented in the empirical literature. Second, we propose that the house price experiences of geographically-distant friends might provide an instrument for house price changes in some empirical studies that analyze the causal effect of house prices on other outcomes.

\subsubsection{House Price Contagion}

In recent work, DeFusco et al. (2015) document economically and statistically significant contagion of house prices during the recent U.S. housing boom. They define contagion as "price spillovers from shocks to a neighboring market that are beyond what can be justified by common aggregate trends." After examining several fundamentals-based mechanisms for the observed contagion, they conclude that their results "yield no evidence that contagion in the housing market is associated with any known fundamental." We believe that the results and mechanism presented in this paper might provide an explanation for the house price contagion documented by DeFusco et al. (2015). In particular, we show that social interactions are a channel through which a house price boom in one market can influence house price expectations, house prices, and trading volume in markets that are connected through friendship links, even in the absence of a fundamental reason for such a relationship.

To investigate this channel further, in columns 7 to 9 of Table 10 we also control for the lagged "distance-weighted" house price movements in other counties. ${ }^{47}$ As before, we instrument this measure with its out-of-state counterpart to control for any common local shocks to counties in the same state. In column 7 we do not include friendship-weighted house price experiences in addition to the distance-weighted house price experiences. Even after controlling for own lagged house price appreciation, the distance-weighted lagged house price appreciation in other counties strongly predicts future county house price growth. This is consistent with the findings in DeFusco et al. (2015).

In column 8 we also control for the lagged across-population mean of friends' house price experiences; in column 9 we further include our measure of the dispersion of friends' house price experiences across the population. The coefficients on the across-population mean and dispersion of friends' house price experiences are very similar to those estimated in columns 4 to 6; in addition, the

\footnotetext{
${ }^{47}$ We construct this measure for each county by finding the weighted average of house price movements in all other U.S. counties, where the weights for each partner county are given by $1 /$ distance $^{2}$ when we measure the distance in miles. We find similar results when we construct the weight as $1 /$ distance.
} 
coefficient on distance-weighted house price experience is now small and statistically insignificant. This suggests that much of the non-fundamental spatial contagion identified in the literature is due to stronger social interactions between geographically-proximate counties.

\subsubsection{A possible instrument for house prices}

A vast research effort across the social sciences aims to understand the effects of housing booms and busts on outcomes such as consumer spending (Campbell and Cocco, 2007; Mian, Rao and Sufi, 2013; Berger et al., 2015), unemployment (Mian and Sufi, 2014), retail prices (Stroebel and Vavra, 2014), educational attainment (Charles, Hurst and Notowidigdo, 2015), entrepreneurship (Hurst and Lusardi, 2004; Kerr, Kerr and Nanda, 2015; Adelino, Schoar and Severino, 2015), and health (Joshi, 2015). The identification of causal effects in this literature is complicated by the potential for omitted variables or reverse causality. For example, a positive correlation between house prices and consumption can arise either because higher house prices cause higher consumption, or because an unobservable income shock caused both house prices and consumption to increase. The literature has approached this identification challenge by exploiting instrumental variables that induce a change in house prices (i.e., have a strong "first stage"), but that, conditional on control variables, do not influence the outcome except through their effect on house prices. The validity of this "exclusion restriction" is inherently untestable and depends on the particular outcome that is studied. As a result, the validity of many commonly-used instruments for house prices is the subject of considerable debate.

We believe that, in many settings, the past house price experiences in geographically-distant counties that are connected through friendship links might constitute a valid instrumental variable for subsequent local house price changes. In particular, the previous results document that housing demand and house prices in county $i$ between times $t$ and $t+1$ are affected by the house price experiences between times $t-1$ and $t$ of geographically-distant friends of people living in county $i$. This suggests that an instrumental variables strategy using these experiences would have a strong first-stage. We argue that this relationship is driven by the effect of friends' house price experiences on individuals' own expectations, which leads to higher housing demand and higher house prices. The exclusion restriction is valid to the extent that friends' house price experiences only affect the outcome of interest through their effect on house prices. As discussed above, one concern with this assumption is that the observed relationship might be explained by common shocks to counties that are connected through friendship links. However, in our empirical approach the scope of such common shocks was minimized by only exploiting house price experiences of friends living in a different state, and by including own lagged house price movements measured over the horizon as the friends' house price experiences. These lagged own house price movements will absorb the effect of many shocks that might constitute a violation of the exclusion restriction. Of course, whether, given this empirical approach, the exclusion restriction is valid depends on the particular question that is studied. Indeed, arguments for the validity of this (and any other) instrument need to be made on a case-by-case basis. 


\section{Conclusion}

We document that the house price experiences within an individual's social network affect her perceptions of the attractiveness of property investments, and through this channel have large effects on her housing market activity. We first show that individuals whose friends experienced larger recent house price increases are more optimistic about property investments. This correlation is larger for individuals who reported to regularly talk to their friends about investing in property. These findings contribute to the literature analyzing how individuals form expectations about economic outcomes.

Building on these findings, we proposed a new methodology to investigate the role of expectations in explaining housing market outcomes. This methodology exploits plausibly exogenous variation in the house price experiences within individuals' social networks as shifters of those individuals' housing market expectations. We find that individuals whose friends experienced larger recent house price increases and individuals whose friends had less dispersed experiences are more likely to buy a house. They are also more likely to buy a larger house, are willing to pay more for a given property, and make larger downpayments. Similarly, when home owners' friends experience less positive and more dispersed house price changes, these home owners are more likely to sell, and more likely to sell at a lower price. These findings provide strong support for theoretical models of trading volume and asset prices based on speculative motives resulting from different housing market expectations.

We also show that these individual-level responses aggregate up to affect county-level housing market outcomes. In particular, we show that the across-county-population average and dispersion of out-of-state friends' house price experiences affects house prices and trading volume. This finding can contribute to our understanding of the geographic contagion of house price shocks. In addition, in many settings the across-population average house price experiences of geographically-distant friends can be a valid instrument for subsequent house price growth.

\section{References}

Abel, Andrew B. 1990. "Asset prices under habit formation and catching up with the Joneses." The American Economic Review, 80(2): 38-42.

Acemoglu, Daron, Giacomo Como, Fabio Fagnani, and Asuman Ozdaglar. 2013. “Opinion fluctuations and disagreement in social networks." Mathematics of Operations Research, 38(1): 1-27.

Acemoglu, Daron, Munther A Dahleh, Ilan Lobel, and Asuman Ozdaglar. 2011. “Bayesian learning in social networks." The Review of Economic Studies, 78(4): 1201-1236.

Acemoglu, Daron, Vasco M Carvalho, Asuman Ozdaglar, and Alireza Tahbaz-Salehi. 2012. "The network origins of aggregate fluctuations." Econometrica, 80(5): 1977-2016.

Adelino, Manuel, Antoinette Schoar, and Felipe Severino. 2015. "House prices, collateral, and selfemployment." Journal of Financial Economics, 117(2): 288-306.

Akerlof, George A, and Robert J Shiller. 2010. Animal spirits: How human psychology drives the economy, and why it matters for global capitalism. Princeton University Press. 
Allen, Franklin, and Ana Babus. 2009. "Networks in finance." The Network Challenge: Strategy, Profit, and Risk in an Interlinked World, 367.

Angeletos, George-Marios, and Jennifer La'O. 2013. “Sentiments." Econometrica, 81(2): 739-779.

Armona, Luis, Andreas Fuster, and Basit Zafar. 2016. "Home Price Expectations and Behavior: Evidence from a Randomized Information Experiment."

Baetschmann, Gregori, Kevin E. Staub, and Rainer Winkelmann. 2015. "Consistent estimation of the fixed effects ordered logit model." Journal of the Royal Statistical Society: Series A (Statistics in Society), 178(3): 685-703.

Bailey, Michael, Ruiqing Cao, Theresa Kuchler, Johannes Stroebel, and Arlene Wong. 2016. "U.S. friendship networks."

Barberis, Nicholas, and Richard Thaler. 2003. "A survey of behavioral finance." Handbook of the Economics of Finance, 1: 1053-1128.

Barberis, Nicholas, Robin Greenwood, Lawrence Jin, and Andrei Shleifer. 2015. "Extrapolation and bubbles." Working Paper.

Barrot, Jean-Noël, and Julien Sauvagnat. 2015. "Input specificity and the propagation of idiosyncratic shocks in production networks."

Bayer, Patrick, Christopher Geissler, Kyle Mangum, and James W Roberts. 2014. "Speculative fever: Investor contagion in the housing bubble."

Berger, David, Veronica Guerrieri, Guido Lorenzoni, and Joseph Vavra. 2015. "House prices and consumer spending." National Bureau of Economic Research.

Beshears, John, James J Choi, David Laibson, Brigitte C Madrian, and Katherine L Milkman. 2015a. "The effect of providing peer information on retirement savings decisions." Journal of Finance, 70(3): 1161-1201.

Beshears, John, James J Choi, David Laibson, Brigitte C Madrian, and Sean Yixiang Wang. $2015 b$. "Who Is Easier to Nudge?" Working Paper.

Bessembinder, Hendrik, Kalok Chan, and Paul J Seguin. 1996. "An empirical examination of information, differences of opinion, and trading activity." Journal of Financial Economics, 40(1): 105-134.

Breza, Emily. 2015. "Peer effects and loan repayment: Evidence from the Krishna Default Crisis."

Breza, Emily, and Arun G Chandrasekhar. 2015. "Social networks, reputation and commitment: Evidence from a savings monitors experiment." National Bureau of Economic Research.

Brown, Jeffrey R, Zoran Ivković, Paul A Smith, and Scott Weisbenner. 2008. "Neighbors matter: Causal community effects and stock market participation." Journal of Finance, 63(3): 1509-1531.

Brunnermeier, Markus K, Alp Simsek, and Wei Xiong. 2014. “A Welfare criterion for models with distorted beliefs." Quarterly Journal of Economics, 129(4): 1753-1797.

Burnside, Craig, Martin Eichenbaum, and Sergio Rebelo. 2016. "Understanding booms and busts in housing markets." Journal of Political Economy, forthcoming.

Campbell, John Y, and Joao F Cocco. 2007. "How do house prices affect consumption? Evidence from micro data." Journal of Monetary Economics, 54(3): 591-621. 
Carlin, Bruce I, Francis A Longstaff, and Kyle Matoba. 2014. "Disagreement and asset prices." Journal of Financial Economics, 114(2): 226-238.

Charles, Kerwin Kofi, Erik Hurst, and Matthew J Notowidigdo. 2015. "Housing booms and busts, labor market opportunities, and college attendance." Working Paper.

Cheng, Ing-Haw, Sahil Raina, and Wei Xiong. 2014. "Wall Street and the housing bubble." American Economic Review, 104(9): 2797-2829.

Choi, James J, David Laibson, Brigitte C Madrian, and Andrew Metrick. 2009. "Reinforcement learning and savings behavior." Journal of Finance, 64(6): 2515-2534.

Cohen, Lauren, Andrea Frazzini, and Christopher Malloy. 2008. "The small world of investing: Board connections and mutual fund returns." Journal of Political Economy, 116(5): 951-979.

Conley, Timothy G, and Christopher R Udry. 2010. “Learning about a new technology: Pineapple in Ghana." American Economic Review, 100(1): 35-69.

Cookson, Anthony, and Marina Niessner. 2016. "Why don't we agree? Evidence from a social network of investors."

Daniel, Kent, and David Hirshleifer. 2015. “Overconfident investors, predictable returns, and excessive trading." The Journal of Economic Perspectives, 29(4): 61-87.

Dávila, Eduardo. 2014. “Optimal financial transaction taxes.” Working Paper.

DeFusco, Anthony A, Wenjie Ding, Fernando V Ferreira, and Joseph Gyourko. 2015. "The role of contagion in the american housing boom." Working Paper.

Duflo, Esther, and Emmanuel Saez. 2002. "Participation and investment decisions in a retirement plan: The influence of colleagues' choices." Journal of Public Economics, 85(1): 121-148.

Duggan, Maeve, Nicole B Ellison, Cliff Lampe, Amanda Lenhart, and Mary Madden. 2015. "Social media update 2014. Pew Research Center."

Facebook. 2015. “Facebook Form 10-K, Annual Report."

Favara, Giovanni, and Zheng Song. 2014. "House price dynamics with dispersed information." Journal of Economic Theory, 149: 350-382.

Feng, Lei, and Mark S Seasholes. 2004. "Correlated trading and location." Journal of Finance, 59(5): 2117-2144.

Foote, Christopher L, Kristopher S Gerardi, and Paul S Willen. 2012. "Why did so many people make so many ex post bad decisions? The causes of the foreclosure crisis." Working Paper.

Geanakoplos, John. 2009. “The leverage cycle." In NBER Macroeconomics Annual 2009, Volume 24. , ed. D. Acemoglu, K. Rogoff and M. Woodford, 1-65. University of Chicago Press.

Geerolf, François. 2015. “Leverage and disagreement." Working Paper.

Giannini, Robert Charles, Paul J Irvine, and Tao Shu. 2015. "The convergence and divergence of investors' opinions around earnings news: Evidence from a social network."

Giglio, Stefano, Matteo Maggiori, and Johannes Stroebel. 2015. "No-bubble condition: Model-free tests in housing markets." Econometrica, Forthcoming. 
Gilbert, Eric, and Karrie Karahalios. 2009. "Predicting tie strength with social media." 211-220, ACM.

Giroud, Xavier, and Holger Mueller. 2016. "Propagation of local demand shocks through firms' internal networks." Working Paper.

Glaeser, Edward L, and Charles G Nathanson. 2015. "An extrapolative model of house price dynamics." Working Paper.

Goetzmann, William N, and Massimo Massa. 2005. "Dispersion of opinion and stock returns." Journal of Financial Markets, 8(3): 324-349.

Goetzmann, William N, Liang Peng, and Jacqueline Yen. 2012. “The subprime crisis and house price appreciation." Journal of Real Estate Finance and Economics, 44(1-2): 36-66.

Greenwood, Robin, and Andrei Shleifer. 2014. "Expectations of returns and expected returns." Review of Financial Studies, 27: 714-746.

Guren, Adam. 2015. “The causes and consequences of house price momentum.”

Hampton, Keith, Lauren Sessions Goulet, Lee Rainie, and Kristen Purcell. 2011. "Social networking sites and our lives. Pew internet and american life project."

Han, Bing, and David Hirshleifer. 2015. "Self-enhancing transmission bias and active investing." Working Paper.

Harris, Milton, and Artur Raviv. 1993. "Differences of opinion make a horse race." Review of Financial Studies, 6(3): 473-506.

Harrison, J Michael, and David M Kreps. 1978. "Speculative investor behavior in a stock market with heterogeneous expectations." Quarterly Journal of Economics, 92(2): 323-336.

Haselmann, Rainer, David Schoenherr, and Vikrant Vig. 2013. "Lending in social networks."

Heimer, Rawley Z, and David Simon. 2012. "Facebook finance: How social interaction propagates active investing."

Hirshleifer, David A, and Siew Hong Teoh. 2009. "Thought and behavior contagion in capital markets." Handbook of Financial Markets: Dynamics and evolution, 1-56.

Hochberg, Yael V, Alexander Ljungqvist, and Yang Lu. 2007. "Whom you know matters: Venture capital networks and investment performance." The Journal of Finance, 62(1): 251-301.

Hong, Harrison, and Jeremy C Stein. 1999. "A unified theory of underreaction, momentum trading, and overreaction in asset markets." Journal of Finance, 54(6): 2143-2184.

Hong, Harrison, and Jeremy C Stein. 2007. "Disagreement and the stock market." Journal of Economic Perspectives, 21(2): 109-128.

Hong, Harrison, Jeffrey D Kubik, and Jeremy C Stein. 2004. "Social interaction and stock-market participation." Journal of Finance, 59(1): 137-163.

Hong, Harrison, Jeffrey D Kubik, and Jeremy C Stein. 2005. "Thy neighbor's portfolio: Word-ofmouth effects in the holdings and trades of money managers." Journal of Finance, 60(6): 2801-2824.

Hurst, Erik, and Annamaria Lusardi. 2004. "Liquidity constraints, household wealth, and entrepreneurship." Journal of Political Economy, 112(2): 319-347. 
Iyer, Rajkamal, and Manju Puri. 2012. "Understanding bank runs: The importance of depositor-bank relationships and networks." American Economic Review, 102(4): 1414-1445.

Jones, Jason J, Jaime E Settle, Robert M Bond, Christopher J Fariss, Cameron Marlow, and James H Fowler. 2013. "Inferring tie strength from online directed behavior." PloS ONE, 8(1): e52168.

Joshi, Nayan Krishna. 2015. "Local house prices and mental health." International Journal of Health Economics and Management, 1-14.

Kaplan, Greg, Kurt Mitman, and Giovanni L Violante. 2015. “Consumption and house prices in the Great Recession: Model meets evidence." NYU Working Paper.

Kelly, Bryan, Hanno Lustig, and Stijn Van Nieuwerburgh. 2013. "Firm volatility in granular networks." National Bureau of Economic Research.

Kelly, Morgan, and Cormac Ó Gráda. 2000. “Market contagion: Evidence from the panics of 1854 and 1857." American Economic Review, 1110-1124.

Kerr, Sari Pekkala, William R Kerr, and Ramana Nanda. 2015. "House money and entrepreneurship." Working Paper.

Kuchler, Theresa, and Basit Zafar. 2015. "Personal experiences and expectations about aggregate outcomes." Federal Reserve Bank of New York Staff Reports, 748.

Landvoigt, Tim. 2014. "Housing demand during the boom: The role of expectations and credit constraints." Working Paper.

Leary, Mark T, and Michael R Roberts. 2014. "Do peer firms affect corporate financial policy?" The Journal of Finance, 69(1): 139-178.

Li, Geng. 2014. "Information sharing and stock market participation: Evidence from extended families." Review of Economics and Statistics, 96(1): 151-160.

Li, Geng, and Dan Li. 2011. "Belief dispersion among household investors and stock trading volume." Working Paper.

Malmendier, Ulrike, and Stefan Nagel. 2011. "Depression babies: Do macroeconomic experiences affect risk taking?" The Quarterly Journal of Economics, 126(1): 373-416.

Malmendier, Ulrike, and Stefan Nagel. 2015. "Learning from inflation experiences." Quarterly Journal of Economics, Forthcoming.

Manski, Charles F. 1993. "Identification of endogenous social effects: The reflection problem." The Review of Economic Studies, 60(3): 531-542.

Mian, Atif, and Amir Sufi. 2014. "What explains the 2007-2009 drop in employment?" Econometrica, 82(6): 2197-2223.

Mian, Atif, Kamalesh Rao, and Amir Sufi. 2013. "Household balance sheets, consumption, and the economic slump." Quarterly Journal of Economics, 128(4): 1687-1726.

Miller, Edward M. 1977. “Risk, uncertainty, and divergence of opinion." Journal of Finance, 32(4): 11511168.

Nathanson, Charles G, and Eric Zwick. 2014. "Arrested development: Theory and evidence of supply-side speculation in the housing market." 
Nielsen, Torben Heien, Søren Leth-Petersen, Raj Chetty, John N Friedman, and Tore Olsen. 2014. "Active vs. Passive Decisions and Crowd-Out in Retirement Savings Accounts: Evidence from Denmark." Quarterly Journal of Economics.

Ozsoylev, Han N, Johan Walden, M Deniz Yavuz, and Recep Bildik. 2014. "Investor networks in the stock market." Review of Financial Studies, 27(5): 1323-1366.

Piazzesi, Monika, and Martin Schneider. 2009. "Momentum traders in the housing market: Survey evidence and a search model." American Economic Review, 99(2): 406-11.

Piazzesi, Monika, Martin Schneider, and Johannes Stroebel. 2015. "Segmented housing search." Working Paper.

Pool, Veronika, Noah Stoffman, and Scott Yonker. 2015. "The people in your neighborhood: social interactions and mutual fund portfolios." Journal of Finance, 70(6): 2679-2732.

Riedl, Maximilian, and Ingo Geishecker. 2014. "Keep it simple: Estimation strategies for ordered response models with fixed effects." Journal of Applied Statistics, 41(11): 2358-2374.

Scheinkman, Jose A, and Wei Xiong. 2003. "Overconfidence and speculative bubbles." Journal of Political Economy, 111(6): 1183-1220.

Shiller, Robert J. 1984. "Stock prices and social dynamics." Brookings Papers on Economic Activity, 1984(2): 457-510.

Shiller, Robert J. 2015. Irrational exuberance. Princeton University Press.

Shiller, Robert J, and John Pound. 1989. "Survey evidence on diffusion of interest and information among investors." Journal of Economic Behavior E Organization, 12(1): 47-66.

Shue, Kelly. 2013. "Executive networks and firm policies: Evidence from the random assignment of MBA peers." Review of Financial Studies, 26(6): 1401-1442.

Simsek, Alp. 2013a. “Belief disagreements and collateral constraints." Econometrica, 81(1): 1-53.

Simsek, Alp. 2013b. "Speculation and risk sharing with new financial assets." Quarterly Journal of Economics, 128(3): 1365-1396.

Stroebel, Johannes, and Joseph Vavra. 2014. "House prices, local demand, and retail prices." Working Paper.

Varian, Hal R. 1989. "Differences of opinion in financial markets." In Financial Risk: Theory, Evidence and Implications. , ed. C. Stone. Kluwer Academic Publications, Boston.

Vissing-Jorgensen, Annette. 2003. "Perspectives on behavioral finance: Does "irrationality" disappear with wealth? Evidence from expectations and actions." In NBER Macroeconomics Annual 2003, Volume 18. 139-208. The MIT Press.

Wheaton, William C. 1990. "Vacancy, search, and prices in a housing market matching model." Journal of Political Economy, 98(6): 1270-1292. 
Table 1: Summary Statistics - Change-of-Tenure Sample

\begin{tabular}{|c|c|c|c|c|c|c|c|c|}
\hline & \multicolumn{8}{|c|}{ Panel A: 2010 Renters } \\
\hline & Mean & SD & SD | Zip & P10 & P25 & P50 & P75 & P90 \\
\hline \multicolumn{9}{|l|}{ Number of Friends } \\
\hline All Friends & 348 & 454 & 446 & 55 & 105 & 212 & 413 & 747 \\
\hline Out-of-Commuting Zone Friends & 155 & 277 & 270 & 17 & 31 & 68 & 164 & 359 \\
\hline Number of Counties with Friends & 59 & 66 & 63 & 14 & 22 & 39 & 73 & 122 \\
\hline \multicolumn{9}{|l|}{ Average Friend Appreciation 2008-10 } \\
\hline All Friends & $-7.17 \%$ & $1.93 \%$ & $1.91 \%$ & $-9.18 \%$ & $-7.85 \%$ & $-6.87 \%$ & $-6.11 \%$ & $-5.51 \%$ \\
\hline Out-of-Commuting Zone Friends & $-10.48 \%$ & $3.62 \%$ & $3.43 \%$ & $-15.17 \%$ & $-12.68 \%$ & $-10.19 \%$ & $-8.11 \%$ & $-6.24 \%$ \\
\hline \multicolumn{9}{|c|}{ Dispersion Friend Appreciation 2008-10 } \\
\hline All Friends & $19.02 \%$ & $5.93 \%$ & $33.42 \%$ & $11.42 \%$ & $15.09 \%$ & $19.00 \%$ & $23.15 \%$ & $26.77 \%$ \\
\hline Out-of-Commuting Zone Friends & $27.60 \%$ & $5.43 \%$ & $20.68 \%$ & $19.80 \%$ & $23.92 \%$ & $29.11 \%$ & $31.86 \%$ & $33.29 \%$ \\
\hline Income 2010 (K\$̦) & 52.00 & 34.37 & 1.29 & 10.0 & 25.0 & 45.0 & 62.5 & 87.5 \\
\hline Income Change 2010-12 (K\$) & 2.34 & 28.08 & 1.18 & -25.0 & 0.0 & 0.0 & 0.0 & 35.0 \\
\hline Household Size 2010 & 1.91 & 1.27 & 13.02 & 1 & 1 & 1 & 2 & 4 \\
\hline Household Size Change 2010-12 & 0.20 & 1.18 & 0.36 & -1 & 0 & 0 & 1 & 1 \\
\hline Age 2010 & 37.23 & 13.12 & 0.45 & 24 & 29 & 36 & 45 & 55 \\
\hline \multicolumn{9}{|c|}{ Family Structure Development 2010-12 } \\
\hline Stayed Married & 0.14 & 0.35 & 0.30 & 0 & 0 & 0 & 0 & 1 \\
\hline Stayed Single & 0.72 & 0.45 & 0.19 & 0 & 0 & 1 & 1 & 1 \\
\hline Got Married & 0.10 & 0.30 & 0.49 & 0 & 0 & 0 & 0 & 0 \\
\hline Got Divorced & 0.04 & 0.19 & 0.48 & 0 & 0 & 0 & 0 & 0 \\
\hline \multicolumn{9}{|l|}{ Education 2010} \\
\hline Has Highschool & 0.54 & 0.50 & 0.30 & 0 & 0 & 1 & 1 & 1 \\
\hline Has College Degree & 0.35 & 0.48 & 0.10 & 0 & 0 & 0 & 1 & 1 \\
\hline \multirow[t]{3}{*}{ Has Graduate Degree } & 0.10 & 0.30 & 63.49 & 0 & 0 & 0 & 0 & 1 \\
\hline & \multicolumn{8}{|c|}{ Panel B: 2010 Owners } \\
\hline & Mean & SD & SD | Zip & P10 & P25 & P50 & P75 & $\mathrm{P} 90$ \\
\hline \multicolumn{9}{|l|}{ Number of Friends } \\
\hline All Friends & 285 & 383 & 379 & 47 & 85 & 172 & 335 & 615 \\
\hline Out-of-Commuting Zone Friends & 113 & 216 & 213 & 16 & 26 & 52 & 113 & 242 \\
\hline Number of Counties with Friends & 50 & 57 & 56 & 14 & 20 & 34 & 60 & 99 \\
\hline \multicolumn{9}{|l|}{ Average Friend Appreciation 2008-10 } \\
\hline All Friends & $-7.05 \%$ & $1.72 \%$ & $1.69 \%$ & $-8.87 \%$ & $-7.68 \%$ & $-6.76 \%$ & $-6.06 \%$ & $-5.55 \%$ \\
\hline Out-of-Commuting Zone Friends & $-10.28 \%$ & $3.29 \%$ & $3.15 \%$ & $-14.48 \%$ & $-12.21 \%$ & $-10.02 \%$ & $-8.16 \%$ & $-6.49 \%$ \\
\hline \multicolumn{9}{|c|}{ Dispersion Friend Appreciation 2008-10 } \\
\hline All Friends & $18.36 \%$ & $5.89 \%$ & $33.42 \%$ & $10.66 \%$ & $14.45 \%$ & $18.37 \%$ & $22.38 \%$ & $26.00 \%$ \\
\hline Out-of-Commuting Zone Friends & $27.66 \%$ & $5.18 \%$ & $20.68 \%$ & $20.33 \%$ & $24.31 \%$ & $28.96 \%$ & $31.61 \%$ & $33.20 \%$ \\
\hline Income 2010 (K\$) & 77.20 & 41.89 & 1.65 & 25.0 & 45.0 & 62.5 & 112.5 & 150.0 \\
\hline Income Change 2010-12 (K\$) & 0.05 & 20.73 & 1.27 & 0.0 & 0.0 & 0.0 & 0.0 & 0.0 \\
\hline Household Size 2010 & 3.47 & 1.70 & 15.34 & 1 & 2 & 3 & 5 & 6 \\
\hline Household Size Change 2010-12 & -0.21 & 1.27 & 0.48 & -2 & -1 & 0 & 0 & 1 \\
\hline Age 2010 & 42.62 & 15.57 & 0.45 & 25 & 32 & 43 & 54 & 63 \\
\hline \multicolumn{9}{|c|}{ Family Structure Development 2010-12 } \\
\hline Stayed Married & 0.60 & 0.49 & 0.21 & 0 & 0 & 1 & 1 & 1 \\
\hline Stayed Single & 0.29 & 0.45 & 0.25 & 0 & 0 & 0 & 1 & 1 \\
\hline Got Married & 0.04 & 0.21 & 0.49 & 0 & 0 & 0 & 0 & 0 \\
\hline Got Divorced & 0.07 & 0.25 & 0.48 & 0 & 0 & 0 & 0 & 0 \\
\hline \multicolumn{9}{|l|}{ Education 2010} \\
\hline Has Highschool & 0.45 & 0.50 & 0.37 & 0 & 0 & 0 & 1 & 1 \\
\hline Has College Degree & 0.38 & 0.48 & 0.08 & 0 & 0 & 0 & 1 & 1 \\
\hline Has Graduate Degree & 0.17 & 0.38 & 56.01 & 0 & 0 & 0 & 0 & 1 \\
\hline
\end{tabular}

Note: Table shows summary statistics on the change-of-tenure regression sample used in Section 3.1. See Section 1.2 for details on the sample construction. Panel A focuses on individuals who are renting their home in 2010, Panel B on individuals who are owning their home in 2010. For each characteristic, we show the mean, standard deviation, within-zip-code standard deviation, and the 10th, 25th, 50th, 75th, and 90th percentiles of the distribution. 
Table 2: Summary Statistics - Transaction Sample

\begin{tabular}{|c|c|c|c|c|c|c|c|c|c|}
\hline & Mean & SD & $S D \mid Q$ & $\begin{array}{l}\text { SD | Q \& } \\
\text { Zip Code }\end{array}$ & P10 & P25 & P50 & P75 & P90 \\
\hline \multicolumn{10}{|l|}{ Number of Friends } \\
\hline All Friends & 408 & 503 & 502 & 482 & 60 & 117 & 245 & 502 & 917 \\
\hline Out-of-Commuting Zone Friends & 156 & 262 & 262 & 249 & 18 & 34 & 74 & 170 & 360 \\
\hline Number of Counties with Friends & 49 & 55 & 55 & 52 & 12 & 19 & 33 & 60 & 98 \\
\hline \multicolumn{10}{|l|}{ Average 24-M Friend Appreciation } \\
\hline All Friends & $7.7 \%$ & $20.1 \%$ & $3.6 \%$ & $3.3 \%$ & $-21.0 \%$ & $-5.7 \%$ & $10.6 \%$ & $21.3 \%$ & $34.0 \%$ \\
\hline Out-of-Commuting Zone Friends & $6.6 \%$ & $15.5 \%$ & $4.0 \%$ & $3.7 \%$ & $-16.9 \%$ & $-2.2 \%$ & $9.4 \%$ & $17.0 \%$ & $23.8 \%$ \\
\hline \multicolumn{10}{|l|}{ Dispersion 24-M Friend Appreciation } \\
\hline All Friends & $23.4 \%$ & $11.1 \%$ & $6.1 \%$ & $5.7 \%$ & $11.5 \%$ & $15.3 \%$ & $20.9 \%$ & $29.8 \%$ & $39.6 \%$ \\
\hline Out-of-Commuting Zone Friends & $29.2 \%$ & $11.3 \%$ & $5.4 \%$ & $5.1 \%$ & $16.9 \%$ & $20.5 \%$ & $26.8 \%$ & $35.8 \%$ & $45.6 \%$ \\
\hline \multicolumn{10}{|l|}{ Transaction Characteristics } \\
\hline Transaction Price (USD) & 403,340 & 293,531 & 263,169 & 180,242 & 125,000 & 175,000 & 325,000 & 550,000 & 750,000 \\
\hline Origination LTV (\%) & 85.44 & 17.26 & 17.07 & 15.31 & 68.18 & 73.33 & 84.62 & 100.00 & 100.00 \\
\hline Is SFR & 0.77 & 0.42 & 0.42 & 0.36 & 0 & 1 & 1 & 1 & 1 \\
\hline Property Size (Sqft) & 1,775 & 870 & 868 & 742 & 988 & 1,217 & 1,566 & 2,107 & 2,829 \\
\hline Lot Size (Sqft) & 9,452 & 9,374 & 9,302 & 8,200 & 2,500 & 7,500 & 7,500 & 7,500 & 15,500 \\
\hline Age of Property (Years) & 40.46 & 24.66 & 24.45 & 17.55 & 5 & 21 & 43 & 56 & 74 \\
\hline Has Pool & 0.23 & 0.42 & 0.42 & 0.38 & 0 & 0 & 0 & 0 & 1 \\
\hline \multicolumn{10}{|l|}{ Buyer Characteristics } \\
\hline Age at Purchase & 34.22 & 14.17 & 13.88 & 13.06 & 16 & 27 & 34 & 42 & 51 \\
\hline Has Highschool Degree & 0.43 & 0.50 & 0.49 & 0.47 & 0 & 0 & 0 & 1 & 1 \\
\hline Has College Degree & 0.38 & 0.49 & 0.49 & 0.47 & 0 & 0 & 0 & 1 & 1 \\
\hline Has Graduate Degree & 0.2 & 0.4 & 0.4 & 0.4 & 0 & 0 & 0 & 0 & 1 \\
\hline Income 2010 (K\$) & 79.5 & 41.2 & 40.8 & 32.0 & 25.0 & 45.0 & 62.5 & 112.5 & 150.0 \\
\hline Household Size 2010 & 3.1 & 1.7 & 1.6 & 1.5 & 1 & 2 & 3 & 4 & 5 \\
\hline Married in 2010 & 0.6 & 0.5 & 0.5 & 0.4 & 0 & 0 & 1 & 1 & 1 \\
\hline
\end{tabular}

Note: Table shows summary statistics for the transaction regression sample used in Sections 3.2 and 3.3. See Section 1.2 for details on the sample construction. For each characteristic, we show the mean, standard deviation, within-quarter standard deviation, within-quarter-zip-code standard deviation, and the 10th, 25th, 50th, 75th, and 90th percentiles of the distribution. 
Table 3: Expectation Whether Buying Property is a Good Investment

\begin{tabular}{|c|c|c|c|c|c|c|c|c|}
\hline & (1) & (2) & (3) & (4) & (5) & (6) & (7) & (8) \\
\hline & OLS & Reduced Form & IV & IV & IV & IV & IV & IV \\
\hline All Friend Appreciation 2013-15 (\%) & $\begin{array}{r}0.039 * * \\
(0.015)\end{array}$ & & $\begin{array}{l}0.04^{* *} \\
(0.017)\end{array}$ & $\begin{array}{l}0.036^{*} \\
(0.019)\end{array}$ & $\begin{array}{c}0.048^{* *} \\
(0.021)\end{array}$ & & & \\
\hline Out-of-CZ Friend Appreciation 2013-15 (\%) & & $\begin{array}{r}0.023^{* *} \\
(0.010)\end{array}$ & & & & & & \\
\hline \multicolumn{9}{|l|}{$\begin{array}{l}\text { All Friend Appreciation 2013-15 (\%) x } \\
\text { Ordering of Question }\end{array}$} \\
\hline Expectation Question Last & & & & & & $\begin{array}{r}0.039 * * \\
(0.021)\end{array}$ & & \\
\hline Expectation Question First & & & & & & $\begin{array}{l}0.048^{*} \\
(0.029)\end{array}$ & & \\
\hline \multicolumn{9}{|l|}{$\begin{array}{l}\text { All Friend Appreciation 2013-15 (\%) x } \\
\text { Knowledge of HP in Friends' Location }\end{array}$} \\
\hline Not at all informed & & & & & & & $\begin{array}{c}0.002 \\
(0.036)\end{array}$ & \\
\hline Somewhat informed & & & & & & & $\begin{array}{c}0.036 \\
(0.023)\end{array}$ & \\
\hline Well informed & & & & & & & $\begin{array}{l}0.068^{*} \\
(0.039)\end{array}$ & \\
\hline Very well informed & & & & & & & $\begin{array}{l}0.119 * \\
(0.069)\end{array}$ & \\
\hline \multicolumn{9}{|l|}{$\begin{array}{l}\text { All Friend Appreciation } 2013-15(\%) \text { x } \\
\text { Talk with Friend about Housing Investment }\end{array}$} \\
\hline Never & & & & & & & & $\begin{array}{l}-0.050 \\
(0.038)\end{array}$ \\
\hline Rarely & & & & & & & & $\begin{array}{c}0.001 \\
(0.028)\end{array}$ \\
\hline Sometimes & & & & & & & & $\begin{array}{c}0.086^{* * *} \\
(0.027)\end{array}$ \\
\hline Often & & & & & & & & $\begin{array}{c}0.096 * * \\
(0.049)\end{array}$ \\
\hline Demographic Controls & Y & Y & Y & $\mathrm{Y}$ & $\mathrm{Y}$ & $\mathrm{Y}$ & $\mathrm{Y}$ & $\mathrm{Y}$ \\
\hline Zip Code Fixed Effects & $\mathrm{Y}$ & $\mathrm{Y}$ & $\mathrm{Y}$ & $\mathrm{Y}$ & $\mathrm{Y}$ & Y & Y & Y \\
\hline Sample & & & & LA in 2012 & $\begin{array}{l}\text { Winzorize } \\
\text { Friend HP } \\
\text { Experience }\end{array}$ & & & \\
\hline $\mathrm{N}$ & 1,242 & 1,242 & 1,242 & 1,110 & 1,242 & 1,242 & 1,242 & 1,242 \\
\hline
\end{tabular}

Note: Table shows results from regression 3. The dependent variable is the answer to survey Question 4: "If someone had a large sum of money that they wanted to invest, would you say that relative to other possible financial investments, buying property in your zip code today is: (1) A very bad investment, (2) A somewhat bad investment, (3) Neither good nor bad as an investment, (4) A somewhat good investment, or (5) A very good investment, with the 5 (ordered) answers recoded to 1-5. The first two columns show OLS estimates of a regression of survey answers to Question 4 on the weighted average house price experiences of all friends (column 1) and the weighted average house price experiences of out-of-commuting zone friends. In all remaining columns, the house price experiences of all friends are instrumented for by their out-of-commuting zone counterparts. Column 4 restricts the sample to respondents who lived in LA in 2012. In column 5, friends' experiences are winsorized at the $5 \%$ level. The last three columns estimate differential effects by the ordering of the questions (column 6), how informed respondents claimed to be about house prices in their friends' zip codes (column 7), and how often they reported talking to their friends about investing in property (column 8). The specifications in columns 6, 7, and 8 also include non-interacted indicator variables for the question ordering, and the possible responses to Questions 2 and 3, respectively; in the interest of space, the corresponding coefficients are not reported. All columns also control for respondent age and gender. Standard errors are in parentheses. Significance Levels: ${ }^{*}(\mathrm{p}<0.10),{ }^{* *}(\mathrm{p}<0.05),{ }^{* * *}(\mathrm{p}<0.01)$. 
Table 4: Probability of Owning in 2012

\begin{tabular}{|c|c|c|c|c|c|c|c|}
\hline & \multicolumn{7}{|c|}{$\begin{array}{c}\text { Panel A - } 2010 \text { Renters } \\
\text { Dependent Variable: P(Owner in 2012) in \% }\end{array}$} \\
\hline & (1) & (2) & (3) & (4) & (5) & (6) & (7) \\
\hline Friend Appreciation 2008-10 (\%) & $\begin{array}{c}0.610^{* * *} \\
(0.041)\end{array}$ & $\begin{array}{c}0.518^{* * *} \\
(0.065)\end{array}$ & $\begin{array}{c}0.515^{* * *} \\
(0.043)\end{array}$ & $\begin{array}{c}1.098^{* * *} \\
(0.106)\end{array}$ & $\begin{array}{c}0.571^{* * *} \\
(0.053)\end{array}$ & $\begin{array}{c}0.508^{* * *} \\
(0.169)\end{array}$ & $\begin{array}{c}0.678^{* * *} \\
(0.043)\end{array}$ \\
\hline Friend Appreciation 2010-12 (\%) & & & & & & & $\begin{array}{c}0.321 * * * \\
(0.043)\end{array}$ \\
\hline Zip code 2010 X Zip code $2012 \mathrm{FE}$ & $\mathrm{Y}$ & Y & Y & $\mathrm{Y}$ & Y & Y & Y \\
\hline Controls & $\mathrm{Y}$ & Y & Y & Y & Y & Y & Y \\
\hline Sample Restriction & & $\begin{array}{l}\text { Only Full Set } \\
\text { of Controls }\end{array}$ & $\begin{array}{l}\text { Stayed in same } \\
\text { zip code }\end{array}$ & $\begin{array}{l}\text { Moved within } \\
\text { LA }\end{array}$ & $\begin{array}{l}\text { Older than } 35 \\
\text { in } 2010\end{array}$ & $\begin{array}{c}\text { Geographically } \\
\text { Non-Clustered } \\
\text { Professions }\end{array}$ & \\
\hline $\mathrm{N}$ & 433,836 & 156,764 & 302,686 & 118,316 & 223,026 & 433,836 & 433,836 \\
\hline R-Squared & 0.434 & 0.463 & 0.125 & 0.407 & 0.442 & 0.434 & 0.434 \\
\hline \multirow[t]{4}{*}{ Mean Dependent Variable } & 17.805 & 19.455 & 10.288 & 28.972 & 19.298 & 17.805 & 17.805 \\
\hline & \multicolumn{7}{|c|}{ Panel B - 2010 Owners } \\
\hline & \multicolumn{7}{|c|}{ Dependent Variable: $\mathrm{P}($ Owner in 2012) in \% } \\
\hline & (1) & (2) & (3) & (4) & (5) & (6) & (7) \\
\hline Friend Appreciation 2008-10 (\%) & $\begin{array}{c}0.203 * * * \\
(0.015)\end{array}$ & $\begin{array}{c}0.148^{* * *} \\
(0.017)\end{array}$ & $\begin{array}{c}0.095^{* * *} \\
(0.013)\end{array}$ & $\begin{array}{c}1.330^{* * *} \\
(0.125)\end{array}$ & $\begin{array}{c}0.131^{* * *} \\
(0.016)\end{array}$ & $\begin{array}{c}0.090^{* * *} \\
(0.032)\end{array}$ & $\begin{array}{c}0.223^{* * *} \\
(0.016)\end{array}$ \\
\hline Friend Appreciation 2010-12 (\%) & & & & & & & $\begin{array}{c}0.094 * * * \\
(0.016)\end{array}$ \\
\hline Zip code 2010 X Zip code 2012 FE & Y & Y & Y & Y & $\mathrm{Y}$ & Y & Y \\
\hline Controls & Y & Y & Y & Y & Y & Y & Y \\
\hline Sample Restriction & & $\begin{array}{l}\text { Only Full Set } \\
\text { of Controls }\end{array}$ & $\begin{array}{l}\text { Stayed in same } \\
\text { zip code }\end{array}$ & $\begin{array}{l}\text { Moved within } \\
\text { LA }\end{array}$ & $\begin{array}{l}\text { Older than } 35 \\
\quad \text { in } 2010\end{array}$ & $\begin{array}{c}\text { Geographically } \\
\text { Non-Clustered } \\
\text { Professions }\end{array}$ & \\
\hline $\mathrm{N}$ & $1,035,523$ & 660,166 & 892,250 & 121,478 & 698,158 & $1,035,523$ & $1,035,523$ \\
\hline R-Squared & 0.564 & 0.589 & 0.136 & 0.434 & 0.559 & 0.564 & 0.564 \\
\hline Mean Dependent Variable & 93.466 & 94.422 & 98.065 & 68.163 & 94.730 & 93.466 & 93.466 \\
\hline
\end{tabular}

Note: Table shows results from regression 4. The dependent variable is an indicator capturing whether the individual is an owner in 2012. Panel A focuses on individuals that are renting in 2010, Panel B on individuals that are owning in 2010. All specifications control for 2010 and 2012 zip code pair fixed effects, as well as individual and household demographic variables. The house price experiences of all friends are instrumented for by their out-of-commuting zone counterparts. Column 2 restricts the sample to individuals for whom the entire set of demographic controls is available, whereas all other columns replace missing demographics with a unique fixed effect. Columns 3 and 4 show results for individuals who stayed in the same zip code, and individuals who moved within LA county, respectively. Column 5 restricts the sample to individuals aged over 35 in 2010. Column 6 only exploits variation in friends' house price appreciation among individuals who are retired or work in non-geographically clustered professions such as education, medicine, and law. Column 7 includes friend house price appreciation between 2010 and 2012 in addition to friend house price appreciation between 2008 and 2010. Standard errors are clustered at the 2010 zip code level. Significance Levels: ${ }^{*}(p<0.10),{ }^{* *}(p<0.05),{ }^{* * *}(p<0.01)$. 
Table 5: Size of Property Purchased

\begin{tabular}{|c|c|c|c|c|c|c|c|}
\hline & \multicolumn{7}{|c|}{ Dependent Variable: 100 x log(Property Size) } \\
\hline & (1) & $(2)$ & (3) & (4) & (5) & (6) & (7) \\
\hline Friend Appreciation Last 24 Months (\%) & $\begin{array}{c}0.329 * * * \\
(0.054)\end{array}$ & $\begin{array}{c}0.326 * * * \\
(0.053)\end{array}$ & $\begin{array}{c}0.249 * * * \\
(0.079)\end{array}$ & $\begin{array}{c}0.312^{* * *} \\
(0.053)\end{array}$ & $\begin{array}{c}0.450 * * * \\
(0.134)\end{array}$ & $\begin{array}{c}0.412^{* * *} \\
(0.056)\end{array}$ & $\begin{array}{c}0.259 * * * \\
(0.039)\end{array}$ \\
\hline Month FE & $\mathrm{Y}$ & $\mathrm{Y}$ & $\mathrm{Y}$ & $\mathrm{Y}$ & Y & Y & $\mathrm{Y}$ \\
\hline Buyer Controls & Y & Y, x Year & $\mathrm{Y}$ & & & & \\
\hline Sample Notes and Additional FE & & & $\begin{array}{c}\text { Geographically } \\
\text { Non-Clustered } \\
\text { Professions }\end{array}$ & $\begin{array}{l}\text { Purchases Since } \\
\text { 2010, Lived in } \\
\text { LA in } 2010\end{array}$ & $\begin{array}{l}\text { Purchases Since } \\
\text { 2010, Rented in } \\
2010\end{array}$ & $\begin{array}{l}\text { Property Type } \\
\text { FE }\end{array}$ & ZIP Code FE \\
\hline $\mathrm{N}$ & 526,594 & 526,594 & 526,594 & 452,693 & 32,990 & 526,006 & 526,594 \\
\hline R-Squared & 0.192 & 0.198 & 0.193 & 0.203 & 0.071 & 0.243 & 0.325 \\
\hline Mean Dependent Variable & 740.0 & 740.0 & 740.0 & 740.0 & 735.0 & 740.0 & 740.0 \\
\hline $\begin{array}{l}\text { Note: Table shows results from re } \\
\text { interpretation of coefficients. San } \\
\text { all friends are instrumented for } b \\
\text { fixed effects, and buyer character } \\
\text { status, income, and household si } \\
\text { effects. Column } 3 \text { only exploits } v \\
\text { non-geographically clustered prot } \\
\text { purchases since } 2010 \text { where the b } \\
\text { since } 2010 \text { where the buyers were } \\
\text { fixed effects to the regression. Star } \\
(p<0.05),{ }^{* * *}(p<0.01) \text {. }\end{array}$ & $\begin{array}{l}\text { ression } 5 \\
\text { ple is the } \\
\text { their ou } \\
\text { istics incl } \\
\text { e. In col } \\
\text { ariation in } \\
\text { essions su } \\
\text { lyers live } \\
\text { renters in } \\
\text { dard erro }\end{array}$ & $\begin{array}{l}\text { he depend } \\
\text { insaction s } \\
\text { f-commuti } \\
\text { ng buyer } \\
\text { n 2, we ir } \\
\text { iends' hou } \\
\text { as educat } \\
\text { Los Ang } \\
0 . \text { Colum } \\
\text { re cluster }\end{array}$ & $\begin{array}{l}\text { nt variable is } \\
\text { mple describ } \\
\mathrm{g} \text { zone coun } \\
\text { ge as well as } \\
\text { eract these b } \\
\text { e price appre } \\
\text { n, medicine, } \\
\text { les county in } \\
6 \text { adds prop } \\
\text { at the purch }\end{array}$ & $\begin{array}{l}s \text { the log of } p \\
\text { oed in Sectiol } \\
\text { terparts. All } \\
\text { s } 2010 \text { measu } \\
\text { ouyer charact } \\
\text { eciation amo } \\
\text { and law. C } \\
2010 \text {. Colun } \\
\text { erty type fixe } \\
\text { hase-month l }\end{array}$ & $\begin{array}{l}\text { roperty size, } \\
\text { n } 1.2 \text {. The ho } \\
\text { columns cor } \\
\text { res of occup } \\
\text { eristics with } \\
\text { ng buyers wl } \\
\text { olumn } 4 \text { restr } \\
\text { nn } 5 \text { restricts } \\
\text { d effects, and } \\
\text { evel. Signific }\end{array}$ & $\begin{array}{l}\text { nultiplied b } \\
\text { use price e } \\
\text { trol for pur } \\
\text { tion, educa } \\
\text { year-of-tran } \\
\text { o are retire } \\
\text { cts the sam } \\
\text { the sample } \\
\text { column } 7 \text { a } \\
\text { nce Levels: }\end{array}$ & $\begin{array}{l}100 \text { to ease } \\
\text { eriences of } \\
\text { hase month } \\
\text { on, marital } \\
\text { action fixed } \\
\text { or work in } \\
\text { le to house } \\
\text { purchases } \\
\text { ds zip code } \\
(p<0.10),\end{array}$ \\
\hline
\end{tabular}




\section{Table 6: Transaction Price}

\begin{tabular}{|c|c|c|c|c|c|c|c|c|}
\hline & \multicolumn{8}{|c|}{ Dependent Variable: $100 \times \log$ (Price) } \\
\hline & (1) & (2) & (3) & (4) & (5) & (6) & (7) & (8) \\
\hline \multicolumn{9}{|l|}{ Friend Appreciation (\%) } \\
\hline Buyer - Last 24 Months & $\begin{array}{c}0.652 * * * \\
(0.039)\end{array}$ & $\begin{array}{c}0.650 * * * \\
(0.039)\end{array}$ & $\begin{array}{c}0.399 * * * \\
(0.055)\end{array}$ & $\begin{array}{c}0.797 * * * \\
(0.085)\end{array}$ & $\begin{array}{c}0.564 * * * \\
(0.083)\end{array}$ & $\begin{array}{c}0.550 * * * \\
(0.125)\end{array}$ & $\begin{array}{c}0.652 * * * \\
(0.039)\end{array}$ & $\begin{array}{c}0.436 * * * \\
(0.080)\end{array}$ \\
\hline Seller - Last 24 Months & & & & & & & $\begin{array}{c}0.523 * * * \\
(0.097)\end{array}$ & $\begin{array}{c}0.345^{* *} \\
(0.148)\end{array}$ \\
\hline Month FE, Zip Code FE & Y & Y & Y & Y & $\mathrm{Y}$ & Y & Y & Y \\
\hline Property Controls & Y & Y & Y & Y & $\mathrm{N}$ & Y & Y & $\mathrm{N}$ \\
\hline Buyer Controls & Y & Y, x Year & Y & Y & Y & $\mathrm{N}$ & Y & Y \\
\hline Specification Notes & & & $\begin{array}{c}\text { Geographically } \\
\text { Non-Clustered } \\
\text { Professions }\end{array}$ & $\begin{array}{l}\text { Purchases Since } \\
2010 \text {, Rented in } \\
2010\end{array}$ & Property FE & Buyer FE & & Property FE \\
\hline $\mathrm{N}$ & 523,299 & 523,299 & 523,299 & 33,013 & 36,892 & 35,656 & 523,299 & 36,892 \\
\hline R-Squared & 0.791 & 0.792 & 0.792 & 0.820 & 0.922 & 0.915 & 0.792 & 0.926 \\
\hline \multicolumn{9}{|c|}{$\begin{array}{l}\text { Note: Table shows results from regression } 6 \text {, where the dependent variable is the log of transaction price of home purchase, } \\
\text { multiplied by } 100 \text { to ease interpretation of coefficients. Sample is the transaction sample described in Section } 1.2 \text {. The house } \\
\text { price experiences of all friends are instrumented for by their out-of-commuting zone counterparts. All columns control for } \\
\text { month-of-purchase fixed effects and zip code fixed effects, as well property characteristics (e.g., property type, size, age, } \\
\text { number of bedrooms and bathrooms, and whether property has a garage and a central heating system), and buyer charac- } \\
\text { teristics (e.g., buyer age and number of friends, and the } 2010 \text { values of marital status, household size, income, education and } \\
\text { occupation). Column } 2 \text { interacts buyer controls with year-of-transaction fixed effects. Column } 3 \text { only exploits variation in } \\
\text { friends' house price appreciation among buyers who are retired or work in non-geographically clustered professions such } \\
\text { as education, medicine, and law. Column } 4 \text { restricts the sample to purchases since } 2010 \text { for which the buyers were renters } \\
\text { in } 2010 \text {. Columns } 5 \text { and } 8 \text { include property fixed effects, column } 6 \text { includes buyer fixed effects. Columns } 7 \text { and } 8 \text { include } \\
\text { the house price experiences of the sellers' social networks. Standard errors are clustered at the zip code level. Significance } \\
\text { Levels: }{ }^{*}(p<0.10), * *(p<0.05),{ }^{* * *}(p<0.01) \text {. }\end{array}$} \\
\hline
\end{tabular}


Table 7: Loan-To-Value Ratio

\begin{tabular}{|c|c|c|c|c|c|c|c|}
\hline & & & Depende & nt Variable: LTV & atio (\%) & & \\
\hline & (1) & (2) & (3) & (4) & (5) & (6) & (7) \\
\hline \multicolumn{8}{|l|}{ Friend Appreciation (\%) } \\
\hline Mean - Last 24 Months & $\begin{array}{c}-0.221 * * * \\
(0.018)\end{array}$ & $\begin{array}{c}-0.222^{* * *} \\
(0.018)\end{array}$ & $\begin{array}{c}-0.171^{* * *} \\
(0.030)\end{array}$ & $\begin{array}{c}-0.802^{* * *} \\
(0.095)\end{array}$ & $\begin{array}{c}-0.206^{* * *} \\
(0.019)\end{array}$ & $\begin{array}{c}-0.128^{* * *} \\
(0.074)\end{array}$ & \\
\hline $\begin{array}{l}\text { Mean - Last } 24 \text { Months } \\
x \text { (Income/Price) }\end{array}$ & & & & & $\begin{array}{l}-0.038^{* * *} \\
(0.019)\end{array}$ & & \\
\hline (Income/Price) & & & & & $\begin{array}{c}-0.072 * * * \\
(0.004)\end{array}$ & & \\
\hline 5th pctile - Last 24 Months & & & & & & $\begin{array}{c}-0.084 * * * \\
(0.030)\end{array}$ & $\begin{array}{c}-0.119 * * * \\
(0.030)\end{array}$ \\
\hline Median - Last 24 Months & & & & & & & $\begin{array}{l}-0.035 \\
(0.101)\end{array}$ \\
\hline 95th pctile - Last 24 Months & & & & & & $\begin{array}{l}0.003 \\
(0.047)\end{array}$ & $\begin{array}{l}-0.047 \\
(0.060)\end{array}$ \\
\hline Month FE, Price Controls & Y & $\mathrm{Y}$ & Y & $\mathrm{Y}$ & Y & Y & Y \\
\hline Buyer Controls & Y & Y, x Year & Y & $\mathrm{Y}$ & Y & $\mathrm{N}$ & Y \\
\hline Specification Notes & & & $\begin{array}{c}\text { Geographically } \\
\text { Non-Clustered } \\
\text { Professions }\end{array}$ & $\begin{array}{l}\text { Purchases Since } \\
\text { 2010, Rented in } \\
2010\end{array}$ & & & \\
\hline $\mathrm{N}$ & 268,204 & 268,204 & 268,204 & 19,584 & 266,954 & 268,204 & 268,204 \\
\hline R-Squared & 0.142 & 0.144 & 0.143 & 0.162 & 0.145 & 0.143 & 0.143 \\
\hline
\end{tabular}

Note: Table shows results from regression 7, where the dependent variable is the loan-to-value ratio at purchase in percent. Sample is those transactions in the transaction sample described in Section 1.2 for which we observe the original mortgage in the Acxiom snapshots. The house price experiences of all friends are instrumented for by their out-of-commuting zone counterparts. All columns control for month-of-purchase fixed effects, buyer characteristics (e.g., buyer age and number of friends, and the 2010 values of marital status, household size, income, education and occupation) and flexible controls for the transaction price. Column 2 interacts buyer controls with year-of-transaction fixed effects. Column 3 only exploits variation in friends' house price appreciation among buyers who are retired or work in non-geographically clustered professions such as education, medicine, and law. Column 4 restricts the sample to purchases since 2010 for which the buyers were renters in 2010. In column 5, we interact the mean of friends' house price experiences with the ratio of the buyer's income to the transaction price. In column 6 and 7 we include other moments from the distribution of friends' house price experiences, all instrumented for by their out-of-commuting zone counterparts. Standard errors are clustered at the purchase-month level. Significance Levels: $\quad *(\mathrm{p}<0.10),{ }^{* *}(\mathrm{p}<0.05),{ }^{* * *}(\mathrm{p}<0.01)$. 


\section{Table 8: Main Specifications Controlling for Economic Conditions in Social Network}

\begin{tabular}{|c|c|c|c|c|c|}
\hline & \multicolumn{5}{|c|}{ Panel A - Income Change Control } \\
\hline & \multicolumn{2}{|c|}{$\mathrm{P}($ Own in 2012) } & \multirow{2}{*}{$\frac{100 \times \log (\text { Size })}{(3)}$} & \multirow{2}{*}{$\frac{100 \times \log (\text { Price })}{(4)}$} & \multirow{2}{*}{$\frac{\text { LTV Ratio }}{(5)}$} \\
\hline & $(1)$ & $(2)$ & & & \\
\hline Average Friend Appreciation Last 24 Months (\%) & $\begin{array}{c}0.552 * * * \\
(0.042)\end{array}$ & $\begin{array}{c}0.192 * * * \\
(0.016)\end{array}$ & $\begin{array}{c}0.297^{* * *} \\
(0.056)\end{array}$ & $\begin{array}{c}0.600 * * * \\
(0.039)\end{array}$ & $\begin{array}{c}-0.191 * * * \\
(0.018)\end{array}$ \\
\hline \multicolumn{6}{|l|}{ Average Friend County Income } \\
\hline Change Last 24 Months (\%) & $\begin{array}{c}0.330 * * * \\
(0.033)\end{array}$ & $\begin{array}{c}0.049 * * * \\
(0.011)\end{array}$ & $\begin{array}{c}0.220 * * \\
(0.104)\end{array}$ & $\begin{array}{c}0.345^{* * *} \\
(0.061)\end{array}$ & $\begin{array}{c}-0.255^{* * *} \\
(0.049)\end{array}$ \\
\hline Controls & $\begin{array}{c}\text { Table } 4 \\
\text { Column } 1 \\
2010 \text { Renters }\end{array}$ & $\begin{array}{c}\text { Table } 4 \\
\text { Column } 1 \\
2010 \text { Owners }\end{array}$ & $\begin{array}{l}\text { Table } 5 \\
\text { Column } 1\end{array}$ & $\begin{array}{c}\text { Table } 6 \\
\text { Column } 1\end{array}$ & $\begin{array}{c}\text { Table } 7 \\
\text { Column } 1\end{array}$ \\
\hline $\mathrm{N}$ & 433,836 & $1,035,523$ & 526,594 & 523,299 & 268,204 \\
\hline \multirow[t]{4}{*}{ R-Squared } & 0.434 & 0.564 & 0.192 & 0.792 & 0.143 \\
\hline & \multicolumn{5}{|c|}{ Panel B - Income and Unemployment Controls, Levels and Changes } \\
\hline & \multicolumn{2}{|c|}{$\mathrm{P}($ Own in 2012) } & $100 \times \log ($ Size $)$ & $100 \times \log ($ Price $)$ & LTV Ratio \\
\hline & $(1)$ & $(2)$ & (3) & (4) & $(5)$ \\
\hline Average Friend Appreciation Last 24 Months (\%) & $\begin{array}{c}0.625^{* * *} \\
(0.051)\end{array}$ & $\begin{array}{c}0.188 * * * \\
(0.019)\end{array}$ & $\begin{array}{c}0.309 * * * \\
(0.056)\end{array}$ & $\begin{array}{c}0.538 * * * \\
(0.043)\end{array}$ & $\begin{array}{c}-0.254^{* * *} \\
(0.028)\end{array}$ \\
\hline \multicolumn{6}{|l|}{ Average Friend County Income } \\
\hline Level & $\begin{array}{c}0.004 * * * \\
(0.000)\end{array}$ & $\begin{array}{c}0.001 * * * \\
(0.000)\end{array}$ & $\begin{array}{c}0.005^{* * *} \\
(0.000)\end{array}$ & $\begin{array}{c}0.008^{* * *} \\
(0.000)\end{array}$ & $\begin{array}{c}-0.003 * * * \\
(0.000)\end{array}$ \\
\hline Change Last 24 Months (\%) & $\begin{array}{c}-0.253^{* * *} \\
(0.040)\end{array}$ & $\begin{array}{c}-0.093^{* * *} \\
(0.015)\end{array}$ & $\begin{array}{c}-0.198 * * \\
(0.096)\end{array}$ & $\begin{array}{c}-0.239 * * * \\
(0.055)\end{array}$ & $\begin{array}{c}0.036 \\
(0.041)\end{array}$ \\
\hline \multicolumn{6}{|l|}{ Average Friend County Unemployment Rate } \\
\hline Level & $\begin{array}{c}0.001 \\
(0.002)\end{array}$ & $\begin{array}{l}-0.001 \\
(0.001)\end{array}$ & $\begin{array}{l}-0.001 \\
(0.002)\end{array}$ & $\begin{array}{c}-0.004 * * * \\
(0.001)\end{array}$ & $\begin{array}{l}-0.000 \\
(0.001)\end{array}$ \\
\hline Change Last 24 Months (ppt) & $\begin{array}{c}0.016 * * * \\
(0.004)\end{array}$ & $\begin{array}{c}0.004^{* *} \\
(0.002)\end{array}$ & $\begin{array}{c}0.025^{* * *} \\
(0.004)\end{array}$ & $\begin{array}{c}0.012^{* * *} \\
(0.003)\end{array}$ & $\begin{array}{c}-0.017^{* * *} \\
(0.003)\end{array}$ \\
\hline Controls & $\begin{array}{c}\text { Table } 4 \\
\text { Column } 1 \\
2010 \text { Renters }\end{array}$ & $\begin{array}{c}\text { Table } 4 \\
\text { Column } 1 \\
2010 \text { Owners }\end{array}$ & $\begin{array}{l}\text { Table } 5 \\
\text { Column } 1\end{array}$ & $\begin{array}{l}\text { Table } 6 \\
\text { Column } 1\end{array}$ & $\begin{array}{c}\text { Table } 7 \\
\text { Column } 1\end{array}$ \\
\hline $\begin{array}{l}\mathrm{N} \\
\mathrm{R} \text {-Squared }\end{array}$ & $\begin{array}{c}433,836 \\
0.435\end{array}$ & $\begin{array}{c}1,035,523 \\
0.564\end{array}$ & $\begin{array}{c}526,594 \\
0.194\end{array}$ & $\begin{array}{c}523,299 \\
0.793\end{array}$ & $\begin{array}{c}268,204 \\
0.146\end{array}$ \\
\hline $\begin{array}{l}\text { Note: Table shows results from the main } \\
\text { conditions in individuals' social networks } \\
\text { experiences of all friends are instrumentec } \\
\text { weighted income changes at the county-le } \\
\text { Panel B controls for friend-weighted incom } \\
\text { weighted employment rate and its change } \\
\text { social networks. Specifications and stand } \\
(p<0.05),{ }^{* * *}(p<0.01) \text {. }\end{array}$ & $\begin{array}{l}\text { regressions in } \\
\text { in addition } t \\
\text { for by their } \\
\text { vel over the } p \\
\text { e level and ch } \\
\text { s over the pa } \\
\text { rd errors as }\end{array}$ & $\begin{array}{l}\text { Tables } 4,5,6, \\
\text { the house pric } \\
\text { tt-of-commuti } \\
\text { t } 24 \text { months } \\
\text { ges at the cou } \\
24 \text { months in } \\
\text { scribed in the }\end{array}$ & $\begin{array}{l}\text { d } 7 \text {, while dire } \\
\text { movements in } \\
\text { zone counterp } \\
\text { all members of } \\
\text { y level over the } \\
\text { ercentage poin } \\
\text { iginal tables. }\end{array}$ & $\begin{array}{l}\text { tly controlling } \mathrm{f} \\
\text { hese networks. } \\
\text { rts. Panel A cor } \\
\text { he individuals' } \\
\text { ast } 24 \text { months, } \\
\text { of all member } \\
\text { gnificance Leve }\end{array}$ & $\begin{array}{l}\text { the econon } \\
\text { e house pri } \\
\text { ls for frien } \\
\text { ial networ } \\
\text { vell as frien } \\
\text { individua } \\
*(p<0.10) \text {, }\end{array}$ \\
\hline
\end{tabular}


Table 9: Effect of Dispersion of Friends' House Price Experiences

\begin{tabular}{|c|c|c|c|c|c|c|}
\hline & \multirow{2}{*}{$\begin{array}{c}\text { Response Q4 } \\
(1)\end{array}$} & \multicolumn{2}{|c|}{$\mathrm{P}($ Own in 2012) } & \multirow{2}{*}{$\frac{100 \times \log (\text { Size })}{(4)}$} & \multirow{2}{*}{$\frac{100 \times \log (\text { Price })}{(5)}$} & \multirow{2}{*}{$\begin{array}{c}\text { LTV Ratio } \\
(6)\end{array}$} \\
\hline & & $(2)$ & (3) & & & \\
\hline Average Friend Appreciation & $0.051^{* *}$ & $0.236^{* * *}$ & $0.089^{* * *}$ & $0.389^{* * *}$ & $0.590^{* * *}$ & $-0.209^{* * *}$ \\
\hline Last 24 Months (\%) & $(0.024)$ & $(0.047)$ & $(0.018)$ & $(0.062)$ & $(0.037)$ & $(0.012)$ \\
\hline Dispersion Friend Appreciation & 0.008 & $-0.243^{* * *}$ & $-0.068^{* \star *}$ & $-0.139^{\star \star *}$ & $-0.400^{* * *}$ & $0.054^{\star * *}$ \\
\hline Last 24 Months (\%) & $(0.013)$ & $(0.021)$ & $(0.007)$ & $(0.046)$ & $(0.030)$ & $(0.013)$ \\
\hline Controls & $\begin{array}{c}\text { Table } 3 \\
\text { Column } 3\end{array}$ & $\begin{array}{c}\text { Table } 4 \\
\text { Column } 1 \\
2010 \text { Renters }\end{array}$ & $\begin{array}{c}\text { Table } 4 \\
\text { Column } 1 \\
2010 \text { Owners }\end{array}$ & $\begin{array}{c}\text { Table } 5 \\
\text { Column } 1\end{array}$ & $\begin{array}{c}\text { Table } 6 \\
\text { Column } 1\end{array}$ & $\begin{array}{c}\text { Table } 7 \\
\text { Column } 1\end{array}$ \\
\hline $\mathrm{N}$ & 1,242 & 433,836 & $1,035,523$ & 526,006 & 523,299 & 268,204 \\
\hline R-Squared & 0.159 & 0.435 & 0.564 & 0.242 & 0.791 & 0.142 \\
\hline
\end{tabular}

Note: Table shows results from the main regressions in Tables 3, 4, 5, 6, and 7, while including the 5-95 percentile range of the house price experiences over the past 24 months of the members of individuals' social networks as an additional control variable. Both the mean and the dispersion of house price experiences of all friends are instrumented for by their out-ofcommuting zone counterparts. Specifications and standard errors as described in the original tables. Significance Levels: * $(\mathrm{p}<0.10),{ }^{* *}(\mathrm{p}<0.05), * * *(\mathrm{p}<0.01)$. 
Table 10: County-Level Turnover and Prices

\begin{tabular}{|c|c|c|c|c|c|c|c|c|c|}
\hline & \multicolumn{3}{|c|}{ Trading Volume (\% of Housing Stock) } & \multicolumn{6}{|c|}{ Change House Prices (\%) } \\
\hline & (1) & (2) & (3) & (4) & (5) & (6) & (7) & (8) & (9) \\
\hline $\begin{array}{l}\text { Lagged Dispersion of Friend } \\
\text { House Price Experience (\%) }\end{array}$ & $\begin{array}{l}0.151^{* * *} \\
(0.043)\end{array}$ & $\begin{array}{l}0.152^{* \star *} \\
(0.043)\end{array}$ & $\begin{array}{l}0.120^{* * *} \\
(0.040)\end{array}$ & & $\begin{array}{l}0.884^{* * *} \\
(0.292)\end{array}$ & $\begin{array}{l}0.774^{\star * *} \\
(0.293)\end{array}$ & & & $\begin{array}{l}0.825^{\star *} \\
(0.325)\end{array}$ \\
\hline $\begin{array}{l}\text { Lagged Avg. Friend House } \\
\text { Price Experience (\%) }\end{array}$ & & $\begin{array}{c}0.007 \\
(0.013)\end{array}$ & $\begin{array}{l}-0.026^{*} \\
(0.014)\end{array}$ & $\begin{array}{l}0.900^{* * *} \\
(0.124)\end{array}$ & $\begin{array}{l}0.849^{* * *} \\
(0.123)\end{array}$ & $\begin{array}{l}0.822^{* \star *} \\
(0.121)\end{array}$ & & $\begin{array}{l}0.931^{* * *} \\
(0.207)\end{array}$ & $\begin{array}{l}0.938^{* * *} \\
(0.217)\end{array}$ \\
\hline $\begin{array}{l}\text { Lagged Trading Volume } \\
\text { (\% of Housing Stock) }\end{array}$ & $\begin{array}{l}0.639^{* * *} \\
(0.021)\end{array}$ & $\begin{array}{l}0.636^{* * *} \\
(0.022)\end{array}$ & $\begin{array}{l}0.636^{* * *} \\
(0.022)\end{array}$ & & & & & & \\
\hline $\begin{array}{l}\text { Lagged Distance-Weighted } \\
\text { House Price Experience (\%) }\end{array}$ & & & & & & & $\begin{array}{l}0.484^{\star * *} \\
(0.059)\end{array}$ & $\begin{array}{l}-0.075 \\
(0.126)\end{array}$ & $\begin{array}{l}-0.132 \\
(0.144)\end{array}$ \\
\hline Income Change (\%) & $\begin{array}{l}0.024^{\star * *} \\
(0.003)\end{array}$ & $\begin{array}{l}0.024^{* * *} \\
(0.003)\end{array}$ & $\begin{array}{l}0.014^{* * *} \\
(0.002)\end{array}$ & $\begin{array}{l}0.274^{* \star *} \\
(0.023)\end{array}$ & $\begin{array}{l}0.294^{* * *} \\
(0.026)\end{array}$ & $\begin{array}{l}0.285^{\star * *} \\
(0.026)\end{array}$ & $\begin{array}{l}0.252^{\star \star \star} \\
(0.021)\end{array}$ & $\begin{array}{l}0.268^{* * *} \\
(0.023)\end{array}$ & $\begin{array}{c}0.289^{* * *} \\
(0.027)\end{array}$ \\
\hline Unemployement Rate (\%) & $\begin{array}{l}-0.002 \\
(0.014)\end{array}$ & $\begin{array}{c}0.006 \\
(0.020)\end{array}$ & $\begin{array}{c}0.009 \\
(0.019)\end{array}$ & $\begin{array}{l}-0.072 \\
(0.086)\end{array}$ & $\begin{array}{l}-0.015 \\
(0.095)\end{array}$ & $\begin{array}{l}-0.018 \\
(0.093)\end{array}$ & $\begin{array}{l}-0.242^{* \star *} \\
(0.072)\end{array}$ & $\begin{array}{l}-0.071 \\
(0.083)\end{array}$ & $\begin{array}{l}-0.023 \\
(0.092)\end{array}$ \\
\hline $\begin{array}{l}\text { Change Unemployment } \\
\text { Rate (ppt) }\end{array}$ & $\begin{array}{l}-0.106^{* * *} \\
(0.016)\end{array}$ & $\begin{array}{l}-0.106^{* * *} \\
(0.016)\end{array}$ & $\begin{array}{c}-0.067^{* * *} \\
(0.013)\end{array}$ & $\begin{array}{c}-1.002^{* * *} \\
(0.107)\end{array}$ & $\begin{array}{l}-1.109^{* * *} \\
(0.118)\end{array}$ & $\begin{array}{c}-1.071^{* * *} \\
(0.114)\end{array}$ & $\begin{array}{l}-0.959^{* * *} \\
(0.106)\end{array}$ & $\begin{array}{l}-0.978^{* * *} \\
(0.105)\end{array}$ & $\begin{array}{c}-1.084^{* * *} \\
(0.119)\end{array}$ \\
\hline Change House Prices (\%) & & & $\begin{array}{l}0.035^{\star * *} \\
(0.004)\end{array}$ & & & & & & \\
\hline $\begin{array}{l}\text { Lagged Change } \\
\text { House Prices (\%) }\end{array}$ & & & & $\begin{array}{l}0.075^{*} \\
(0.043)\end{array}$ & $\begin{array}{l}0.079^{\star} \\
(0.045)\end{array}$ & $\begin{array}{l}0.074^{*} \\
(0.043)\end{array}$ & $\begin{array}{l}0.139^{* * *} \\
(0.032)\end{array}$ & $\begin{array}{l}0.078^{* *} \\
(0.038)\end{array}$ & $\begin{array}{l}0.090^{* *} \\
(0.039)\end{array}$ \\
\hline $\begin{array}{l}\text { Trading Volume } \\
\text { (\% of Housing Stock) }\end{array}$ & & & & & & $\begin{array}{l}0.396^{* * *} \\
(0.097)\end{array}$ & $\begin{array}{l}0.437^{\star * *} \\
(0.093)\end{array}$ & $\begin{array}{l}0.452^{* * *} \\
(0.098)\end{array}$ & $\begin{array}{c}0.404^{* * *} \\
(0.097)\end{array}$ \\
\hline Fixed Effects & $\begin{array}{l}\text { County, } \\
\text { Year }\end{array}$ & $\begin{array}{l}\text { County, } \\
\text { Year }\end{array}$ & $\begin{array}{l}\text { County, } \\
\text { Year }\end{array}$ & $\begin{array}{l}\text { County, } \\
\text { Year }\end{array}$ & $\begin{array}{l}\text { County, } \\
\text { Year }\end{array}$ & $\begin{array}{l}\text { County, } \\
\text { Year }\end{array}$ & $\begin{array}{l}\text { County, } \\
\text { Year }\end{array}$ & $\begin{array}{l}\text { County, } \\
\text { Year }\end{array}$ & $\begin{array}{l}\text { County, } \\
\text { Year }\end{array}$ \\
\hline Other Controls & $\mathrm{Y}$ & Y & Y & Y & $\mathrm{Y}$ & Y & Y & $\mathrm{Y}$ & $\mathrm{Y}$ \\
\hline $\mathrm{N}$ & 10,068 & 10,068 & 10,068 & 10,068 & 10,068 & 10,068 & 10,068 & 10,068 & 10,068 \\
\hline R-Squared & 0.783 & 0.783 & 0.791 & 0.590 & 0.552 & 0.565 & 0.618 & 0.592 & 0.553 \\
\hline
\end{tabular}

Note: Table shows results from regression 10 in columns 1-3, and from regression 11 in columns 4-9. The unit of observation is a county-year, the horizon is 1998-2012. All specifications include county fixed effects, year fixed effects, and year-specific controls for the share of the population without a high school degree. Standard errors are clustered at the county level. Significance Levels: ${ }^{*}(\mathrm{p}<0.10),{ }^{* *}(\mathrm{p}<0.05),{ }^{* * *}(\mathrm{p}<0.01)$. 


\section{Figure 1: Distribution of House Price Experiences}

(A) Change-of-Tenure Sample - All Experience

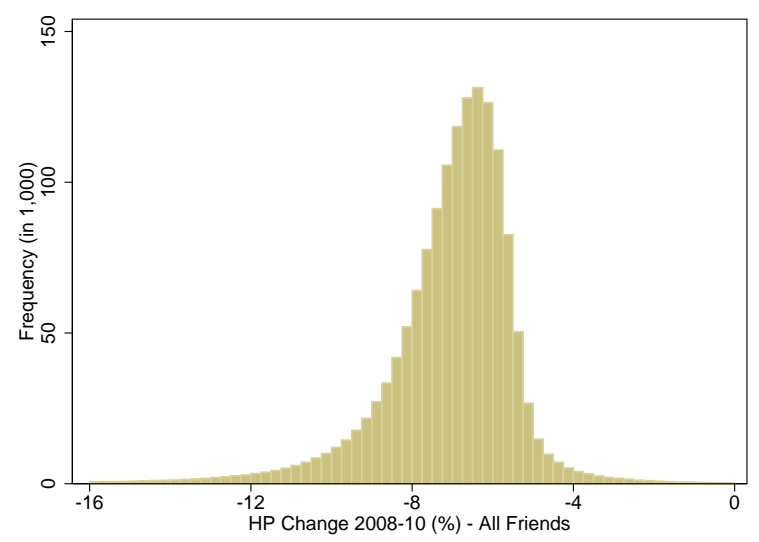

(C) Transaction Sample - All Experience

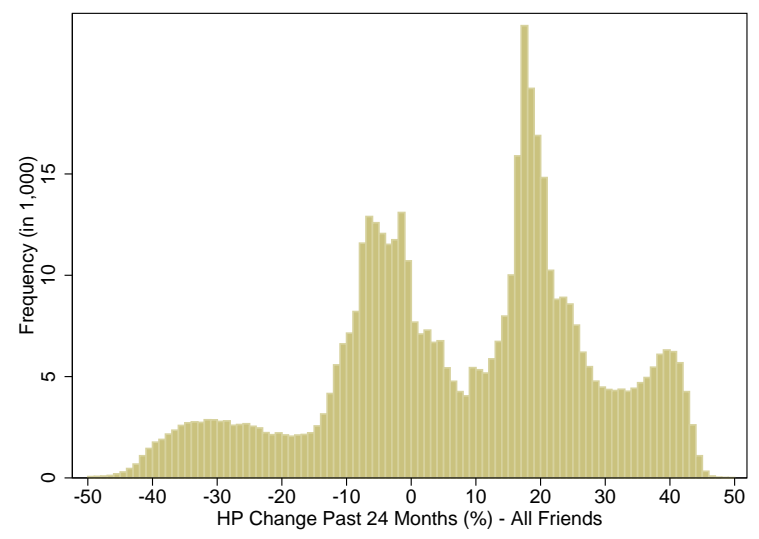

(E) Change-of-Tenure Sample - Dispersion

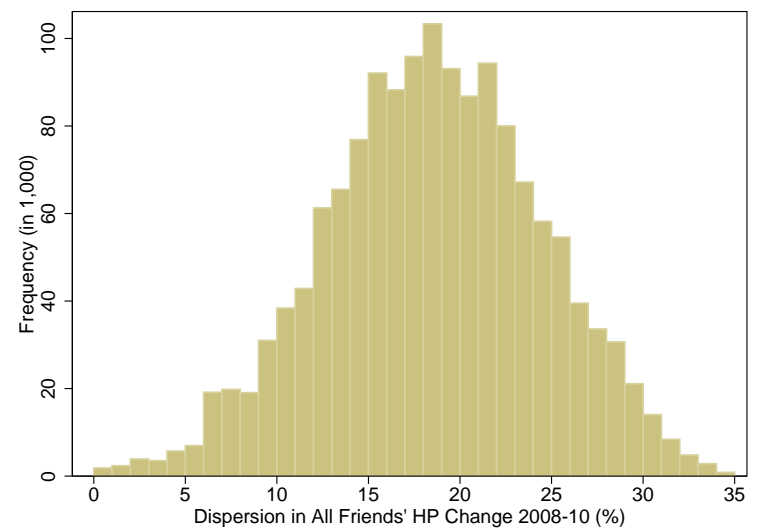

(B) Change-of-Tenure Sample - Out-of-CZ Experience

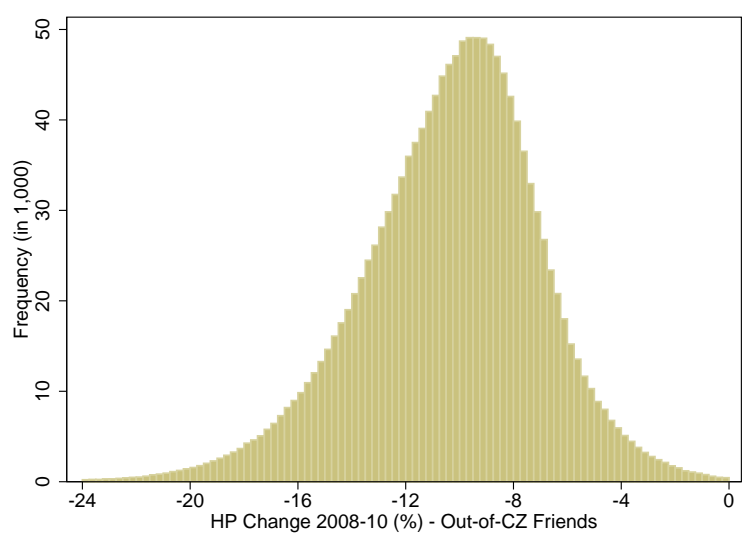

(D) Transaction Sample - Out-of-CZ Experience

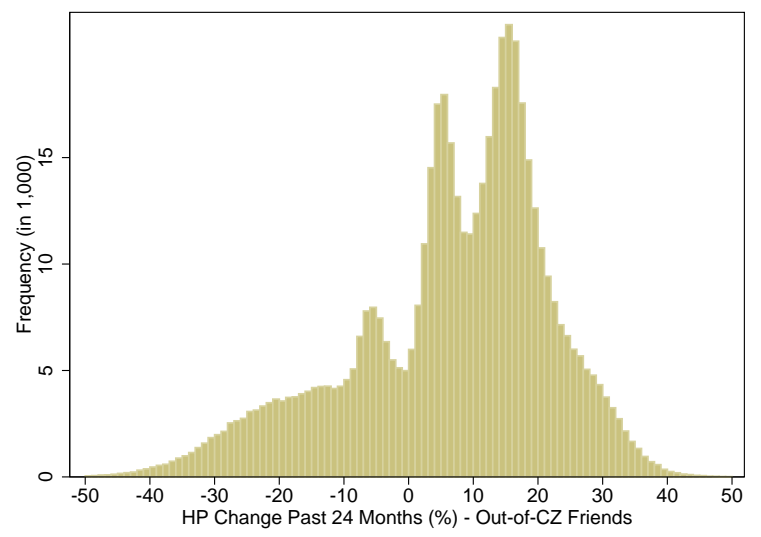

(F) Transaction Sample - Dispersion

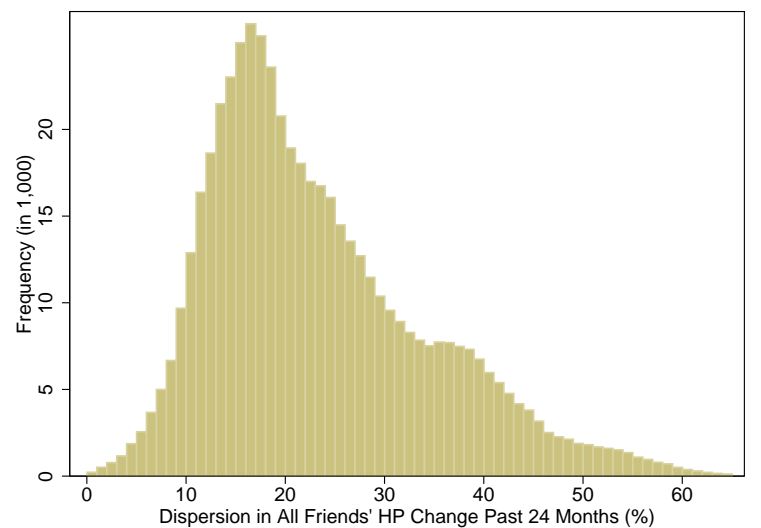

Note: Panels A and B show the distribution of FriendHPExp $p_{i, 2008,2010}^{N}$ in the change-of-tenure sample across all friends and all out-of-commuting zone friends. Panels C and D show the distribution of FriendHPExp $p_{i, t, t-24 m}^{N}$ in the transaction sample across all friends and all out-of-commuting zone friends. The shape of the distributions is affected by pooling transactions across years with very different levels of national house price changes. Panels E and F show the distribution of the 5-95 percentile within-individual difference ("dispersion") of friends' house price experience in the change-of-tenure sample and the transaction sample, respectively. In Panels A and B, the bucket size is 0.25 percentage points. In Panels C, D, E, and F, the bucket size is 1 percentage point. 


\section{Figure 2: Examples of Individual-Level Friend Distributions}

(A) Example 1 - Chicago Focus

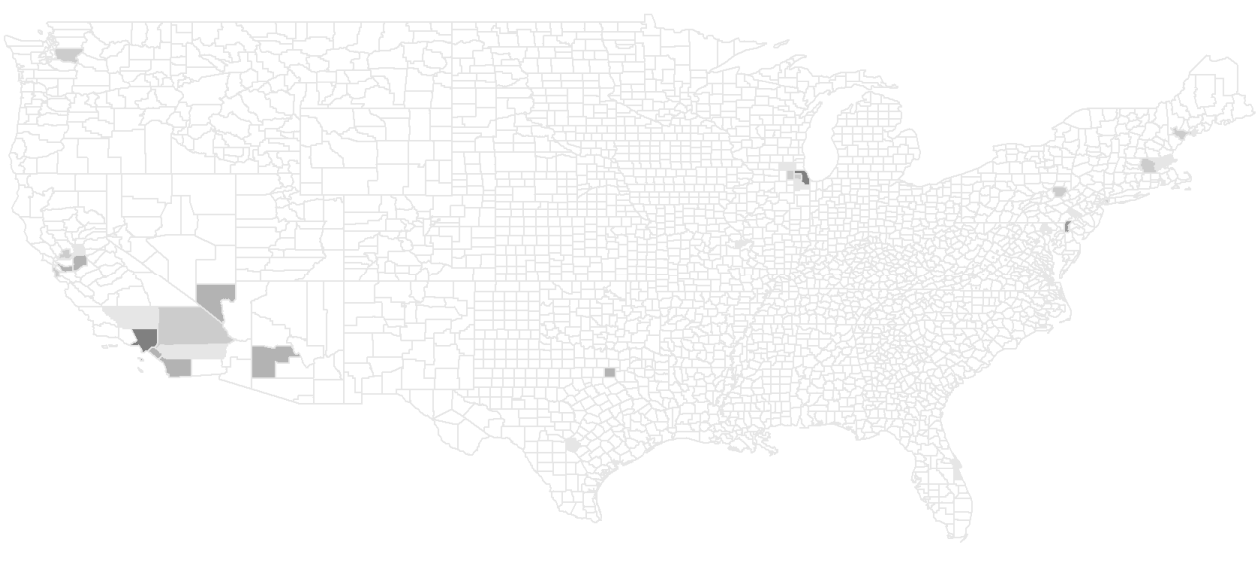

(B) Example 2 - Oklahoma Focus

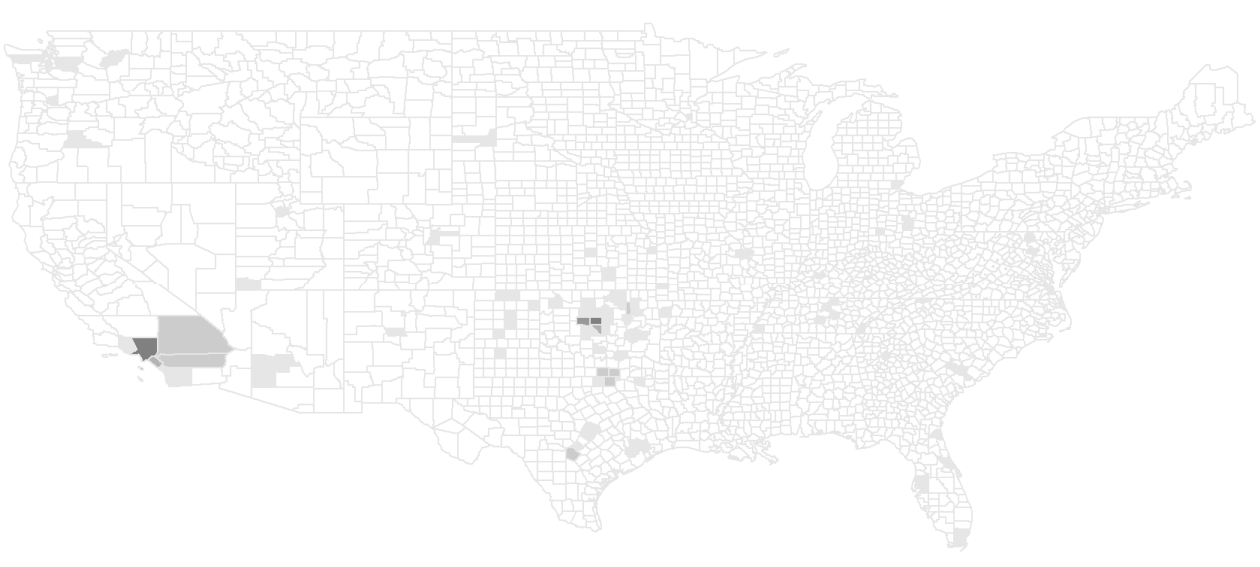

(C) Example 3 - U.S.-Wide Spread

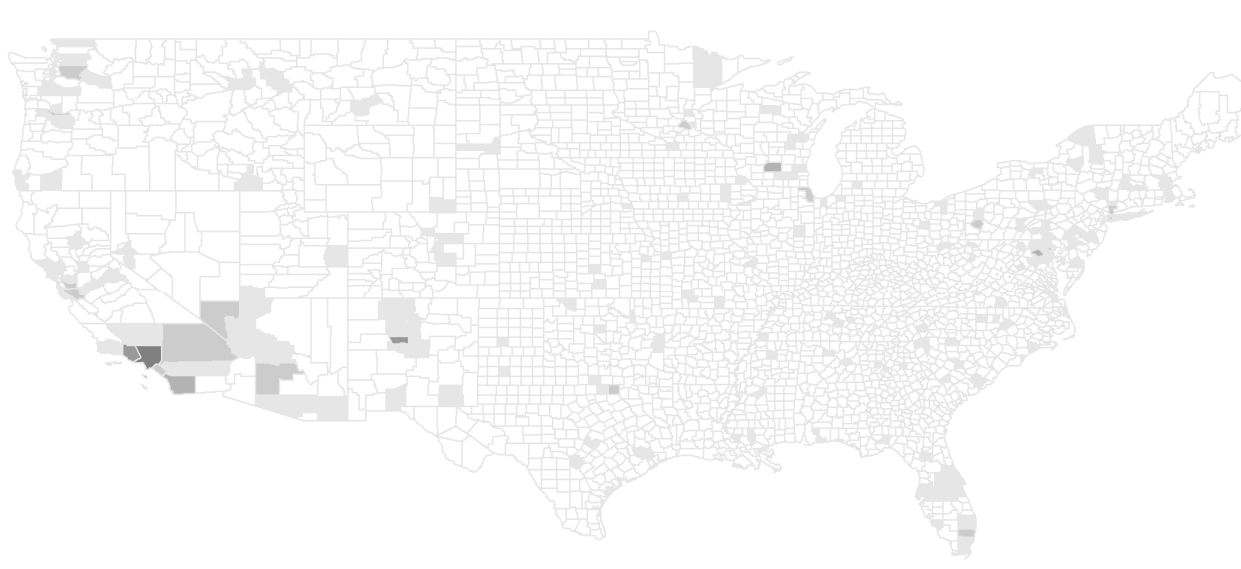

Note: Figure shows the geographic distribution of friends of three Facebook users living as renters in Los Angeles county in 2010. Panel A shows an individual with disproportionately many friends clustered in Chicago. Panel B shows an individual with disproportionately many friends clustered in Oklahoma. Panel C shows an individual with friends in most U.S. population centers. 
Figure 3: Expectations Survey

(A) Question 1

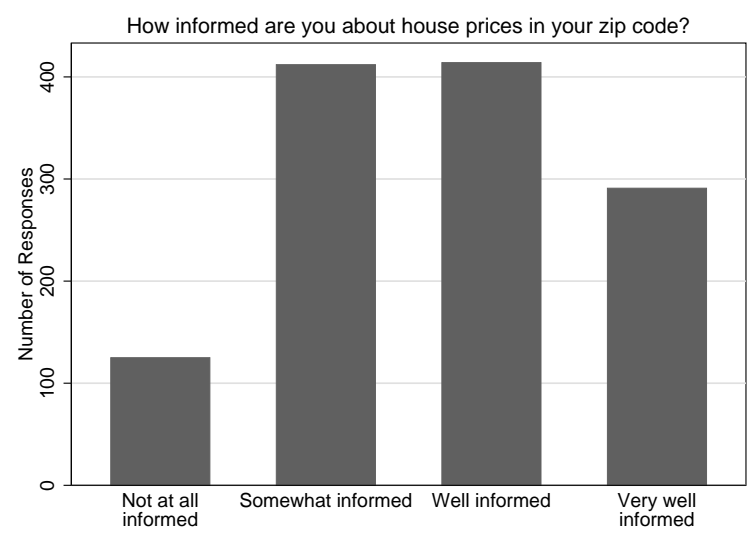

(C) Question 3

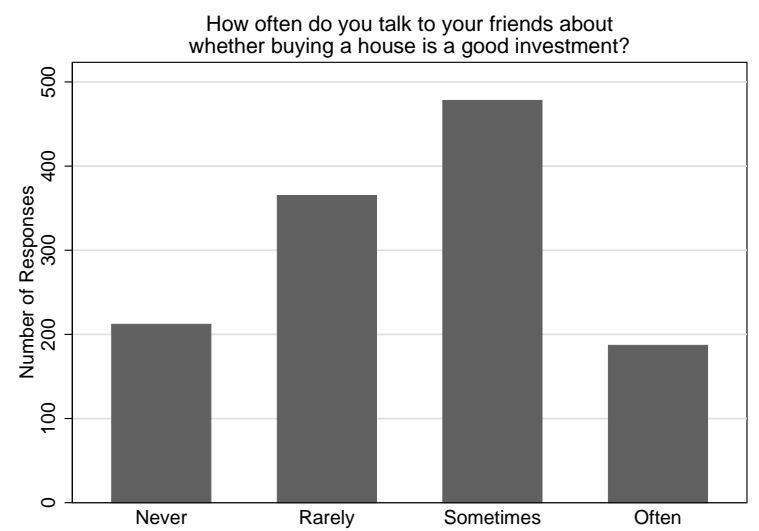

(E) All Friends

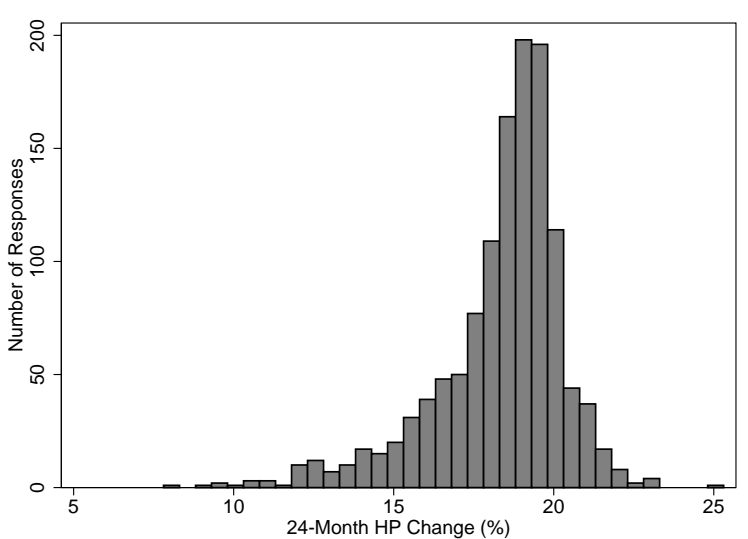

(B) Question 2

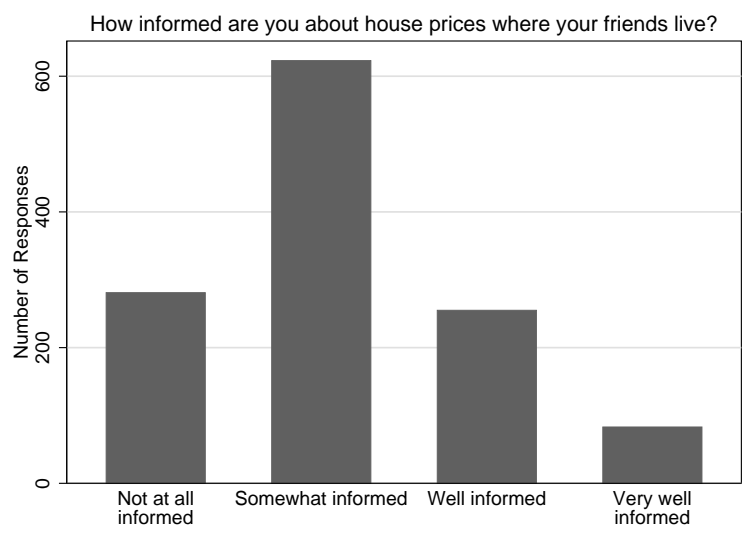

(D) Question 4

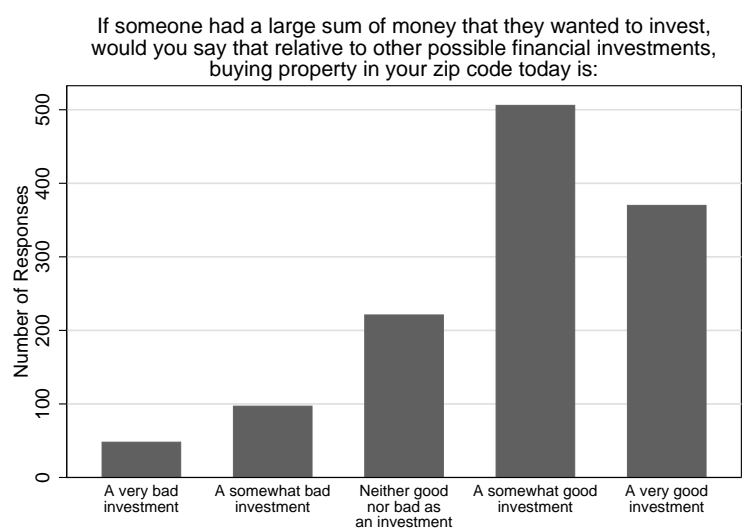

(F) Out-of-Commuting Zone Friends

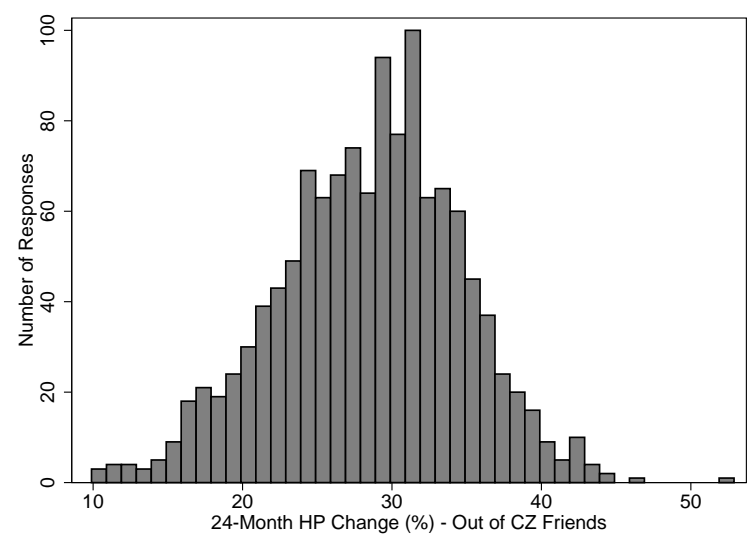

Note: Panels A to D present the distribution of responses to the expectations survey conducted by Facebook in November 2015, which we analyze and describe in Section 2. Panels E and F provide the average house price experience in the survey respondents' social network in the 24 months prior to taking the survey. 


\section{Figure 4: Experience Dispersion vs. Trading Volume}

(A) Experience Dispersion vs. Concentration of Friends

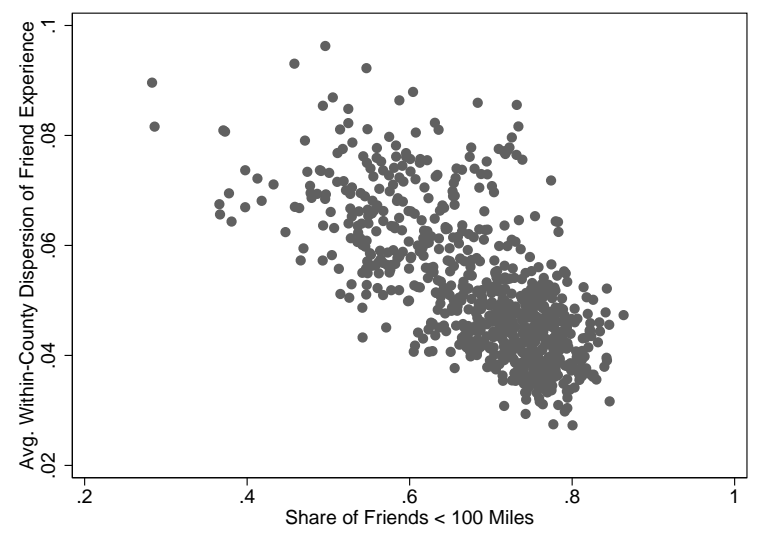

(C) Experience Dispersion vs. Turnover

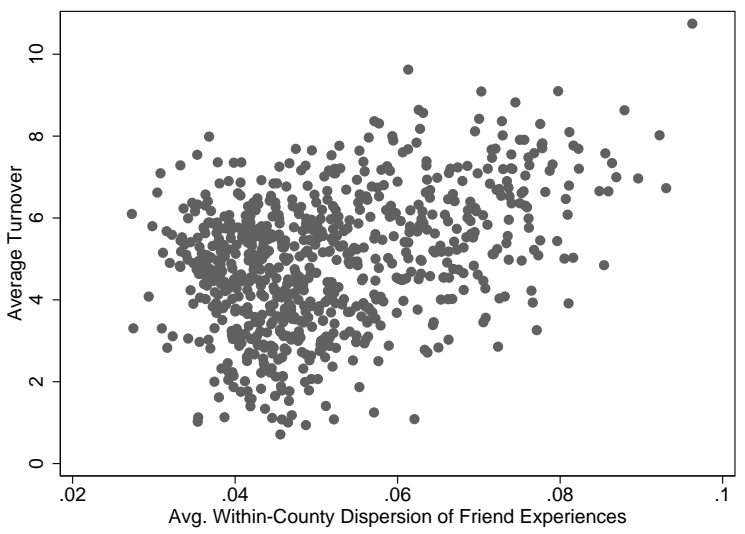

(E) Experience Dispersion vs. Turnover

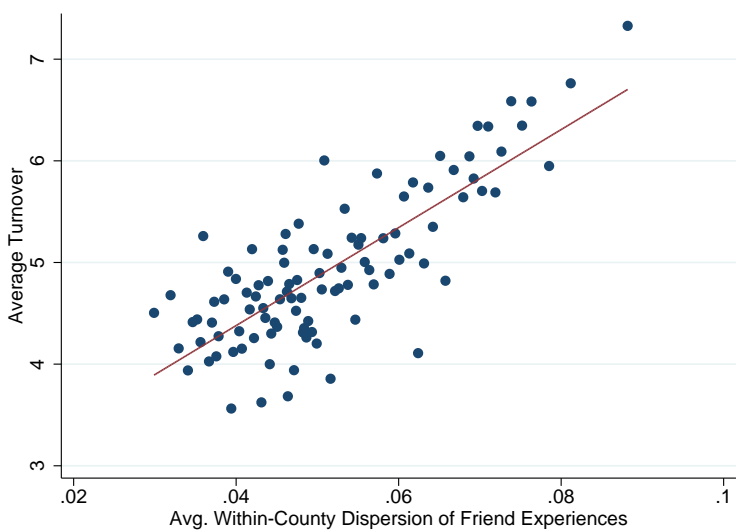

(B) Experience Dispersion vs. Concentration of Friends

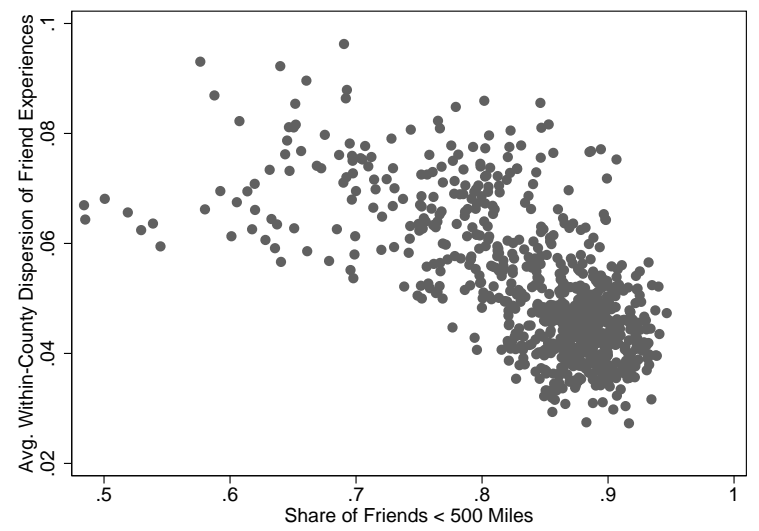

(D) SD Experience Dispersion vs. SD Turnover

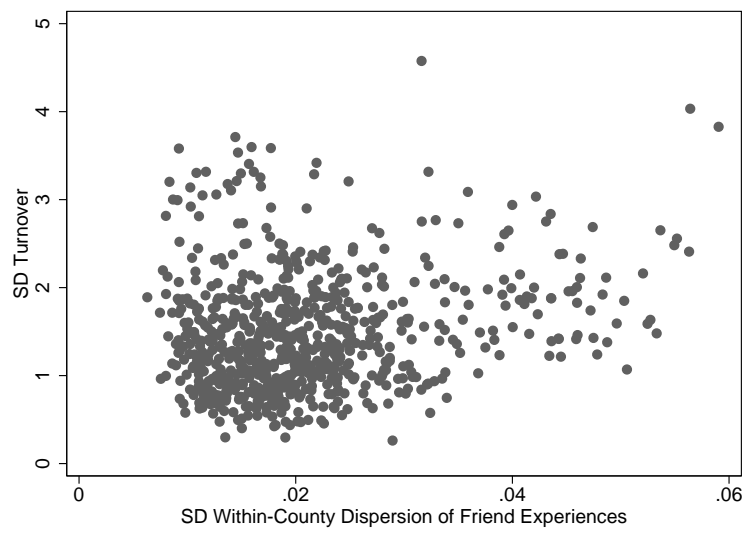

(F) SD Experience Dispersion vs. SD Turnover

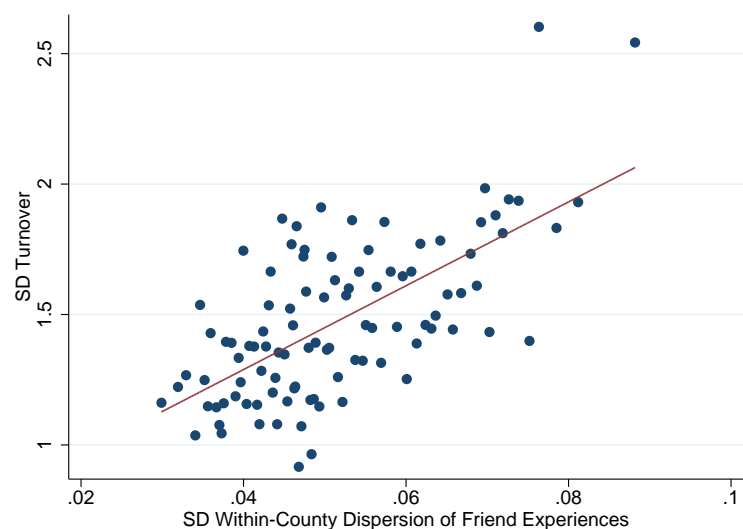

Note: Panels A and B present county-level scatter plots of the share of friends that live within 100 and 500 miles, respectively, and the average dispersion of house price experiences within that county, Dis $p_{c, t}^{N}$, constructed as in equation 9, between 1998 and 2013. Panel C shows a scatter plot of the average dispersion and the average trading volume. Panel D shows a scatter plot of the standard deviation of the dispersion and the standard deviation of the trading volume. Panels $\mathrm{E}$ and $\mathrm{F}$ show bin-scatter plots of these relationships, conditional on the county-level logincome, log-population, unemployment rate, and median age. 
Table A1: Expectation Whether Buying Property is a Good Investment

\begin{tabular}{|c|c|c|c|c|c|}
\hline & (1) & (2) & (3) & (4) & (5) \\
\hline All Friend Appreciation 2013-15 (\%) & $\begin{array}{l}1.075^{* *} \\
(0.032)\end{array}$ & $\begin{array}{c}1.091^{* *} \\
(0.039)\end{array}$ & & & \\
\hline \multicolumn{6}{|l|}{ All Friend Appreciation 2013-15 (\%) x } \\
\hline Expectation Question Last & & & $\begin{array}{c}1.069 * * \\
(0.032)\end{array}$ & & \\
\hline Expectation Question First & & & $\begin{array}{c}1.091 * * * \\
(0.034)\end{array}$ & & \\
\hline \multicolumn{6}{|l|}{$\begin{array}{l}\text { All Friend Appreciation 2013-15 (\%) x } \\
\text { Knowledge of HP in Friends' Location }\end{array}$} \\
\hline Not at all informed & & & & $\begin{array}{l}1.008 \\
(0.061)\end{array}$ & \\
\hline Somewhat informed & & & & $\begin{array}{l}1.086 \\
(0.056)\end{array}$ & \\
\hline Well informed & & & & $\begin{array}{c}1.099 \\
(0.078)\end{array}$ & \\
\hline Very well informed & & & & $\begin{array}{l}1.216 \\
(0.173)\end{array}$ & \\
\hline $\begin{array}{l}\text { All Friend Appreciation 2013-15 (\%) } \\
\text { Talk with Friend about Housing Inv }\end{array}$ & & & & & \\
\hline Never & & & & & $\begin{array}{c}0.959 \\
(0.057)\end{array}$ \\
\hline Rarely & & & & & $\begin{array}{c}1.013 \\
(0.048)\end{array}$ \\
\hline Sometimes & & & & & $\begin{array}{l}1.13^{* * *} \\
(0.053)\end{array}$ \\
\hline Often & & & & & $\begin{array}{r}1.253^{* *} \\
(0.144)\end{array}$ \\
\hline Demographic Controls & Y & Y & Y & Y & Y \\
\hline Zip Code Fixed Effects & Y & Y & Y & Y & Y \\
\hline Sample & & $\begin{array}{l}\text { Winzorize Friend } \\
\text { HP Experience }\end{array}$ & & & \\
\hline $\mathrm{N}$ & 1,242 & 1,242 & 1,242 & 1,242 & 1,242 \\
\hline
\end{tabular}

Note: Table shows results from a conditional ordered logit estimation of regression 3 . The dependent variable is the answer to survey Question 4: "If someone had a large sum of money that they wanted to invest, would you say that relative to other possible financial investments, buying property in your zip code today is: A very good investment, A somewhat good investment, Neither good nor bad as an investment, A somewhat bad investment, A very bad investment." Column 1 shows the baseline estimates. In column 2, friends' experiences are winsorized at the 5\% level. The last three columns estimate differential effects by the ordering of the questions (column 3), how informed respondents claimed to be about their friends' house price experiences (column 4) and how often respondents report talking to their friends about whether buying property is a good investment (column 5). The specifications in columns 3,4 , and 5, also include non-interacted indicator variables for the question ordering, and the possible responses to Questions 2 and 3, respectively; in the interest of space, the corresponding coefficients are not reported. All columns also control for respondent age and gender. Standard errors are in parentheses. Significance Levels: ${ }^{*}(p<0.10),{ }^{* *}$ $(p<0.05),{ }^{* * *}(p<0.01)$. 
Table A2: Robustness Check with Out-of-State Friends' Price Experience as Instrument

\begin{tabular}{|c|c|c|c|c|c|c|}
\hline & Response Q4 & PlOwn & n 2012) & $100 \times \log ($ Size $)$ & $100 \times \log$ (Price) & LTV Ratio \\
\hline & $(1)$ & (2) & (3) & (4) & (5) & (6) \\
\hline $\begin{array}{l}\text { Average Friend Appreciation } \\
\text { Last } 24 \text { Months (\%) }\end{array}$ & $\begin{array}{c}0.047^{* *} \\
(0.020)\end{array}$ & $\begin{array}{c}0.529 * * * \\
(0.044)\end{array}$ & $\begin{array}{c}0.163^{* * *} \\
(0.018)\end{array}$ & $\begin{array}{c}0.387^{* * *} \\
(0.071)\end{array}$ & $\begin{array}{c}0.803^{* * *} \\
(0.045)\end{array}$ & $\begin{array}{c}-0.246 * * * \\
(0.026)\end{array}$ \\
\hline Controls & $\begin{array}{c}\text { Table } 3 \\
\text { Column } 3\end{array}$ & $\begin{array}{c}\text { Table } 4 \\
\text { Column } 1 \\
2010 \text { Renters }\end{array}$ & $\begin{array}{c}\text { Table } 4 \\
\text { Column } 1 \\
2010 \text { Owners }\end{array}$ & $\begin{array}{l}\text { Table } 5 \\
\text { Column } 1\end{array}$ & $\begin{array}{l}\text { Table } 6 \\
\text { Column } 1\end{array}$ & $\begin{array}{l}\text { Table } 7 \\
\text { Column } 1\end{array}$ \\
\hline $\mathrm{N}$ & 1,242 & 433,757 & $1,035,296$ & 526,473 & 523,179 & 268,136 \\
\hline R-Squared & 0.160 & 0.434 & 0.564 & 0.192 & 0.792 & 0.142 \\
\hline
\end{tabular}

Note: Table shows robustness of the results from the main instrumental variables regressions in Tables 3, 4, 5, 6, and 7 to using average house price experiences over the past 24 months of individuals' out-of-state friends, instead of the experiences of their out-of-commuting-zone friends, to instrument for the house price experiences of all friends. Specifications and standard errors are as described in the original tables. Significance Levels: ${ }^{*}(p<0.10),{ }^{* *}(p<0.05),{ }^{* *}(p<0.01)$. 
Table A3: Control Variables on Purchasing Regression

\begin{tabular}{|c|c|c|c|c|c|}
\hline & Coefficient & $\begin{array}{l}\text { Standard } \\
\text { Error }\end{array}$ & & Coefficient & $\begin{array}{c}\text { Standarc } \\
\text { Error }\end{array}$ \\
\hline Occupation (relative to "unknown") & & & Income 2010 (relative to "less than $\$ 15,000 "$ ) & & \\
\hline Professional/Technical & 1.84 & 0.24 & $\$ 15,000-\$ 19,999$ & 0.36 & 0.23 \\
\hline Administration/Managerial & 0.67 & 0.28 & $\$ 20,000-\$ 29,999$ & 1.12 & 0.19 \\
\hline Sales/Service & 0.14 & 0.41 & $\$ 30,000-\$ 39,999$ & 1.44 & 0.20 \\
\hline Clerical/White Collar & 0.10 & 0.18 & $\$ 40,000-\$ 49,999$ & 2.37 & 0.22 \\
\hline Craftsman/Blue Collar & 0.75 & 0.28 & $\$ 50,000-\$ 74,999$ & 4.52 & 0.24 \\
\hline Student & 2.00 & 0.47 & $\$ 75,000-\$ 99,999$ & 8.26 & 0.37 \\
\hline Homemaker & 0.11 & 0.40 & $\$ 100,000-\$ 124,999$ & 9.87 & 0.45 \\
\hline Retired & 0.47 & 0.62 & Greater than $\$ 124,999$ & 16.61 & 0.64 \\
\hline Farmer & 1.51 & 2.86 & Unknown & -8.41 & 1.73 \\
\hline Self Employed & 0.64 & 0.51 & & & \\
\hline Educator & 1.30 & 1.24 & Change in Income 2010 - 2012 (K\$) & 0.10 & 0.00 \\
\hline Legal Professional & 0.32 & 0.57 & & & \\
\hline Medical Professional & 3.16 & 0.47 & Number of Friends & & \\
\hline Military & -0.74 & 1.96 & 2nd quintile & 0.05 & 0.19 \\
\hline \multirow[t]{2}{*}{ Religious } & -2.57 & 5.57 & 3rd quintile & 0.38 & 0.22 \\
\hline & & & 4th quintile & 0.57 & 0.26 \\
\hline Household Size (relative to size of 1) & & & 5th quintile & 0.14 & 0.32 \\
\hline 2 & 0.41 & 0.15 & & & \\
\hline 3 & 1.65 & 0.23 & Number of Out-Of-Commuting Zone Friends & & \\
\hline 4 & 3.56 & 0.29 & 2nd quintile & -0.02 & 0.19 \\
\hline 5 & 6.32 & 0.42 & 3rd quintile & -0.36 & 0.20 \\
\hline 6 & 9.33 & 0.60 & 4th quintile & -0.24 & 0.25 \\
\hline 7 & 10.41 & 0.89 & 5th quintile & -0.96 & 0.32 \\
\hline \multirow[t]{2}{*}{8} & 12.37 & 1.76 & & & \\
\hline & & & Age (relative to "18-24") & & \\
\hline \multirow[t]{2}{*}{ Change in Household Size 2010 - 2012} & 5.82 & 0.14 & $25-29$ & 1.05 & 0.21 \\
\hline & & & 30-34 & 3.38 & 0.24 \\
\hline \multicolumn{2}{|c|}{ Change in Family Structure (rel. to "stayed married") } & & 35-39 & 4.41 & 0.27 \\
\hline Stayed Single & -1.17 & 0.23 & $40-44$ & 4.55 & 0.26 \\
\hline Got Married & 20.66 & 0.39 & $45-49$ & 4.37 & 0.26 \\
\hline \multirow[t]{2}{*}{ Got Divorced } & 8.43 & 0.45 & $50-54$ & 4.67 & 0.29 \\
\hline & & & $55-59$ & 5.12 & 0.36 \\
\hline Education (relative to "unknown") & & & $60-64$ & 4.78 & 0.39 \\
\hline Completed Highschool & 0.46 & 0.15 & $65+$ & 6.92 & 0.45 \\
\hline Completed College & 1.41 & 0.18 & Unknown & 3.55 & 0.36 \\
\hline Completed Graduate School & 3.88 & 0.32 & & & \\
\hline
\end{tabular}

Note: Table shows coefficients and associated standard errors on the control variables of column 1 in Table 4 . 
Table A4: Control Variables on Property Size Regression

\begin{tabular}{|c|c|c|c|c|c|}
\hline & Coefficient & $\begin{array}{c}\text { Standard } \\
\text { Error }\end{array}$ & & Coefficient & $\begin{array}{c}\text { Standard } \\
\text { Error }\end{array}$ \\
\hline Occupation (relative to "unknown") & & & Income 2010 (relative to "less than $\$ 15,000 "$ ) & & \\
\hline Professional/Technical & 3.42 & 0.19 & $\$ 15,000-\$ 19,999$ & -0.49 & 0.50 \\
\hline Administration/Managerial & 0.13 & 0.25 & $\$ 20,000-\$ 29,999$ & -1.63 & 0.43 \\
\hline Sales/Service & -0.73 & 0.45 & $\$ 30,000-\$ 39,999$ & -1.31 & 0.44 \\
\hline Clerical/White Collar & -0.89 & 0.21 & $\$ 40,000-\$ 49,999$ & 0.41 & 0.45 \\
\hline Craftsman/Blue Collar & -5.86 & 0.26 & $\$ 50,000-\$ 74,999$ & 3.89 & 0.44 \\
\hline Student & 2.21 & 0.58 & $\$ 75,000-\$ 99,999$ & 13.66 & 0.41 \\
\hline Homemaker & 3.13 & 0.40 & $\$ 100,000-\$ 124,999$ & 22.19 & 0.38 \\
\hline Retired & 2.07 & 0.57 & Greater than $\$ 124,999$ & 41.29 & 0.40 \\
\hline Farmer & 8.84 & 2.22 & Unknown & 17.60 & 2.79 \\
\hline Self Employed & 4.58 & 0.51 & & & \\
\hline Educator & -0.97 & 0.82 & Age (relative to "18-24") & & \\
\hline Legal Professional & 3.10 & 0.50 & $25-29$ & -4.71 & 0.26 \\
\hline Medical Professional & 7.85 & 0.31 & 30-34 & -1.20 & 0.24 \\
\hline Military & -0.30 & 1.16 & 35-39 & 3.44 & 0.27 \\
\hline \multirow[t]{2}{*}{ Religious } & 0.77 & 3.23 & $40-44$ & 6.70 & 0.25 \\
\hline & & & $45-49$ & 7.46 & 0.28 \\
\hline Household Size (relative to size of 1 ) & & & $50-54$ & 6.99 & 0.32 \\
\hline 2 & 4.06 & 0.22 & $55-59$ & 7.04 & 0.39 \\
\hline 3 & 7.79 & 0.23 & $60-64$ & 7.80 & 0.52 \\
\hline 4 & 10.31 & 0.26 & $65+$ & 2.70 & 0.37 \\
\hline 5 & 11.99 & 0.31 & Unkown & 2.24 & 0.26 \\
\hline 6 & 13.38 & 0.37 & & & \\
\hline 7 & 14.08 & 0.48 & Number of Friends & & \\
\hline \multirow[t]{2}{*}{8} & 13.51 & 0.64 & 2nd quintile & 0.24 & 0.16 \\
\hline & & & 3rd quintile & 0.99 & 0.18 \\
\hline Education (relative to "unknown") & & & 4th quintile & 1.87 & 0.18 \\
\hline Completed Highschool & -2.46 & 0.19 & 5th quintile & 6.07 & 0.23 \\
\hline Completed College & -1.76 & 0.20 & & & \\
\hline Completed Graduate School & 1.78 & 0.25 & & & \\
\hline \multicolumn{6}{|l|}{ Married (relative to "unknown") } \\
\hline Single & -1.79 & 0.80 & & & \\
\hline Married & 2.39 & 0.78 & & & \\
\hline
\end{tabular}

Note: Table shows coefficients and associated standard errors on the control variables of column 1 in Table 5. 
Table A5: Control Variables on Property Price Regression

\begin{tabular}{|c|c|c|c|c|c|}
\hline & Coefficient & $\begin{array}{c}\text { Standard } \\
\text { Error }\end{array}$ & & Coefficient & $\begin{array}{c}\text { Standard } \\
\text { Error }\end{array}$ \\
\hline \multicolumn{3}{|c|}{ Property Type (relative to "single family residence") } & \multicolumn{3}{|l|}{ Occupation (relative to "unknown") } \\
\hline Condo / Coop & -25.94 & 1.74 & Professional/Technical & 1.46 & 0.18 \\
\hline Multi-family (2-4 units) & -11.13 & 1.17 & Administration/Managerial & -0.48 & 0.24 \\
\hline \multirow[t]{2}{*}{ Multi-family (5+ units) } & -21.67 & 1.71 & Sales/Service & -1.02 & 0.33 \\
\hline & & & Clerical/White Collar & -1.35 & 0.20 \\
\hline Home Size (relative to smallest category) & & & Craftsman/Blue Collar & -2.67 & 0.23 \\
\hline Category 2 & 22.20 & 1.05 & Student & 0.59 & 0.39 \\
\hline Category 3 & 35.70 & 1.33 & Homemaker & 0.28 & 0.36 \\
\hline Category 4 & 45.43 & 1.47 & Retired & 0.19 & 0.53 \\
\hline Category 5 & 53.66 & 1.54 & Farmer & -2.31 & 1.74 \\
\hline Category 6 & 61.74 & 1.60 & Self Employed & -1.08 & 0.46 \\
\hline Category 7 & 71.57 & 1.66 & Educator & -1.15 & 0.75 \\
\hline Category 8 & 83.07 & 1.84 & Legal Professional & 1.07 & 0.42 \\
\hline Category 9 & 93.13 & 2.04 & Medical Professional & 1.47 & 0.26 \\
\hline Category 10 & 101.54 & 2.24 & Military & 0.74 & 1.06 \\
\hline Category 11 & 113.50 & 2.71 & Religious & -1.19 & 2.15 \\
\hline Category 12 & 124.78 & 3.03 & & & \\
\hline Category 13 & 125.94 & 4.49 & Household Size (relative to size of 1 ) & & \\
\hline Category 14 & 122.00 & 4.48 & 2 & 0.22 & 0.21 \\
\hline \multirow[t]{2}{*}{ Unknown } & 76.59 & 3.00 & 3 & -0.35 & 0.23 \\
\hline & & & 4 & -1.40 & 0.30 \\
\hline Lot Size (relative to smallest category) & & & 5 & -1.92 & 0.34 \\
\hline Category 2 & 5.90 & 0.72 & 6 & -2.72 & 0.39 \\
\hline Category 3 & 12.02 & 0.75 & 7 & -2.67 & 0.45 \\
\hline Category 4 & 17.68 & 0.91 & 8 & -3.17 & 0.68 \\
\hline Category 5 & 17.79 & 1.08 & & & \\
\hline Category 6 & 14.29 & 1.31 & Education (relative to "unknown") & & \\
\hline Category 7 & 9.93 & 1.45 & Completed Highschool & 0.14 & 0.16 \\
\hline Category 8 & 6.33 & 1.79 & Completed College & 0.78 & 0.15 \\
\hline Category 9 & -0.18 & 1.87 & Completed Graduate School & 2.57 & 0.21 \\
\hline \multirow[t]{2}{*}{ Unknown } & 7.15 & 0.79 & & & \\
\hline & & & Married (relative to "unknown") & & \\
\hline \multirow[t]{2}{*}{ Has Pool } & 4.66 & 0.31 & Single & 2.23 & 0.34 \\
\hline & & & Married & 3.04 & 0.36 \\
\hline \multicolumn{6}{|l|}{ Property Age (relative to less than 5 years old) } \\
\hline $5-9$ & -2.70 & 0.74 & Income 2010 (relative to "less than $\$ 15,000 "$ ) & & \\
\hline $10-14$ & -2.19 & 0.92 & $\$ 15,000-\$ 19,999$ & 0.87 & 0.48 \\
\hline $15-19$ & -7.85 & 0.98 & $\$ 20,000-\$ 29,999$ & 1.42 & 0.48 \\
\hline $20-24$ & -12.63 & 1.17 & $\$ 30,000-\$ 39,999$ & 2.15 & 0.59 \\
\hline $30-34$ & -16.34 & 1.12 & $\$ 40,000-\$ 49,999$ & 3.74 & 0.66 \\
\hline $35-39$ & -17.55 & 1.07 & $\$ 50,000-\$ 74,999$ & 6.10 & 0.69 \\
\hline $40-44$ & -17.49 & 1.08 & $\$ 75,000-\$ 99,999$ & 9.14 & 0.71 \\
\hline $45-49$ & -16.19 & 1.21 & $\$ 100,000-\$ 124,999$ & 11.09 & 0.72 \\
\hline $50-54$ & -15.45 & 1.21 & Greater than $\$ 124,999$ & 15.93 & 0.79 \\
\hline $55-59$ & -14.52 & 1.32 & Unknown & 11.60 & 1.61 \\
\hline $60-64$ & -12.73 & 1.37 & & & \\
\hline $65-79$ & -9.73 & 1.40 & Age (relative to "18-24") & & \\
\hline $70-74$ & -9.77 & 1.43 & $25-29$ & 0.77 & 0.22 \\
\hline $75-80$ & -9.87 & 1.48 & $30-34$ & 2.58 & 0.28 \\
\hline $80+$ & -11.66 & 1.50 & $35-39$ & 3.56 & 0.29 \\
\hline \multirow[t]{2}{*}{ Unknown } & -10.49 & 1.50 & $40-44$ & 3.41 & 0.31 \\
\hline & & & $45-49$ & 2.90 & 0.31 \\
\hline Number of Friends & & & $50-54$ & 3.11 & 0.40 \\
\hline 2nd quintile & 0.51 & 0.14 & $55-59$ & 3.00 & 0.43 \\
\hline 3rd quintile & 0.77 & 0.17 & $60-64$ & 3.69 & 0.60 \\
\hline 4th quintile & 1.23 & 0.19 & $65+$ & 2.70 & 0.37 \\
\hline 5th quintile & 1.85 & 0.24 & Unkown & 1.74 & 0.26 \\
\hline
\end{tabular}

Note: Table shows coefficients and associated standard errors on the control variables of column 1 in Table 6 . 
Table A6: Differential Effect by Type of Social Network

\begin{tabular}{|c|c|c|c|c|c|}
\hline & \multicolumn{5}{|c|}{ Panel A: Family Network } \\
\hline & \multicolumn{2}{|c|}{$\mathrm{P}($ Own in 2012) } & \multirow{2}{*}{$\frac{100 \times \log (\text { Size })}{(3)}$} & \multirow{2}{*}{$\frac{100 \times \log (\text { Price })}{(4)}$} & \multirow{2}{*}{$\frac{\text { LTV Ratio }}{(4)}$} \\
\hline & (1) & $(2)$ & & & \\
\hline Average Friend Appreciation & $0.630 * * *$ & $0.244 * * *$ & $0.376 * * *$ & $0.532 * * *$ & $-0.217 * * *$ \\
\hline Last 24 Months (\%) & $(0.120)$ & $(0.048)$ & $(0.075)$ & $(0.059)$ & $(0.033)$ \\
\hline \multirow[t]{3}{*}{ Controls } & Table 4 & Table 4 & Table 5 & Table 6 & Table 7 \\
\hline & Column 1 & Column 1 & Column 1 & Column 1 & Column 1 \\
\hline & 2010 Renters & 2010 Owners & & & \\
\hline $\bar{N}$ & 266,882 & 597,903 & 320,777 & 319,059 & 161,028 \\
\hline \multirow[t]{4}{*}{ R-Squared } & 0.470 & 0.602 & 0.195 & 0.792 & 0.144 \\
\hline & \multicolumn{5}{|c|}{ Panel B: Same College Network } \\
\hline & \multicolumn{2}{|c|}{$\mathrm{P}($ Own in 2012) } & $100 \times \log ($ Size $)$ & 100 x Log(Price) & LTV Ratio \\
\hline & (1) & (2) & (3) & (4) & (4) \\
\hline Average Friend Appreciation & $0.645^{* * *}$ & $0.267 * * *$ & $0.554 * * *$ & $0.635 * * *$ & $-0.259 * * *$ \\
\hline Last 24 Months (\%) & $(0.151)$ & $(0.062)$ & $(0.101)$ & $(0.078)$ & $(0.043)$ \\
\hline \multirow[t]{3}{*}{ Controls } & Table 4 & Table 4 & Table 5 & Table 6 & Table 6 \\
\hline & Column 1 & Column 1 & Column 1 & Column 1 & Column 1 \\
\hline & 2010 Renters & 2010 Owners & & & \\
\hline $\bar{N}$ & 131,371 & 303,393 & 161,788 & 160,423 & 85,250 \\
\hline \multirow[t]{4}{*}{ R-Squared } & 0.512 & 0.652 & 0.211 & 0.794 & 0.135 \\
\hline & \multicolumn{5}{|c|}{ Panel C: Same Employer Network } \\
\hline & \multicolumn{2}{|c|}{$\mathrm{P}($ Own in 2012) } & $100 \times \log ($ Size $)$ & $100 \times \log ($ Price) & LTV Ratio \\
\hline & $(1)$ & $(2)$ & (3) & (4) & (4) \\
\hline Average Friend Appreciation & $0.946 * * *$ & $0.419 * * *$ & $0.361 * * *$ & $0.701 * * *$ & $-0.251 * * *$ \\
\hline Last 24 Months (\%) & $(0.256)$ & $(0.114)$ & $(0.138)$ & $(0.117)$ & $(0.059)$ \\
\hline \multirow[t]{3}{*}{ Controls } & Table 4 & Table 4 & Table 5 & Table 6 & Table 6 \\
\hline & Column 1 & Column 1 & Column 1 & Column 1 & Column 1 \\
\hline & 2010 Renters & 2010 Owners & & & \\
\hline $\mathrm{N}$ & 83,041 & 177,207 & 122,755 & 121,918 & 64,917 \\
\hline R-Squared & 0.560 & 0.711 & 0.205 & 0.797 & 0.136 \\
\hline
\end{tabular}

Note: Table shows robustness of the results from the main instrumental variables regressions in Tables 3, 4, 5, 6, and 7, when we instrument for the overall house price experiences within an individual's social network with the experience of three subsets of their out-of-commuting zone friends: members of their family (Panel A), individuals who went to the same college (Panel B), and individuals who have the same employer (Panel C). Not all individuals link their family members, or report their college and employer, so the sample sizes are smaller than in the baseline regressions. Specifications and standard errors are as described in the original tables. Significance Levels: ${ }^{*}(p<0.10),{ }^{* *}(p<0.05),{ }^{* *}(p<0.01)$. 
Table A7: Robustness Check with Sample Restrictions on Hometown

\begin{tabular}{|c|c|c|c|c|c|}
\hline & \multicolumn{5}{|c|}{ Panel A - Hometown Los Angeles } \\
\hline & \multicolumn{2}{|c|}{$\mathrm{P}(\mathrm{Own}$ in 2012) } & $100 \times \log ($ Size $)$ & $100 \times$ Log(Price) & LTV Ratio \\
\hline & (1) & $(2)$ & (3) & (4) & (5) \\
\hline Average Friend Appreciation & $1.186 * * *$ & $0.293^{* * *}$ & $0.465^{* * *}$ & $0.850 * * *$ & $-0.357 * * *$ \\
\hline Last 24 Months (\%) & $(0.104)$ & $(0.033)$ & $(0.104)$ & $(0.066)$ & $(0.039)$ \\
\hline \multirow[t]{3}{*}{ Controls } & Table 4 & Table 4 & Table 5 & Table 6 & Table 7 \\
\hline & Column 1 & Column 1 & Column 1 & Column 1 & Column 1 \\
\hline & 2010 Renters & 2010 Owners & & & \\
\hline $\mathrm{N}$ & 143,768 & 374,733 & 166,118 & 165,469 & 80,477 \\
\hline \multirow[t]{4}{*}{ R-Squared } & 0.435 & 0.610 & 0.183 & 0.782 & 0.161 \\
\hline & \multicolumn{5}{|c|}{ Panel B - Hometown Outside US } \\
\hline & \multicolumn{2}{|c|}{$\mathrm{P}($ Own in 2012) } & $100 \times \log ($ Size $)$ & $100 \times \log ($ Price) & LTV Ratio \\
\hline & (1) & (2) & (3) & (4) & $(5)$ \\
\hline Average Friend Appreciation & $0.427^{* * *}$ & $0.170 * * *$ & $0.493 * * *$ & $0.788 * * *$ & $-0.206 * * *$ \\
\hline Last 24 Months (\%) & $(0.093)$ & $(0.039)$ & $(0.082)$ & $(0.066)$ & $(0.044)$ \\
\hline \multirow[t]{3}{*}{ Controls } & Table 4 & Table 4 & Table 5 & Table 6 & Table 7 \\
\hline & Column 1 & Column 1 & Column 1 & Column 1 & Column 1 \\
\hline & 2010 Renters & 2010 Owners & & & \\
\hline $\mathrm{N}$ & 63,998 & 122,115 & 74,300 & 74,006 & 39,104 \\
\hline R-Squared & 0.481 & 0.622 & 0.177 & 0.809 & 0.157 \\
\hline
\end{tabular}

Note: Table shows robustness of the results from the main instrumental variables regressions in Tables 3, 4, 5, 6, and 7, when we restrict the sample to individuals whose hometown is Los Angeles (Panel A), and when we restrict the sample to individuals whose hometown is outside the United States (Panel B). Specifications and standard errors are as described in the original tables. Significance Levels: ${ }^{*}(\mathrm{p}<0.10),{ }^{* *}(\mathrm{p}<0.05),{ }^{* * *}(\mathrm{p}<0.01)$. 
Table A8: Differential Effect by Network Size

\begin{tabular}{|c|c|c|c|c|c|}
\hline & \multicolumn{2}{|c|}{$\mathrm{P}($ Own in 2012) } & \multirow{2}{*}{$\frac{100 \times \log (\text { Size })}{(3)}$} & \multirow{2}{*}{$\frac{100 \times \log (\text { Price })}{(4)}$} & \multirow{2}{*}{$\frac{\text { LTV Ratio }}{\text { (5) }}$} \\
\hline & $(1)$ & $(2)$ & & & \\
\hline \multicolumn{6}{|c|}{ Average Friend Appreciation Last 24 Months (\%) } \\
\hline \multirow[t]{2}{*}{ Below Median Number of Counties } & $0.612^{* * *}$ & $0.162^{* * *}$ & $0.332^{* * *}$ & $0.637^{* * *}$ & $-0.222^{* * *}$ \\
\hline & $(0.056)$ & $(0.019)$ & $(0.054)$ & $(0.038)$ & $(0.018)$ \\
\hline \multirow[t]{2}{*}{ Above Median Number of Counties } & $0.611^{* * *}$ & $0.289^{\star \star *}$ & $0.353^{* * *}$ & $0.605^{\star * *}$ & $-0.235^{\star * *}$ \\
\hline & $(0.061)$ & $(0.028)$ & $(0.058)$ & $(0.036)$ & (0.019) \\
\hline \multirow[t]{3}{*}{ Controls } & Table 4 & Table 4 & Table 5 & Table 6 & Table 6 \\
\hline & Column 1 & Column 1 & Column 1 & Column 1 & Column 1 \\
\hline & 2010 Renters & 2010 Owners & & & \\
\hline $\bar{N}$ & 433,836 & $1,035,523$ & 526,594 & 523,299 & 268,204 \\
\hline R-Squared & 0.434 & 0.564 & 0.192 & 0.792 & 0.142 \\
\hline
\end{tabular}

Note: Table shows results from the main instrumental variables regressions in Tables 3, 4, 5, 6, and 7, where we analyze the effect of friends' house price experiences separately by the number of counties in which individuals have friends. We also report statistics for an F-test of the equality of the effect for highschool-graduates relative to the effect for individuals with graduate degrees. Specifications and standard errors are as described in the original tables. Significance Levels: ${ }^{*}(p<0.10)$, $* *(p<0.05))^{* * *}(p<0.01)$.

Table A9: Robustness Check with Trading Volume Controls

\begin{tabular}{|c|c|c|c|c|c|}
\hline & \multicolumn{2}{|c|}{$\mathrm{P}($ Own in 2012) } & \multirow{2}{*}{$\begin{array}{c}100 \times \log (\text { Size }) \\
(3)\end{array}$} & \multirow{2}{*}{$\frac{100 \times \log (\text { Price })}{(4)}$} & \multirow{2}{*}{$\begin{array}{c}\text { LTV Ratio } \\
(5) \\
\end{array}$} \\
\hline & $(1)$ & $(2)$ & & & \\
\hline Average Friend Appreciation Last 24 Months (\%) & $\begin{array}{c}0.519 * * * \\
(0.047)\end{array}$ & $\begin{array}{c}0.178 * * * \\
(0.017)\end{array}$ & $\begin{array}{c}0.291^{* * *} \\
(0.051)\end{array}$ & $\begin{array}{c}0.637^{* * *} \\
(0.039)\end{array}$ & $\begin{array}{c}-0.233^{* * *} \\
(0.018)\end{array}$ \\
\hline \multicolumn{6}{|l|}{ Average Friend County Trading Volume } \\
\hline Level & $\begin{array}{c}-0.011 * * * \\
(0.001)\end{array}$ & $\begin{array}{c}-0.002^{* * *} \\
(0.001)\end{array}$ & $\begin{array}{c}0.001 \\
(0.003)\end{array}$ & $\begin{array}{c}-0.023^{* * *} \\
(0.002)\end{array}$ & $\begin{array}{c}1.494 * * * \\
(0.087)\end{array}$ \\
\hline Change Last 24 Months (\%) & $\begin{array}{c}0.011^{* * *} \\
(0.002)\end{array}$ & $\begin{array}{l}0.001^{*} \\
(0.001)\end{array}$ & $\begin{array}{l}-0.004 \\
(0.004)\end{array}$ & $\begin{array}{c}0.031^{* * *} \\
(0.003)\end{array}$ & $\begin{array}{c}-1.239 * * * \\
(0.197)\end{array}$ \\
\hline Controls & $\begin{array}{c}\text { Table } 4 \\
\text { Column } 1 \\
2010 \text { Renters }\end{array}$ & $\begin{array}{c}\text { Table } 4 \\
\text { Column } 1 \\
2010 \text { Owners }\end{array}$ & $\begin{array}{l}\text { Table } 5 \\
\text { Column } 1\end{array}$ & $\begin{array}{l}\text { Table } 6 \\
\text { Column } 1\end{array}$ & $\begin{array}{c}\text { Table } 7 \\
\text { Column } 1\end{array}$ \\
\hline $\bar{N}$ & 433,813 & $1,035,495$ & 389,504 & 386,238 & 237,008 \\
\hline R-Squared & 0.434 & 0.564 & 0.175 & 0.785 & 0.140 \\
\hline
\end{tabular}

Note: Table shows robustness of the results from the main instrumental variables regressions in Tables 3, 4, 5, 6, and 7 , when we also include average county trading volume and its changes over the past 24 months of all members of individuals' social networks as control variables. This trading volume is measured as the fraction of the housing stock that transacts every period. Specifications and standard errors are as described in the original tables. Significance Levels: $*(\mathrm{p}<0.10),{ }^{* *}(\mathrm{p}<0.05),{ }^{* * *}(\mathrm{p}<0.01)$. 
Table A10: Robustness Check with Price Experiences of Renter Friends as Instrument

\begin{tabular}{|c|c|c|c|c|c|}
\hline & \multicolumn{2}{|c|}{$\mathrm{P}(\mathrm{Own}$ in 2012) } & \multirow{2}{*}{$\frac{100 \times \log (\text { Size })}{(3)}$} & \multirow{2}{*}{$\frac{100 \times \log (\text { Price })}{(4)}$} & \multirow{2}{*}{$\frac{\text { LTV Ratio }}{(5)}$} \\
\hline & $(1)$ & $(2)$ & & & \\
\hline Average Friend Appreciation & $0.702 * * *$ & $0.244 * * *$ & $0.402 * * *$ & $0.763 * * *$ & $-0.262 * * *$ \\
\hline Last 24 Months (\%) & $(0.076)$ & $(0.031)$ & $(0.069)$ & $(0.053)$ & $(0.026)$ \\
\hline \multirow[t]{3}{*}{ Controls } & Table 4 & Table 4 & Table 5 & Table 6 & Table 7 \\
\hline & Column 1 & Column 1 & Column 1 & Column 1 & Column 1 \\
\hline & 2010 Renters & 2010 Owners & & & \\
\hline $\mathrm{N}$ & 413,676 & 974,702 & 500,363 & 497,116 & 255,238 \\
\hline R-Squared & 0.438 & 0.570 & 0.192 & 0.792 & 0.141 \\
\hline
\end{tabular}

Note: Table shows robustness of the results from the main instrumental variables regressions in Tables 3, 4, 5, 6, and 7, when we use the average house price changes over the past 24 months of out-of-commuting-zone friends identified as renters in 2010 to instrument for all friends' experiences. Specifications and standard errors as described in the original tables. Significance Levels: ${ }^{*}(\mathrm{p}<0.10),{ }^{* *}(\mathrm{p}<0.05),{ }^{* * *}(\mathrm{p}<0.01)$.

Table A11: Differential Effect by Predictive Power of Social Network House Price Experience

\begin{tabular}{|c|c|c|c|c|c|}
\hline & \multicolumn{2}{|c|}{$\mathrm{P}($ Own in 2012) } & \multirow{2}{*}{$\frac{100 \times \log (\text { Size })}{(3)}$} & \multirow{2}{*}{$\frac{100 \times \log (\text { Price })}{(4)}$} & \multirow{2}{*}{$\frac{\text { LTV Ratio }}{(5)}$} \\
\hline & (1) & $(2)$ & & & \\
\hline \multicolumn{6}{|c|}{ Average Friend Appreciation Last 24 Months (\%) } \\
\hline Correlation $<0.5$ & $\begin{array}{l}0.473^{\star * *} \\
(0.042)\end{array}$ & $\begin{array}{l}0.174^{\star * *} \\
(0.017)\end{array}$ & $\begin{array}{l}0.313^{\star * *} \\
(0.054)\end{array}$ & $\begin{array}{l}0.794^{\star \star *} \\
(0.051)\end{array}$ & $\begin{array}{c}-0.262^{\star \star \star} \\
(0.018)\end{array}$ \\
\hline $0.5=<$ Correlation $<0.6$ & $\begin{array}{l}0.561^{\star \star *} \\
(0.040)\end{array}$ & $\begin{array}{l}0.218^{\star \star \star} \\
(0.017)\end{array}$ & $\begin{array}{l}0.303^{* * *} \\
(0.051)\end{array}$ & $\begin{array}{l}0.734^{* * *} \\
(0.046)\end{array}$ & $\begin{array}{c}-0.238^{\star \star \star} \\
(0.017)\end{array}$ \\
\hline Correlation $>=0.6$ & $\begin{array}{l}0.472^{\star * *} \\
(0.048)\end{array}$ & $\begin{array}{l}0.209^{* * *} \\
(0.019)\end{array}$ & $\begin{array}{l}0.318^{\star * *} \\
(0.050)\end{array}$ & $\begin{array}{l}0.672^{\star \star \star} \\
(0.042)\end{array}$ & $\begin{array}{c}-0.225^{\star \star *} \\
(0.018)\end{array}$ \\
\hline Controls & $\begin{array}{c}\text { Table } 4 \\
\text { Column } 1 \\
2010 \text { Renters }\end{array}$ & $\begin{array}{c}\text { Table } 4 \\
\text { Column } 1 \\
2010 \text { Owners }\end{array}$ & $\begin{array}{l}\text { Table } 5 \\
\text { Column } 1\end{array}$ & $\begin{array}{l}\text { Table } 6 \\
\text { Column } 1\end{array}$ & $\begin{array}{l}\text { Table } 7 \\
\text { Column } 1\end{array}$ \\
\hline $\mathrm{N}$ & 433,836 & $1,035,523$ & 484,882 & 480,906 & 244,608 \\
\hline R-Squared & 0.434 & 0.564 & 0.202 & 0.799 & 0.145 \\
\hline
\end{tabular}

Note: Table shows results from the main instrumental variables regressions in Tables 3, 4, 5, 6, and 7, where we analyze the effect of friends' house price experiences separately for individuals whose out-of-commuting zone friends' house price experiences are differentially correlated with subsequent LA house price movements. Specifications and standard errors are as described in the original tables. Significance Levels: ${ }^{*}(p<0.10),{ }^{* *}(p<0.05),{ }^{* * *}(p<0.01)$. 
Table A12: Differential Effect by Education Level

\begin{tabular}{|c|c|c|c|c|c|}
\hline & \multicolumn{2}{|c|}{$\mathrm{P}($ Own in 2012) } & \multirow{2}{*}{$\frac{100 \times \log (\text { Size })}{(3)}$} & \multirow{2}{*}{$\frac{100 \times \log (\text { Price })}{(4)}$} & \multirow{2}{*}{$\frac{\text { LTV Ratio }}{(5)}$} \\
\hline & (1) & $(2)$ & & & \\
\hline \multicolumn{6}{|c|}{ Average Friend Appreciation Last 24 Months (\%) } \\
\hline Highschool & $\begin{array}{l}0.516^{* * *} \\
(0.078)\end{array}$ & $\begin{array}{l}0.172^{* \star \star} \\
(0.027)\end{array}$ & $\begin{array}{l}0.313^{* \star *} \\
(0.054)\end{array}$ & $\begin{array}{c}0.637^{\star * *} \\
(0.039)\end{array}$ & $\begin{array}{c}-0.228^{* * *} \\
(0.018)\end{array}$ \\
\hline College & $\begin{array}{l}0.521^{* * *} \\
(0.094)\end{array}$ & $\begin{array}{l}0.150^{* * *} \\
(0.027)\end{array}$ & $\begin{array}{l}0.292^{* * *} \\
(0.053)\end{array}$ & $\begin{array}{c}0.602^{* * *} \\
(0.037)\end{array}$ & $\begin{array}{c}-0.220^{* * *} \\
(0.018)\end{array}$ \\
\hline Graduate School & $\begin{array}{l}0.474^{\star * *} \\
(0.185)\end{array}$ & $\begin{array}{l}0.105^{\star * *} \\
(0.035)\end{array}$ & $\begin{array}{l}0.304^{\star * *} \\
(0.056)\end{array}$ & $\begin{array}{c}0.544^{\star * *} \\
(0.035)\end{array}$ & $\begin{array}{c}-0.203^{* \star *} \\
(0.017)\end{array}$ \\
\hline Controls & $\begin{array}{c}\text { Table } 4 \\
\text { Column } 1 \\
2010 \text { Renters }\end{array}$ & $\begin{array}{c}\text { Table } 4 \\
\text { Column } 1 \\
2010 \text { Owners }\end{array}$ & $\begin{array}{l}\text { Table } 5 \\
\text { Column } 1\end{array}$ & $\begin{array}{l}\text { Table } 6 \\
\text { Column } 1\end{array}$ & $\begin{array}{c}\text { Table } 7 \\
\text { Column } 1\end{array}$ \\
\hline F-Stat (Highschool == Graduate School) & 0.04 & 2.21 & 68.9 & 67.7 & 22.83 \\
\hline P-Value (Highschool == Graduate School) & 0.841 & 0.138 & 0.000 & 0.000 & 0.000 \\
\hline $\mathrm{N}$ & 433,836 & $1,035,523$ & 526,594 & 523,299 & 268,204 \\
\hline R-Squared & 0.434 & 0.564 & 0.192 & 0.792 & 0.142 \\
\hline
\end{tabular}

Note: Table shows results from the main instrumental variables regressions in Tables $3,4,5,6$, and 7 , where we analyze the effect of friends' house price experiences separately by the education level of individuals. We also report statistics for an F-test of the equality of the effect for highschool graduates relative to the effect for individuals with graduate degrees. Specifications and standard errors are as described in the original tables. Significance Levels: ${ }^{*}(p<0.10),{ }^{* *}(p<0.05),{ }^{* * *}$ $(\mathrm{p}<0.01)$.

\section{Table A13: County-Level Relationship between Dispersion and Trading Volume}

\begin{tabular}{|c|c|c|c|c|}
\hline & \multicolumn{2}{|c|}{ Average Volume } & \multicolumn{2}{|c|}{ SD Volume } \\
\hline & (1) & (2) & (3) & (4) \\
\hline Average Dispersion & $\begin{array}{c}48.8^{* * *} \\
(4.291)\end{array}$ & $\begin{array}{c}48.2^{* * *} \\
(3.615)\end{array}$ & & \\
\hline SD Dispersion & & & $\begin{array}{l}11.4^{* * * *} \\
(0.000)\end{array}$ & $\begin{array}{c}13.3^{* * *} \\
(0.000)\end{array}$ \\
\hline Log(Income) & & $\begin{array}{c}2.24 * * * \\
(0.225)\end{array}$ & & $\begin{array}{c}0.742^{* * *} \\
(0.117)\end{array}$ \\
\hline Unemployment Rate (\%) & & $\begin{array}{c}0.067^{* *} \\
(0.029)\end{array}$ & & $\begin{array}{c}0.023 \\
(0.015)\end{array}$ \\
\hline Log(Population) & & $\begin{array}{c}0.48^{* * *} \\
(0.000)\end{array}$ & & $\begin{array}{l}-0.032 \\
(0.023)\end{array}$ \\
\hline Median Age (Years) & & $\begin{array}{c}-0.037^{* * *} \\
(0.000)\end{array}$ & & $\begin{array}{l}-0.01^{*} \\
(0.005)\end{array}$ \\
\hline $\bar{N}$ & 754 & 754 & 754 & 754 \\
\hline R-Squared & 0.147 & 0.451 & 0.040 & 0.097 \\
\hline Mean Dependent Variable & 4.937 & 4.937 & 1.475 & 1.475 \\
\hline
\end{tabular}

Note: Table shows coefficients and associated standard errors for regressions corresponding to Panels C - F of Figure 4. The dependent variables are the average (columns 1-2) and standard deviation (columns 3-4) of annual county-level measures of trading volume between 1998 and 2013. Trading volume is measured as transactions as a percentage of the total housing stock. The key dependent variable is the average and standard deviation of the within-county dispersion of friends' house price experiences, as defined by equation 9 . 
Figure A1: Distribution of Number of Friends

(A) Change-of-Tenure Sample

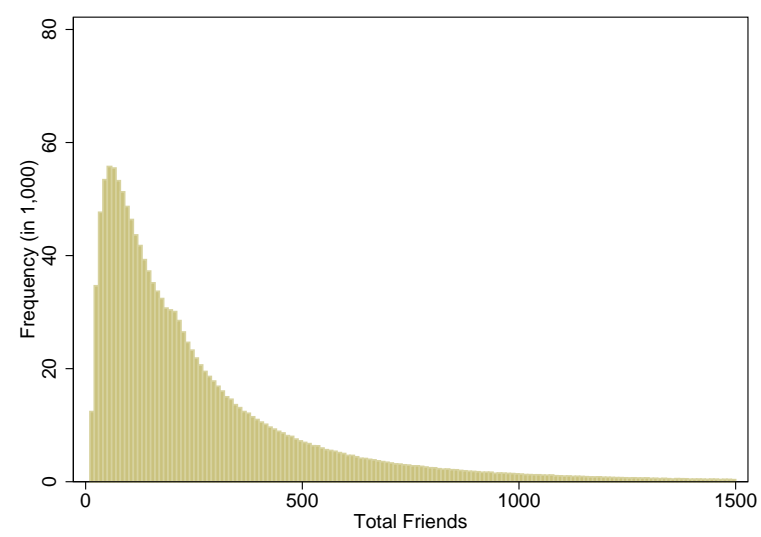

(C) Transaction Sample

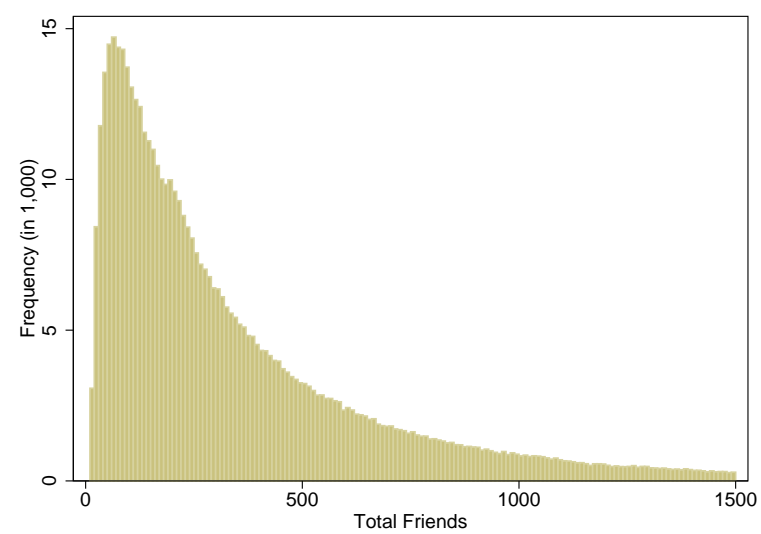

(B) Change-of-Tenure Sample

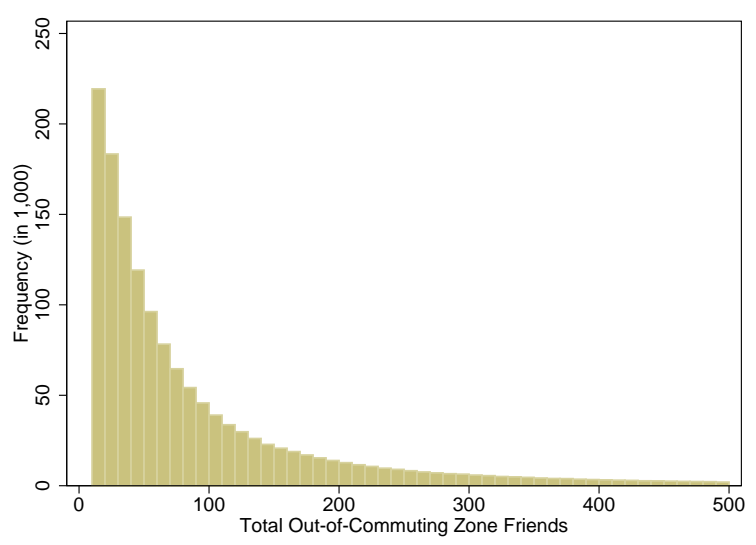

(D) Transaction Sample

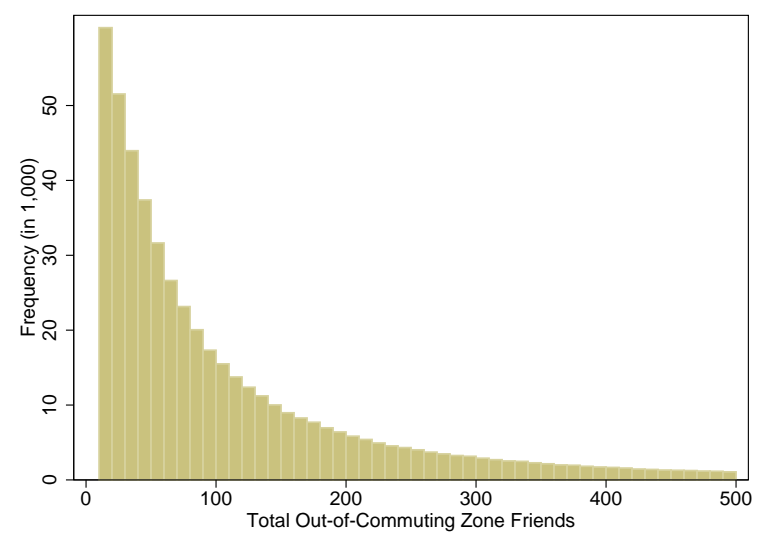

Note: Figure plots the distribution of the total number of Facebook friends (left column) and the total number of out-ofcommuting zone friends (right column) for the change-of-tenure sample used in Section 3.1 (top row) and the transaction sample used in Sections 3.2 and 3.3. Buckets are in steps of 10 friends. 


\section{Figure A2: Examples of Individual-Level Friend Distributions}

(A) Example 1 - Pennsylvania Focus

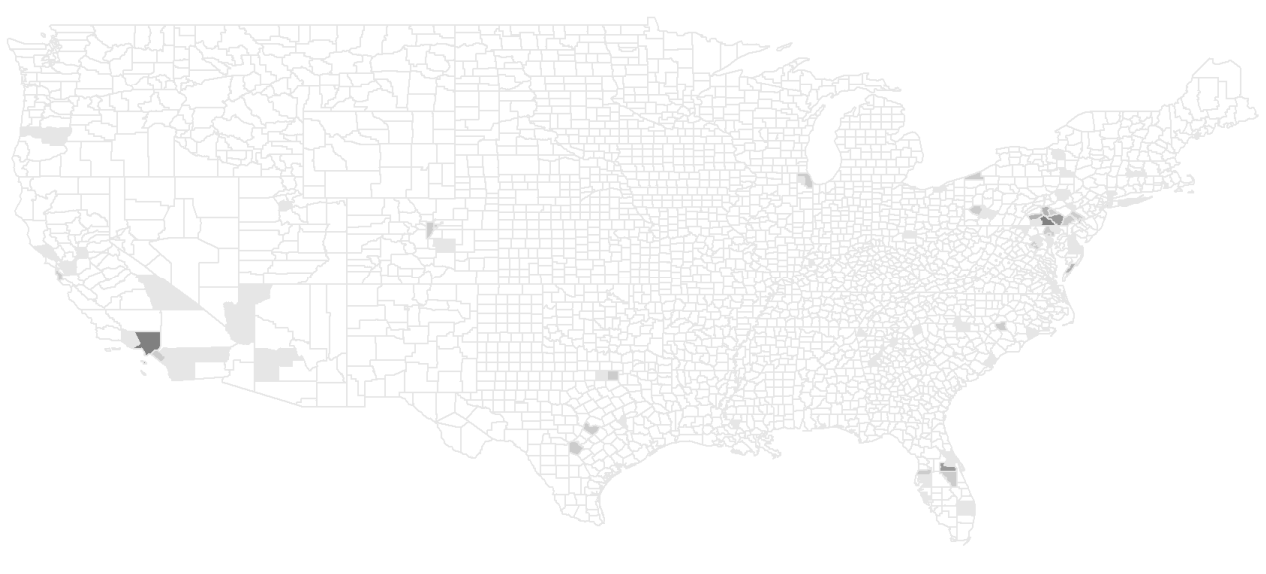

(B) Example 2 - Missouri Focus

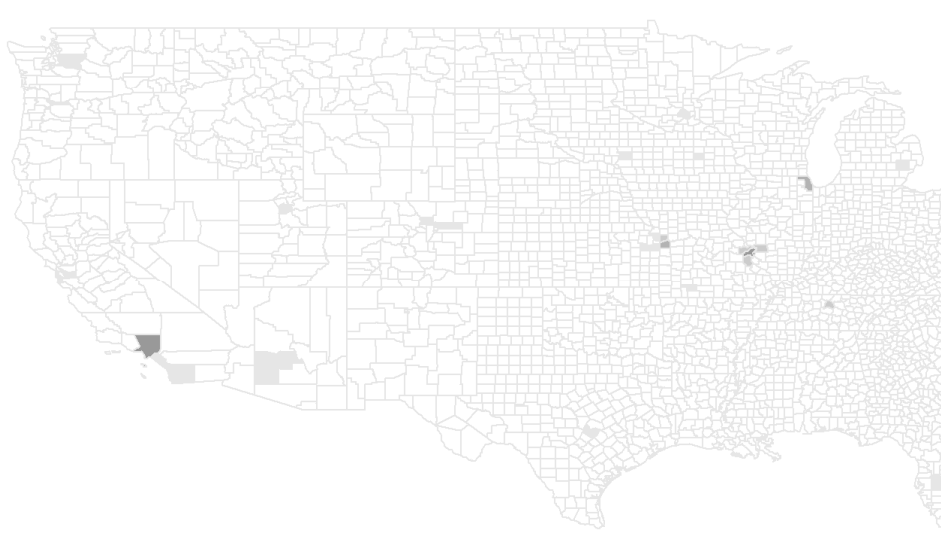

(C) Example 3 - Florida Focus

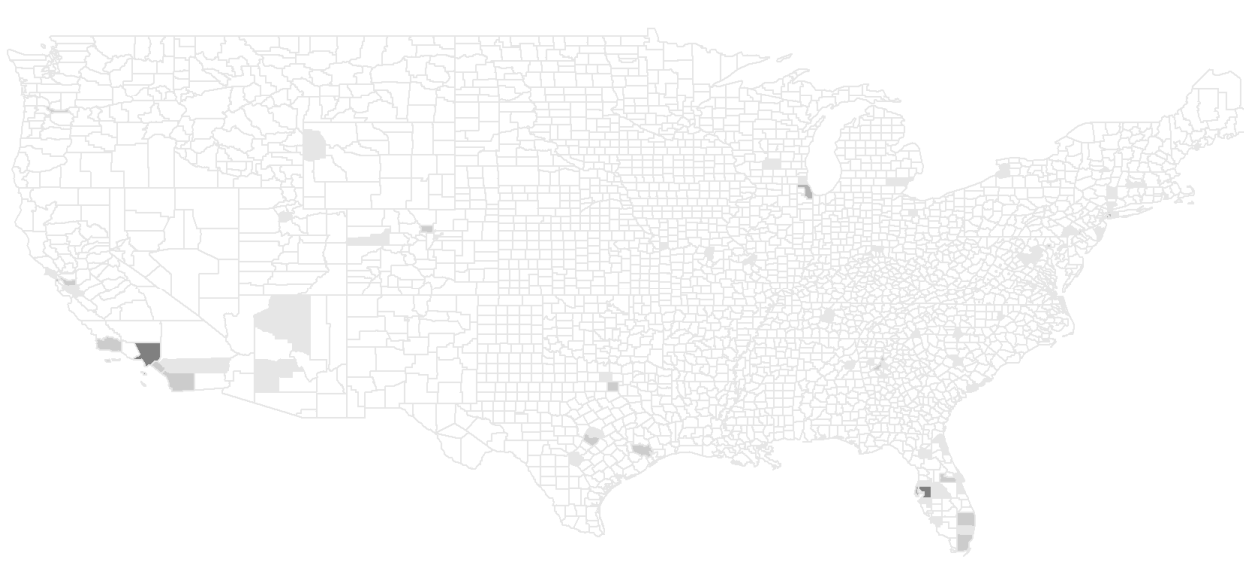

Note: Figure shows the geographic distribution of friends for three different individuals living in Los Angeles County in 2010. The friendship networks for these three individuals are clustered in Pennsylvania, Missouri, and Florida, as shown in Panel A, B, and C, respectively. 


\section{Figure A3: Examples of Individual-Level Friend Distributions}

(A) Example 1 - North Carolina Focus

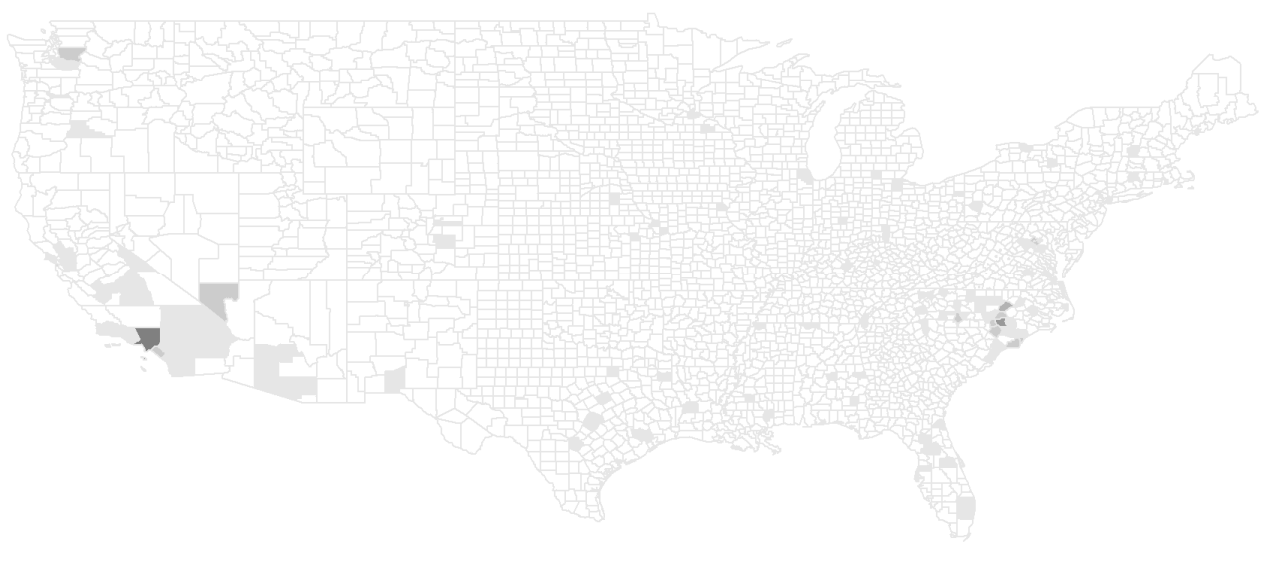

(B) Example 2 - Bay Area Focus

(C) Example 3 - Nevada \& Georgia Focus

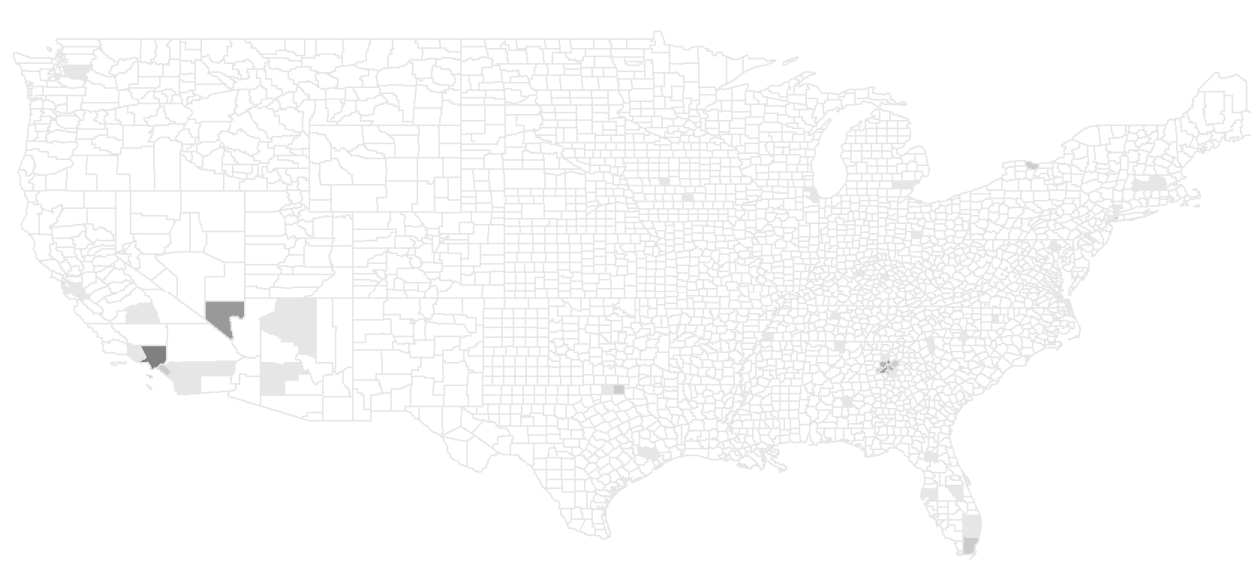

Note: Figure shows the geographic distribution of friends for three different individuals living in Los Angeles County in 2010. The friendship networks for these three individuals are clustered in North Carolina, the Bay Area, and Nevada/Georgia, as shown in Panel A, B, and C, respectively. 


\section{Figure A4: Interface of Expectations Survey}

Facebook is helping researchers understand what real people think about the economy. Your survey responses will be combined with the information that you publicly share on Facebook and average housing prices to help us better understand the housing economy. Help us out by answering the following questions, your responses will be kept anonymous:

If someone had a large sum of money that they wanted to invest, would you say that relative to other possible financial investments, buying property in your zip code today is:

A very bad investment A somewhat bad investment $\quad \begin{gathered}\text { Neither good nor bad as an } \\ \text { investment }\end{gathered}$ A somewhat good investment

How informed are you about house prices in your zip code?

Not at all informed Somewhat informed Well informed Very well informed

How informed are you about house prices where your friends live?

Not at all informed Somewhat informed Well informed Very well informed

How often do you talk to your friends about whether buying a house is a good investment?

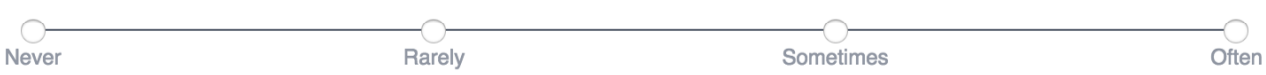

Thanks for participating in this survey!

Note: Figure shows the graphical interface of the survey conducted by Facebook. We analyze the results of this survey in Section 2. 


\section{Figure A5: Persistence of Friend Experiences}

(A) Absolute Appreciation

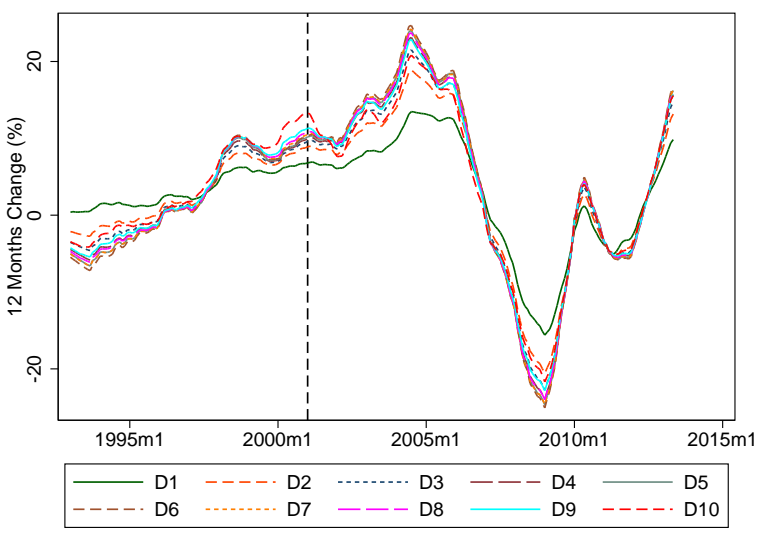

(C) Relative $\triangle H P$ : 2002-2004 vs. 2004-2006

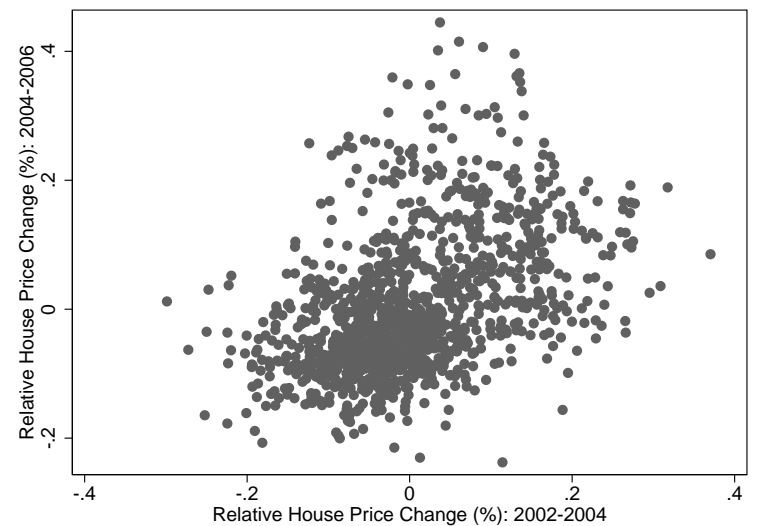

(E) Relative $\triangle H P$ : 2006-2008 vs. 2008-2010

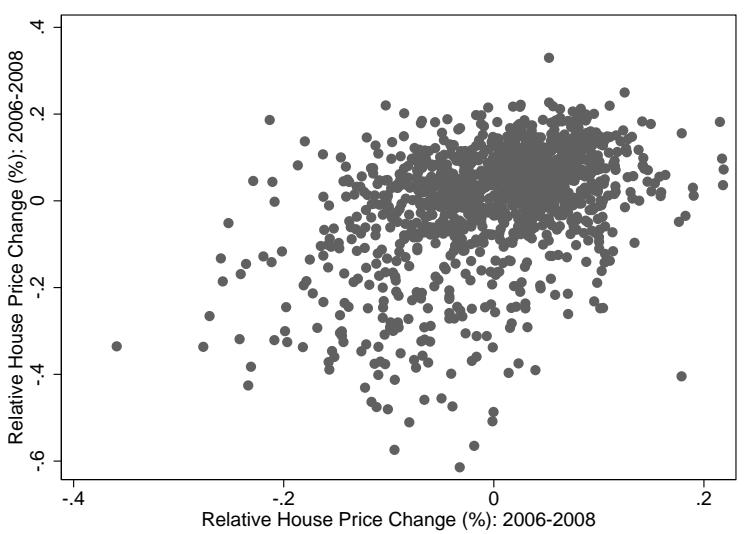

(B) Relative Appreciation

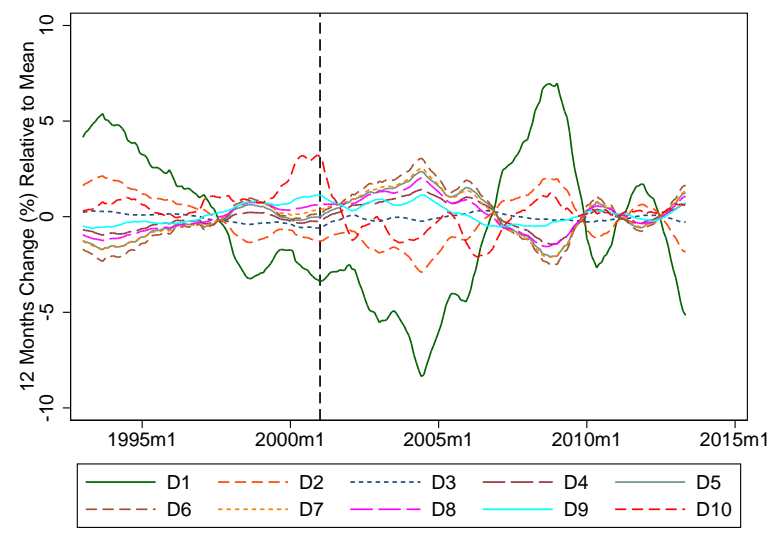

(D) Relative $\triangle H P$ : 2004-2006 vs. 2006-2008

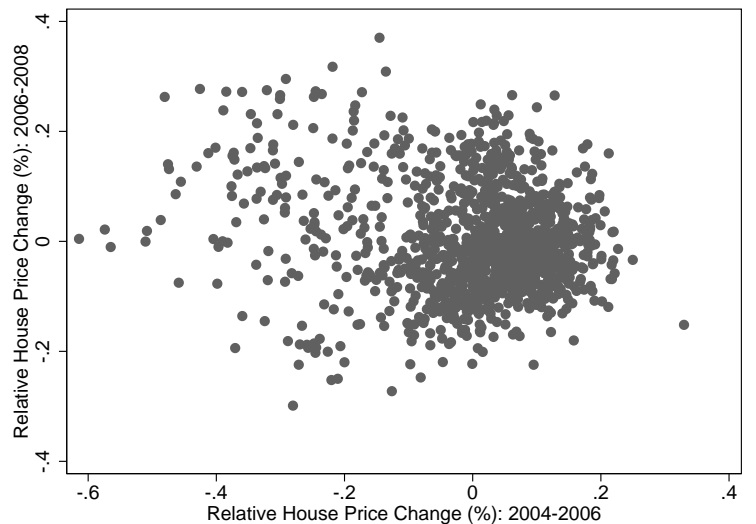

(F) Relative $\triangle H P: 2008-2010$ vs. 2010-2012

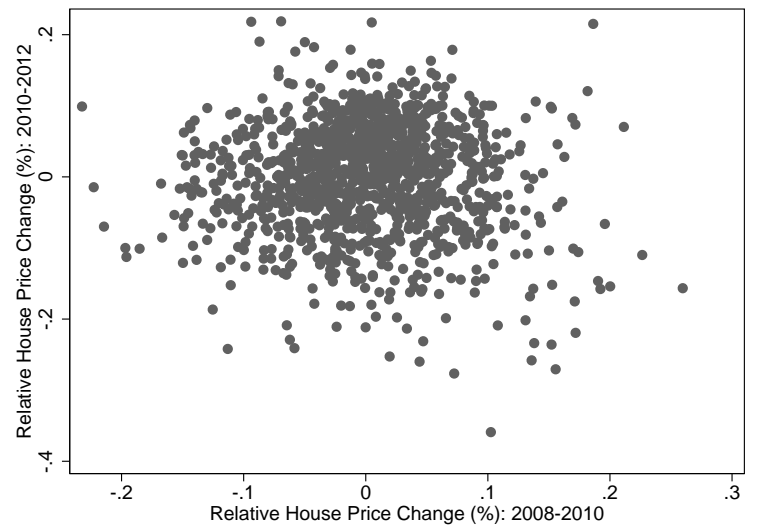

Note: Figure analyzes the persistence of house price experiences within a given social network. For Panels A and B, we split all individuals identified as buyers in the transaction sample into deciles depending on the house price appreciation of their friends in the 24 months before January 2001. We then plot the average house price experience of friends of people in that decile over time, both in absolute terms (Panel A) and relative to mean monthly appreciation (Panel B). In Panels C - F, we show county-level scatter plots of the relative house price movements in those counties across two-year horizons. 
Figure A6: Correlation Between Experiences in Different Networks

(A) Family Friends vs. College Friends

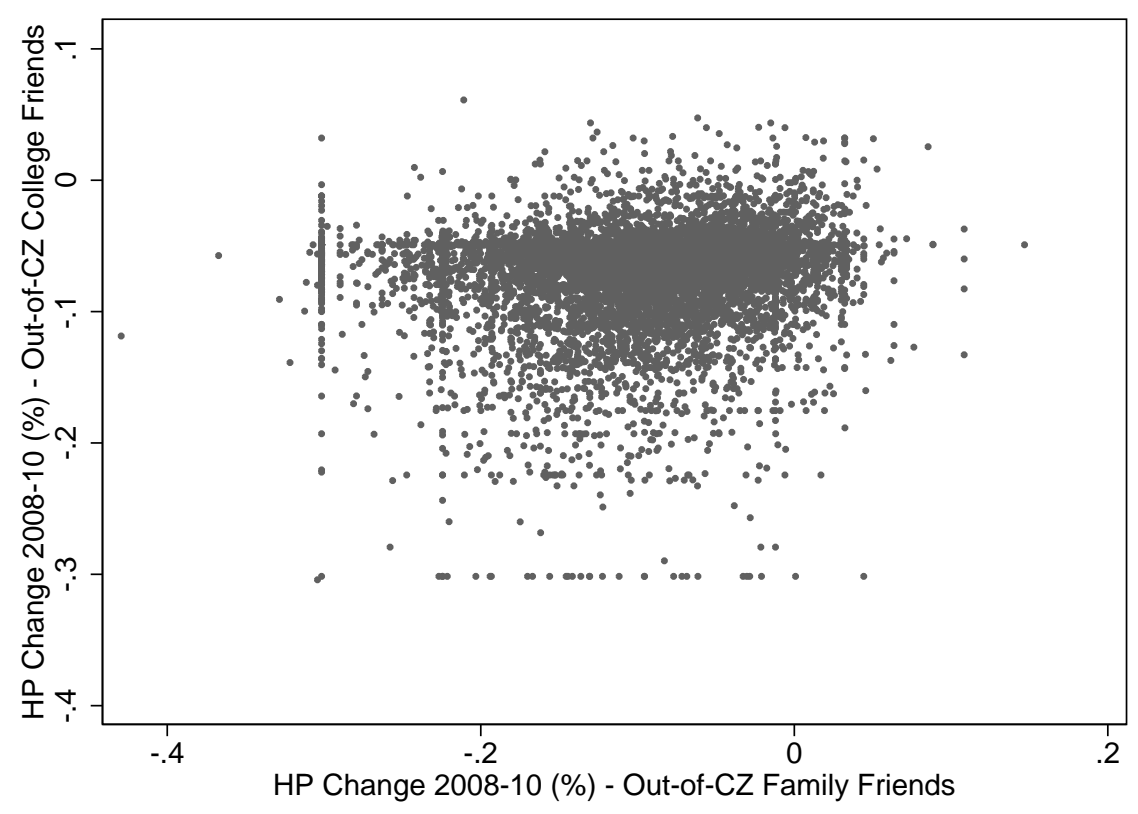

(B) Family Friends vs. Work Friends

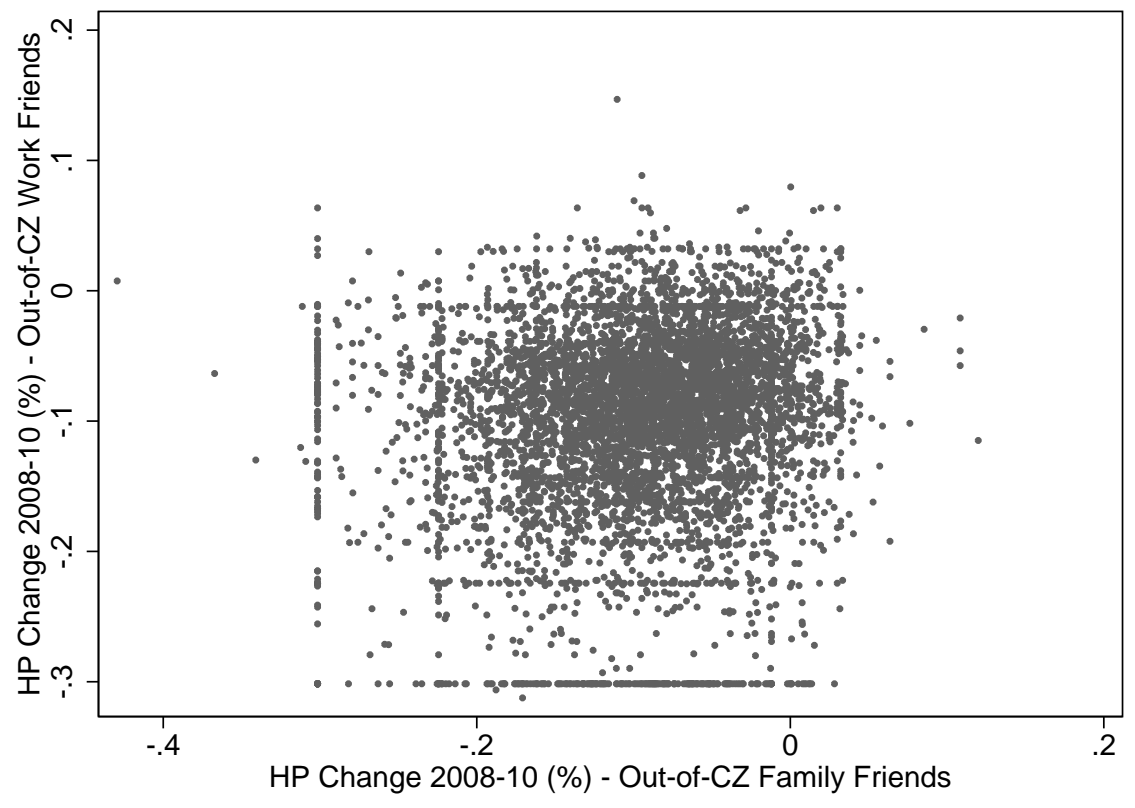

Note: Figure shows the correlation between the 2008-2010 house price experiences of out-of-commuting zone family members and out-of-commuting zone college friends (Panel A), and between of out-of-commuting zone family members and out-of-commuting zone work friends (Panel B). 


\section{Figure A7: Examples of County-Level Friend Distributions}

(A) Example 1 - Cook County, IL (Chicago)

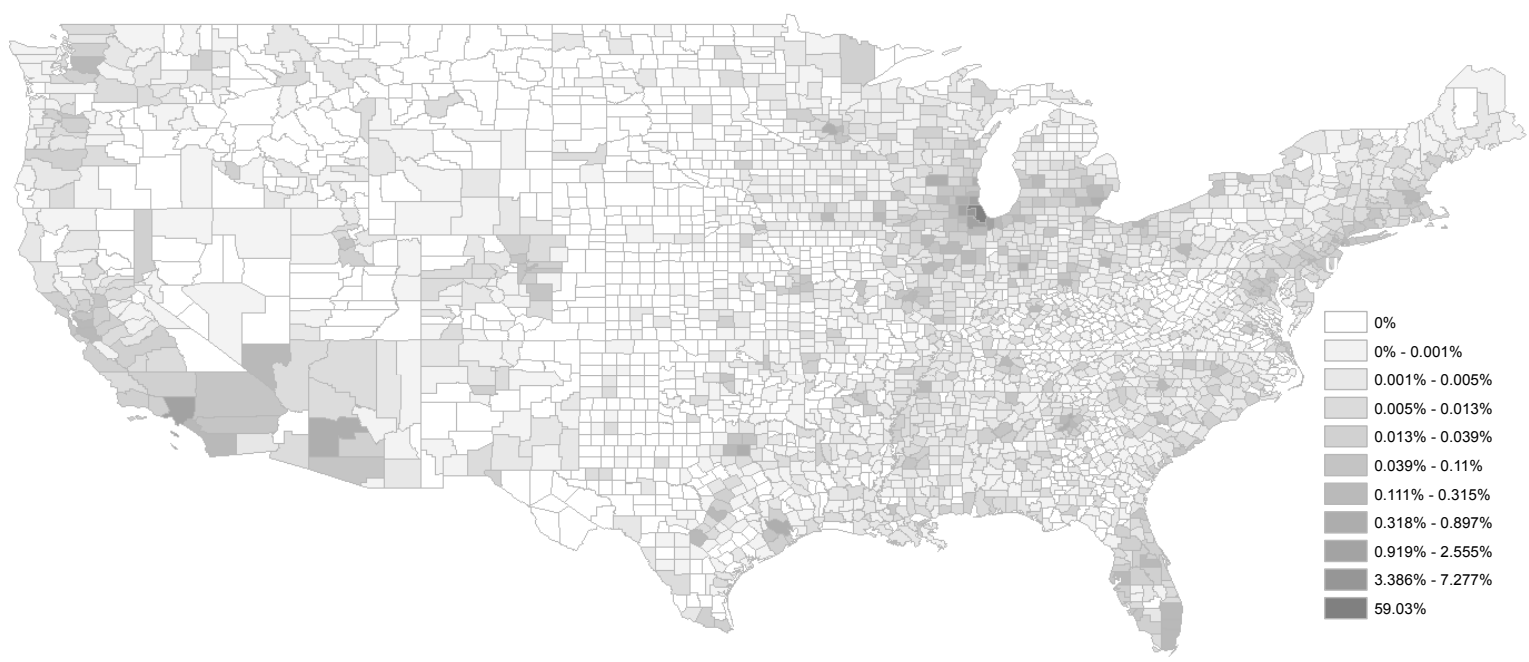

(B) Example 2 - Cuyahoga County, OH (Cleveland)

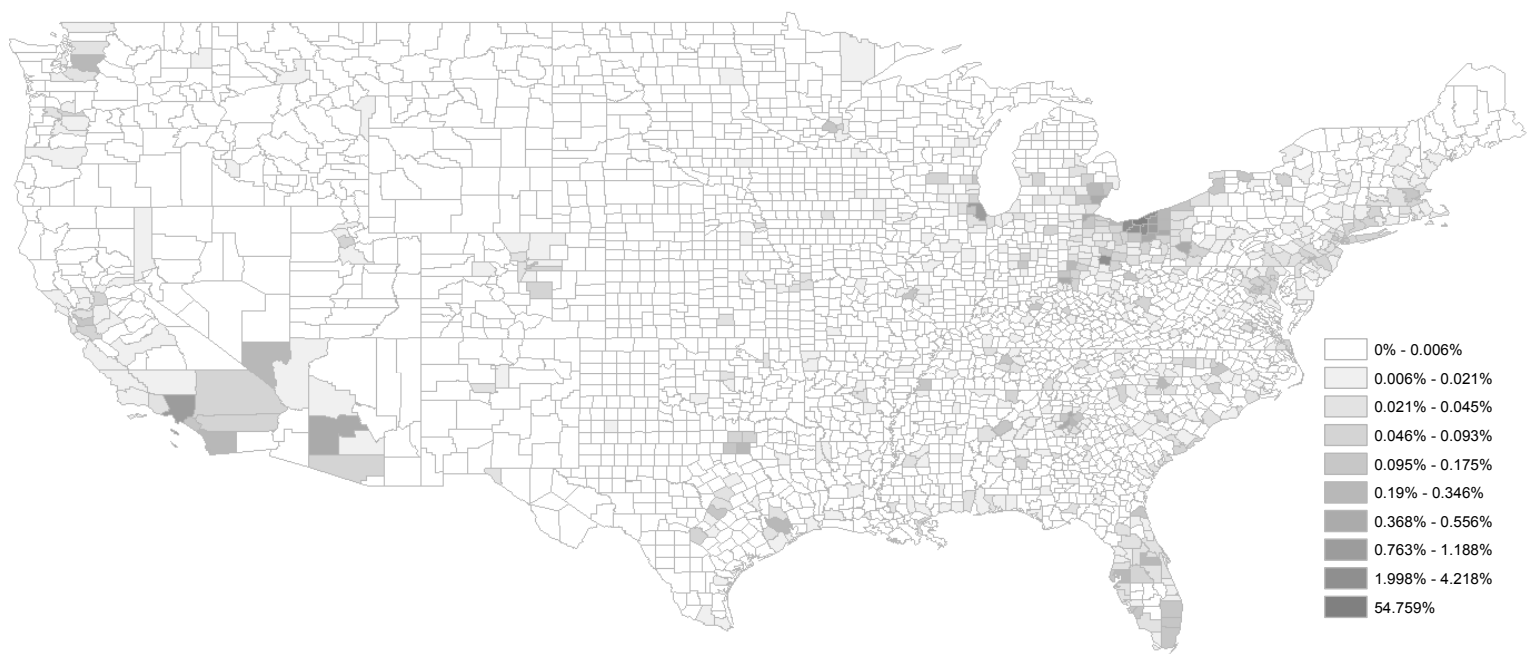

Note: Figure shows the geographical distribution of friends for all individuals living in Cook County, IL (Chicago) and Cyhahoga County, OH (Cleveland). 


\section{Figure A8: Examples of County-Level Friend Distributions}

(A) Example 1 - Laramie County, WY

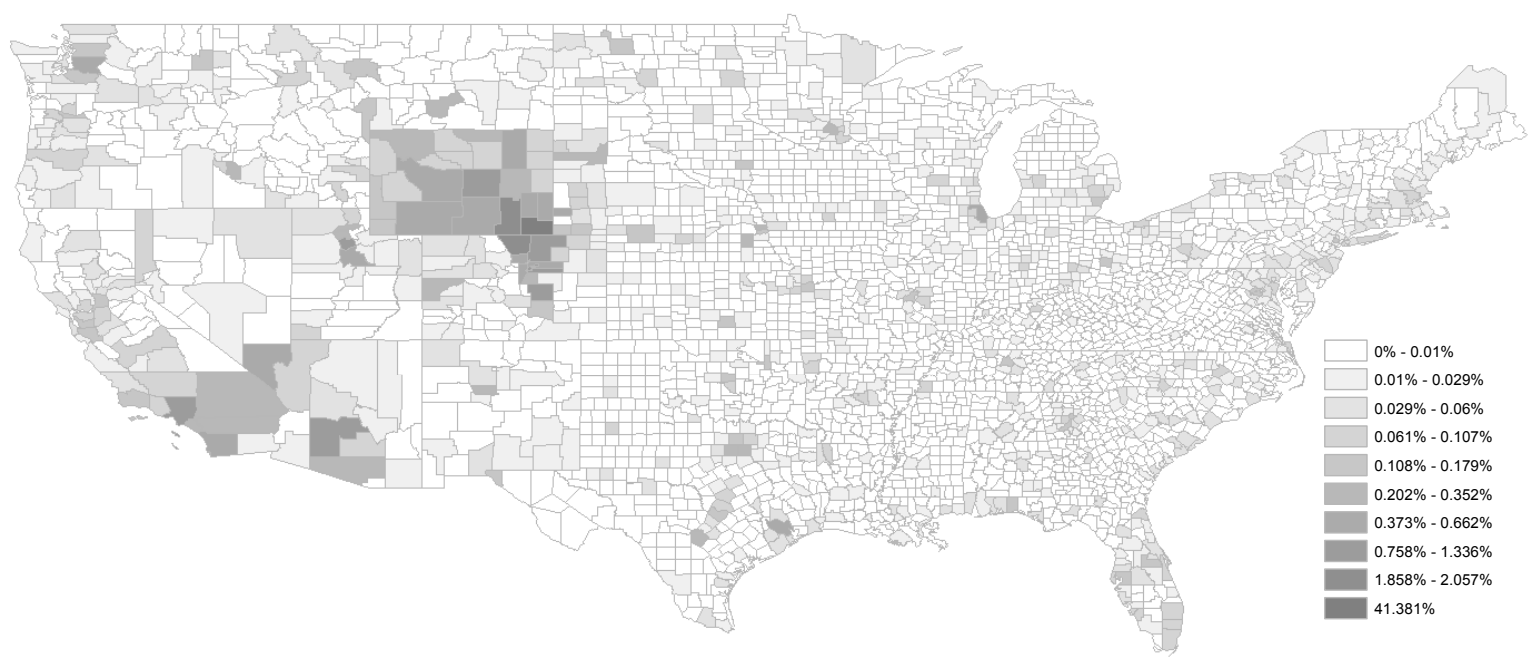

(B) Example 2 - Harris County, TX (Houston)

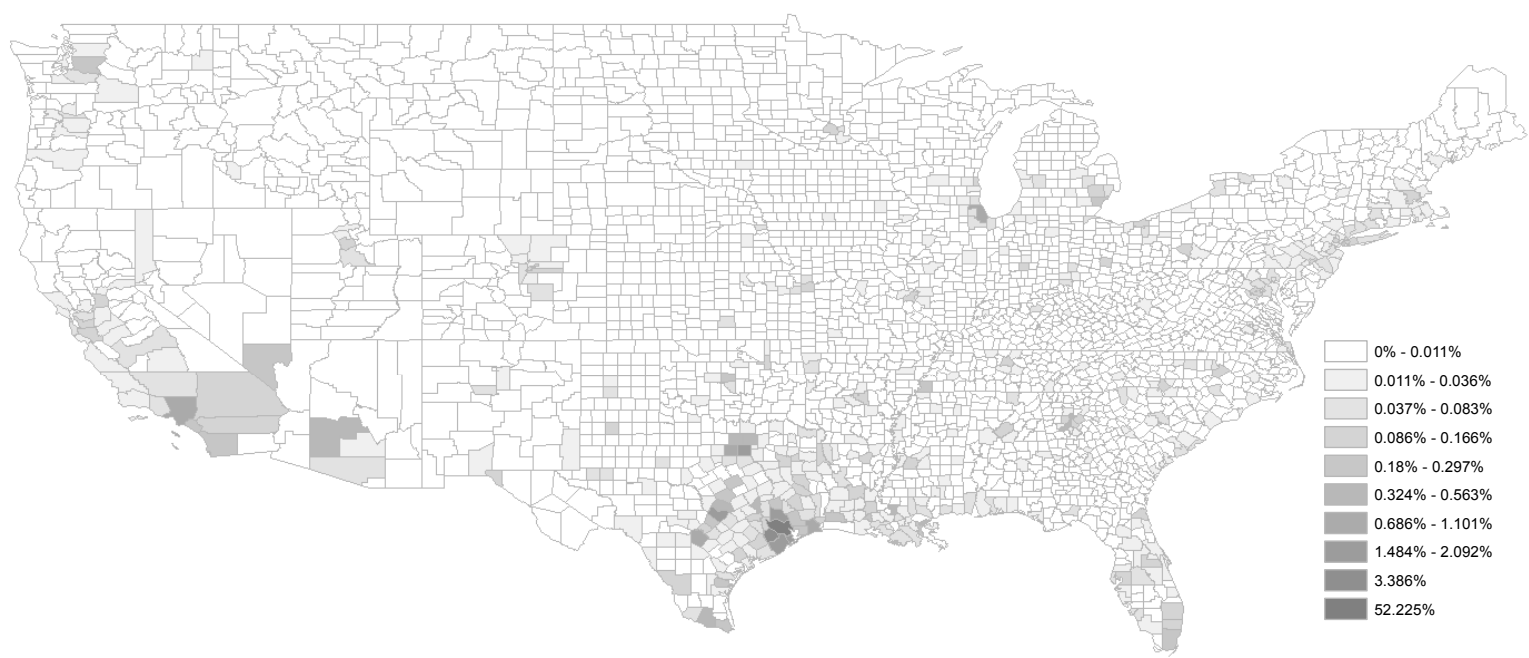

Note: Figure shows the geographical distribution of friends for all individuals living in Laramie County, WY and Harris County, TX (Houston). 


\section{Figure A9: Examples of County-Level Friend Distributions}

(A) Example 1 - Caldwell County, LA

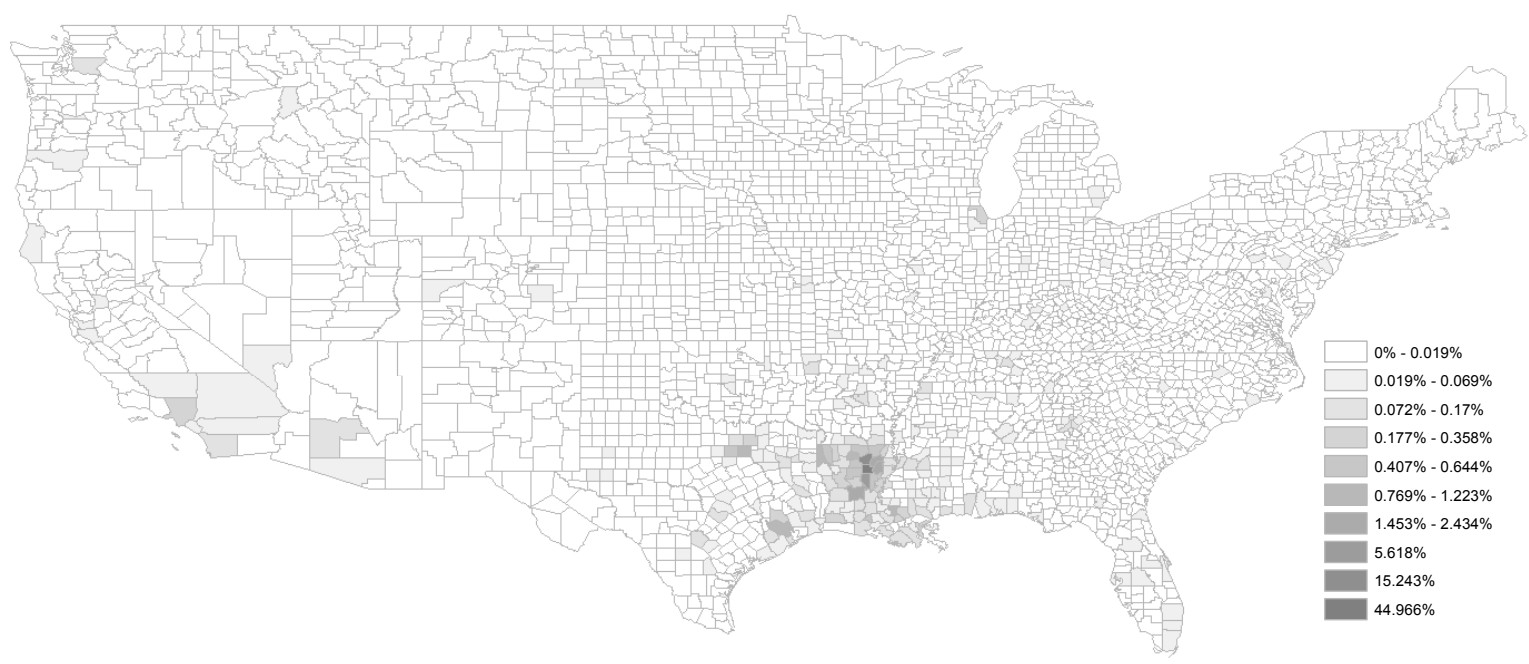

(B) Example 2 - Caribou County, ID

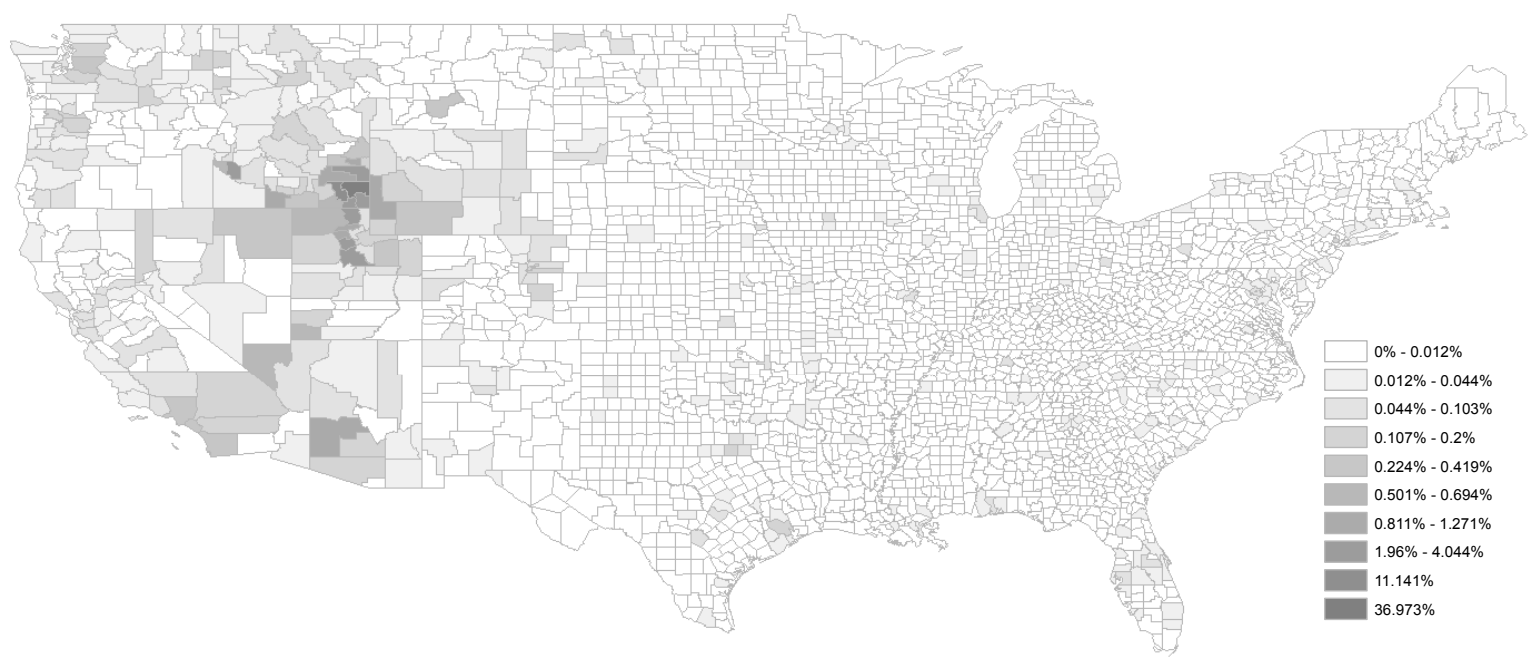

Note: Figure shows the geographical distribution of friends for all individuals living in Caldwell County, LA, and Caribou County, ID. 


\section{Figure A10: Geographic Concentration of Friends}

(A) Share of Friends within 100 miles

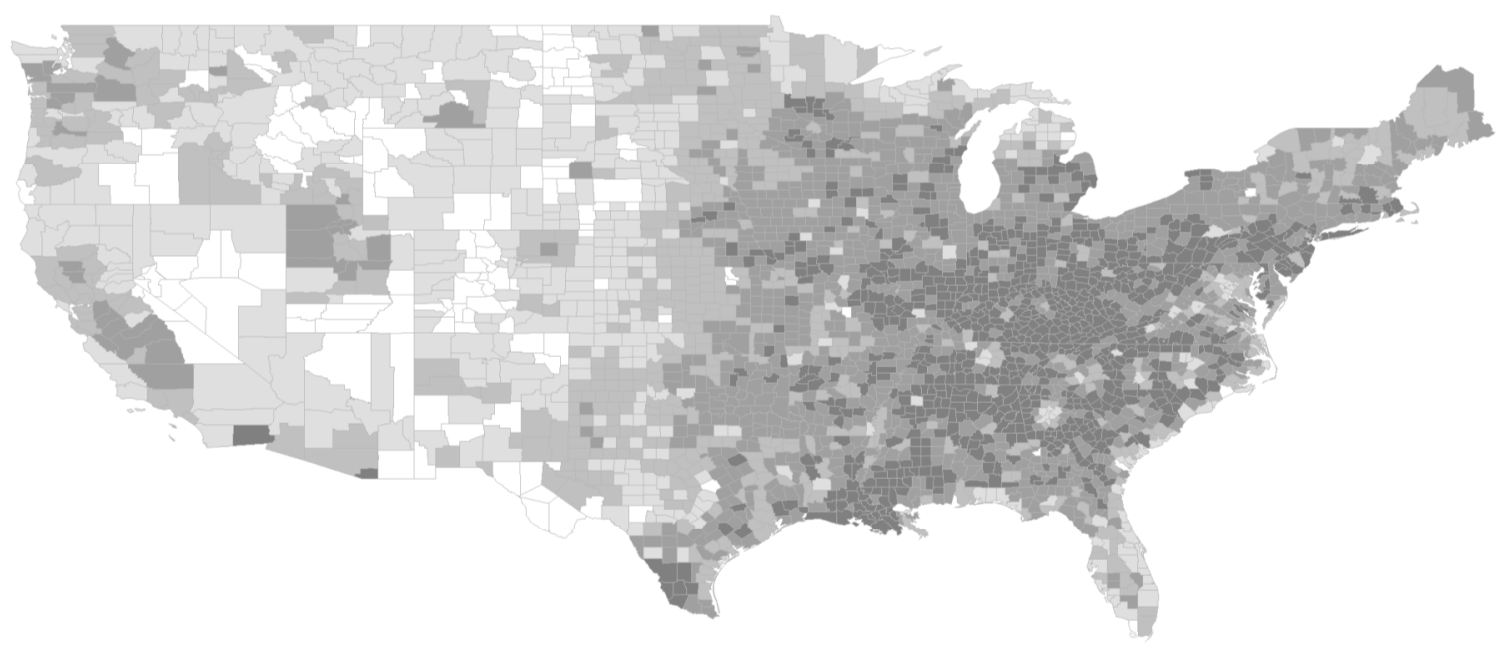

(B) Share of Friends within 500 miles

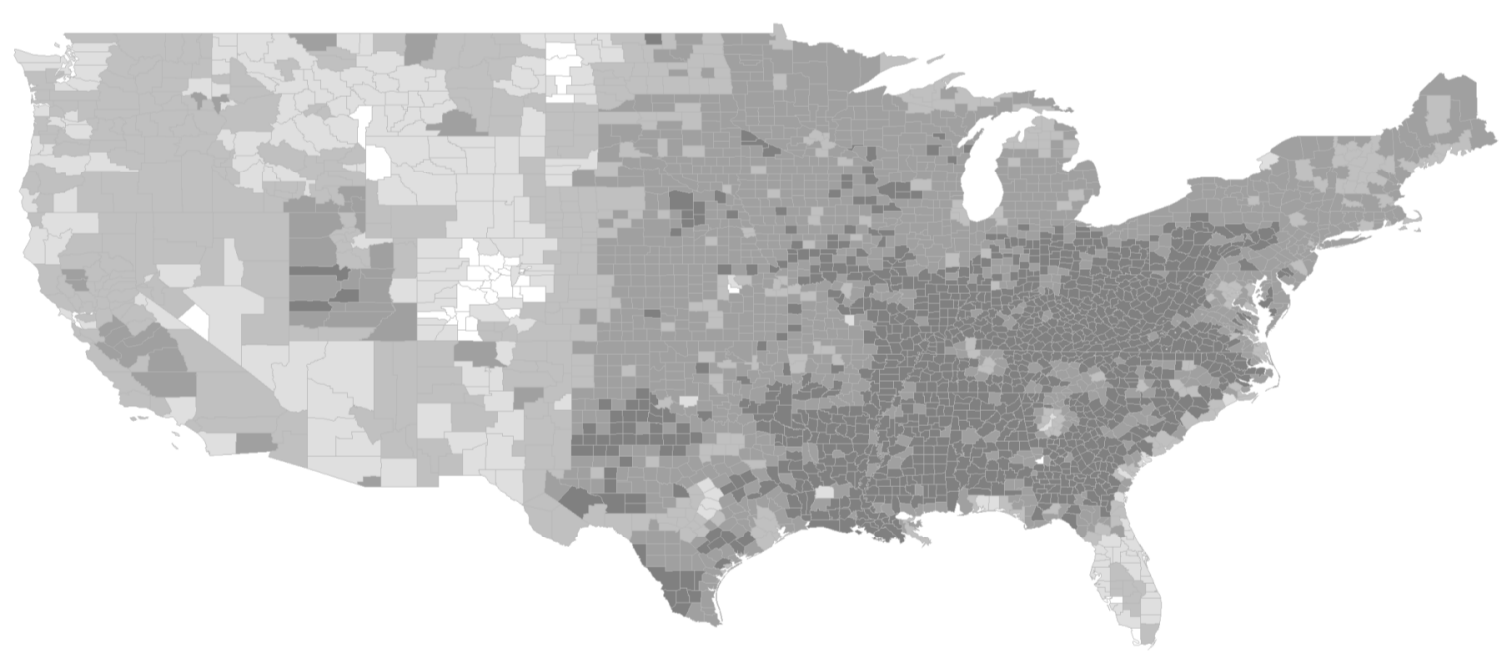

Note: Figure shows, for each county, the share of friends that live within 100 miles (Panel A) and 500 miles (Panel B). 